\title{
WestVirginiaUniversity
}

THE RESEARCH REPOSITORY @ WVU

Graduate Theses, Dissertations, and Problem Reports

2007

\section{Characterization of myosin I in the inner ear}

Kelli R. Phillips

West Virginia University

Follow this and additional works at: https://researchrepository.wvu.edu/etd

\section{Recommended Citation}

Phillips, Kelli R., "Characterization of myosin I in the inner ear" (2007). Graduate Theses, Dissertations, and Problem Reports. 4326.

https://researchrepository.wvu.edu/etd/4326

This Dissertation is protected by copyright and/or related rights. It has been brought to you by the The Research Repository @ WVU with permission from the rights-holder(s). You are free to use this Dissertation in any way that is permitted by the copyright and related rights legislation that applies to your use. For other uses you must obtain permission from the rights-holder(s) directly, unless additional rights are indicated by a Creative Commons license in the record and/ or on the work itself. This Dissertation has been accepted for inclusion in WVU Graduate Theses, Dissertations, and Problem Reports collection by an authorized administrator of The Research Repository @ WVU.

For more information, please contact researchrepository@mail.wvu.edu. 


\title{
Characterization of Myosin I in the Inner Ear
}

\author{
Kelli R. Phillips \\ Dissertation submitted to the School of Medicine \\ at West Virginia University \\ in partial fulfillment of the requirements \\ for the degree of \\ Doctor of Philosophy \\ in \\ Biochemistry and Molecular Biology
}

Janet L. Cyr, Ph.D., West Virginia University; committee chair

Ashok Bidwai, Ph.D., West Virginia University

Peter M. Mathers, Ph.D., West Virginia University

Lisa M. Salati, Ph.D., West Virginia University

George Spirou, Ph.D., West Virginia University

Paul Fuchs, Ph.D., John Hopkins University; external examiner

\author{
Department of Biochemistry \\ Sensory Neuroscience Research Center \\ Morgantown, WV
}




\section{Abstract}

\section{Characterization of Myosin I in the Inner Ear}

\section{Kelli R. Phillips}

Specialized epithelial cells, called hair cells, detect stimuli perceived by the organs of the inner ear. Such stimuli deflect the sensing organelle of the hair cell, the hair bundle. This force is proposed to create tension in the tip link, an extracellular filamentous structure, and open mechanically-gated ion channels. This process, called mechanotransduction, allows ions to enter the hair cell and results in its depolarization. During prolonged stimuli, the sensitivity of the hair cell is maintained by adaptation. To date, little is known about the molecular mechanisms that regulate either mechanotransduction or adaptation.

Myosin-1c (Myo1c) has been proposed to be the adaptation motor. As such, it must interact with other components of the mechanotransduction complex. Using an in situ binding assay, we previously demonstrated that Myolc interacts with molecules in the hair bundle, the site of mechanotransduction, through the calmodulin (CaM)-binding IQ domains in its neck region. In the current study, we identify the second CaM-binding IQ domain as a region of Myo1c that mediates CaM-sensitive binding to the hair bundle. As well, we show that the binding of Myo1c in the hair bundle is disrupted by treatments that break tip links.

Recent data indicate that Myo1c interacts in vitro with Cadherin-23 (Cdh23), a component of the tip link, and phosphotidyl-inositol bisphosphate, a phospholipid recently shown to be essential to mechanotransduction. It is not known, however, whether these interactions occur in hair cells. To determine if either of these components contribute to the binding observed in in situ binding assays, we examined Myo1c binding in mice whose hair cells lack Cdh23. In such samples, Myo1c binding was not observed. Additional experiments confirm the correct localization of $\mathrm{PIP}_{2}$ in $\mathrm{Cdh} 23$ mutant mice. Collectively, our data suggest that Myo1c and Cdh23 interact in the hair bundle and that this interaction is modulated by CaM.

Myosin-1a (Myo1a), the predominant unconventional myosin expressed in the enteryocyte, has also been implicated in hearing disorders. Using antibodies raised against Myola we failed to detect Myola in the hair cells of murine cochlea. However, alternative, potentially novel, antigens were detected and will be pursued in future work. 


\section{Acknowledgments}

"The features that, at least to my mind, help make a good or a great scientist really are not some of the ones that our society most often points to. It isn't just enormous intelligence or enormously rapid thought but a couple of other properties are particularly important. One is innovative thought, ideas that run counter to some preconceived notions. Another is simply perseverance. People, in order to work out the details of scientific inquiry, need a lot of time and a lot of patience. And it's very rare that one has a sudden blinding or overwhelming insight that one can promptly follow through. More often one has a hunch or an intuition that one then tries to trace over many months or many years until one finally has the full picture. And it's only in an intuitive sense that you then try to get on paper, in terms of concrete experimentation. Making that transition can be extremely hard but when it's successful it's remarkably rewarding."

-J.A. Hudspeth, Becoming a Scientist, HHMI Lecture Series

Like many of the pivotal events in scientific history, serendipity led me to the laboratory of Dr. Janet Cyr. Retrospectively, I am unsure how I would have completed graduate school without her presence in my life. Together we have spent countless hours at the bench, at the microscope, and in her office. Following her example, I have learned to never settle for mediocrity and to assume responsibility for my decisions. Everyday she teaches me about compassion and fortitude. She has taught me how to lead, to follow, and most importantly, to care in the face of twelve-hour days and negative results.

On an accompanying note, I would like to especially thank Song Tong and Matt Roberts, our laboratory technicians during my tenure. They not only provided me with a steady stream of experimental reagents and protocols, but also filled my hours at the bench with interesting conversations and mischief. As well, I must also recognize my fellow labmates, Anindita Biswas and Jeff Christiansen. If not for simply spreading Janet's attention, but for keeping the experimental bar high and our chocolate drawer fully stocked.

During the course of my education, I also had the opportunity to work with several scientists at other institutions who significantly contributed to my scientific approach. Specifically, I would like to thank Guy P. Richardson at Sussex University, UK, and Matthew J. Tyska at Vanderbilt University, TN. Both scientists were always available with technical support and rewarding interactions. They each provided me with the diversified perspective that is vital to practicing good science.

The experience I have had with the members of my dissertation committee has been very rewarding. They have acted as my mentors, advocates, and colleagues. Despite busy schedules, each of them has taken time to give me guidance in both my immediate and long-term goals. I would like to thank them for sharing with me both their time and insight.

Finally, I would like to recognize my family. My successes are a direct reflection of the support I have received from them throughout my life. My husband and son relinquish me daily to my science. My parents and grandparents have remained a constant positive presence in my life. They are proud of me when I succeed and when I fail. It is their love and understanding that continuously fuels my fire 


\section{Table of Contents}

Characterization of Myosin I in the Inner Ear i

Abstract ii

Dedication and Acknowledgments iii

Table of Contents iv

List of Abbreviations vi

I. Introduction 1

A. Sensory mechanoreceptors $\quad 1$

B. Perception of sound and movement 2

C. The hair cell 4

D. The hair bundle $\quad 6$

E. Actin cross-linkers $\quad \mathbf{1 0}$

F. Mechanotransduction and the tip link 12

$\begin{array}{ll}\text { The tip link } & 12\end{array}$

Potential components of the tip link 13

Mechanotransduction and adaptation in the hair cell 16

G. Additional lateral links of the hair bundle 19

H. Myosins of the hair bundle $\quad 20$

$\begin{array}{ll}\text { Myosin-1c } & 22\end{array}$

$\begin{array}{ll}\text { Myosin-7a } & 24\end{array}$

$\begin{array}{ll}\text { Myosin-6 } & 25\end{array}$

Myosin-15a 26

$\begin{array}{ll}\text { Myosin-3a } & 26\end{array}$

Myosin-1a 27

I. Hurdles of hair-cell research 28

Hair-cell biochemistry $\quad 28$

Genetic screening and mass spectrometry 29

J. Significance of hair-cell research 30

K. Summary and research goals 31

References

II. Stereociliary myosin-1c receptors are sensitive to calcium chelation and absent from cadherin-23 mutant mice 51

Abstract $\quad \mathbf{5 2}$

Materials and Methods $\quad \mathbf{5 4}$

Results $\quad 60$

The second IQ domain of Myo1c is necessary, but not sufficient, for interaction with stereociliary receptors $\quad 60$

The second IQ domain of Myo1c mediates CaM-sensitive binding to $\mathrm{PIP}_{2}$ in vitro 63

Tip-link loss abolishes Myo1c binding to stereociliary receptors 64

Effects of tip-link loss on Cdh23 immunolocalization in bullfrog sacculi and 
mouse cochlea

Interaction of Myo1c-T701 and stereociliary receptors does not occur in $C d h 23^{v 2}$ mice

Interaction of Myo1c-T701 and stereociliary receptors occurs in Myo7a ${ }^{6 \mathrm{~J}}$ mice

$\mathrm{PIP}_{2}$ is present in $C d h 23^{v 2 J}$ hair bundles

Discussion

The second IQ domain of Myo1c mediates binding to intracellular receptors

Myo1c binding to $\mathrm{PIP}_{2}$

Which molecules are the observed Myo1c receptors

Myolc interactions with transduction components

References

III. Two novel antigens in the hair bundle detected using myosin-1A directed antibodies

Results

Cochlear morphology of Myo1 $\mathrm{a}^{-/-}$mice

Immunoflourescent localization of the anti-brush border I $(\alpha B B I)$ antibody

Immunoflourescent localization of the $3 \mathrm{p} 1 / 4 \mathrm{p} 1$ antibody

Cochlear immunoblots using 3p1/4p1 antibody

The Myo1a-/- mouse may express a novel Myo1a isoform, Myo1aTAIL 98

Detection of cochlear-specific Myo1a transcripts 99

$\begin{array}{ll}\text { Cochlear morphology of Myo1 }{ }^{-/-} \text {mice } & 100\end{array}$

Immunofluorescent localization of the aBBI and the 3p1/4p1 antibodies $\quad 100$

Cochlear immunoblots using 3p1/4p1 antibody 


\section{List of Abbreviations}

3THD

$\alpha B B 1$

ALA

BB

CaM

CD1

Cdh23

Cdh $23^{v 2 J}$

DEG/ENaC

FERM

IHC

MAGUK

MET

MV

Myo15a

Myo1c

Myo1c-N2

Myo1c-T701

Myo1c-T701 IQ1RG1

Myo1c-T701 IQ2

Myo3a

Myo6

Myo7a

$\operatorname{Myo} 7 a^{6 J}$

MyTH4

NOMPC

OHC myosin III tail homology domain

antibody recognizing Brushborder I (Myo1a)

ankle link antigen

brushborder

calmodulin

C-like-domain 1

cadherin-23

Cadherin-23 mutant mice

degenerin epithelial sodium channel

$\mathrm{F}$ for 4.1, $\mathrm{E}$ for Ezrin, $\mathrm{R}$ for radixin and $\mathrm{M}$ for moesin; a unique module involved in the linkage of cytoplasmic proteins to the membrane

inner hair cell

membrane associated guanlyate kinase

mechanosensitive transduction

microvilliar

myosin-15a

myosin-1c

Myo1c IQ2 domain recombinant protein

Myo1c neck and tail recombinant protien

Myo1c-T701 with mutations in IQ1

Myo1c-T701 with mutation in IQ2

myosin-3a

myosin-6

myosin-7a

myosin-7a mutant mice

myosin tail homology 4

no mechanoreceptor potential C

outer hair cell 


$\begin{array}{ll}\text { PAB } & \text { parallel actin bundle } \\ \text { PBI } & \text { PDZ binding interfaces } \\ \text { Pcdh15 } & \text { protocadherin-15 } \\ \text { PDZ } & \text { PSD-95/SAP90 DISCS-largeZ0-1 homologous } \\ \text { PH } & \text { pleckstrin homology } \\ \text { PIP } & \text { phosphatidylinositol bisphosphate } \\ \text { PLC81 } & \text { phospholipase C81 } \\ \text { PMCA } & \text { plasma membrane Ca2+ ATPase } \\ \text { SH3 } & \text { src homology } 3 \\ \text { TH1 } & \text { basic tail homology 1 } \\ \text { TLA } & \text { tip link antigen } \\ \text { TM } & \text { tectorial membrane }\end{array}$




\section{Introduction}

\section{A. Sensory mechanoreceptors}

Environmental perception is vital to the survival of all organisms. This is achieved largely by the process of mechanosensation; a sensory pathway common to an exhaustive array of biological systems. The breadth of this process ranges from an organism's detection of pain to a cell's sensation of fluid flow. Of particular interest are the specialized systems that have evolved to detect minute stimuli; transforming small physical energies into vital neurological messages. Our senses of touch, hearing and balance are three such crucial examples.

To date, very little is known about the details of tactual perception in vertebrates. Because a diverse group of touch receptors are interspersed among the non-sensory cells of the epidermis, the identification of unifying molecules playing a role in somatosensation has been difficult. In the case of the Merkel cell-neurite complex, responsible for vertebrate perception of soft-touch, controversy surrounds the function of each cellular component. It was only recently, following more than a century of debate, that pre-synaptic molecules were identified in the Merkel cell, strongly supporting its role in mechanosensation (Haeberle et al., 2004). In contrast, the identification of the mechanosensory cell of the acousticolateralis system, the hair cell, occurred over 150 years ago and its proposed function has remained undisputed (Corti, 1851). However, as is the case with the somatosensory system, hair cells are sparse in number and traditional biochemical techniques have been only marginally successful in the identification of molecular components.

Common to each of these sensory systems is the mode of signal transduction. In each system, regardless of the specific cellular receptor, a physical force, such as surface pressure, sound waves or gravity, acts to open mechanosensitive transduction (MET) channels. These channels are predicted to work as a part of a complex of proteins that 
anchor the MET channel to the cytoskeleton of the receptor cell and to couple it to the cell's extracellular surface where the stimulation occurs. A large-scale mutagenesis screen in Caenhorabditis elegans enabled the initial identification of a collection of proteins that when mutated (mec mutants) adversely affected MET-mediated touch (Chalfie and Sulston, 1981; Chalfie and Au, 1989; reviewed in Gillespie and Walker, 2001). From this pool, the degenerin/epithelial sodium channel (DEG/ENaC) family became a popular candidate for the MET channel involved in the perception of touch in C. elegans (Huang and Chalfie, 1994). A similar screen was later repeated in Drosophila (Kernan et al., 1994; reviewed in Gillespie and Walker, 2001). These results implicated the transient receptor potential (TRP) and the transient receptor potential-vanilloid (TRPV) as strong candidates for the MET channels involved in touch and hearing in flies

(Walker et al., 2000; Hamill and Martinac, 2001; Gong et al., 2004; reviewed in Gillespie et al., 2005; reviewed in Nicolson, 2005b; Cheung and Corey, 2006). Later experiments that examined mutations in the TRP protein, NOMPC, which led to the loss of mechanosensation in the fly, confirmed the original hypotheses (Walker et al., 2000). However, investigating these leads in mammals has been challenging. Knockout animals lacking the alpha subunit of the $\mathrm{DEG} / \mathrm{ENaC}$ channel were shown to exhibit no abnormalities in mechanotransduction (Rusch and Hummler, 1999). In addition, the TRP channels identified in invertebrates to mediate mechanotransduction do not have exact homologues in mammals (Walker et al., 2000; Kim et al., 2003; Gong et al., 2004). As a result, investigators have been screening close mammalian correlates with minimal success (Kwan et al., 2006). To date, the identity of these channels and the complete complement of interacting proteins in mammals are still unknown. It is the long-term goal of our research to elucidate these molecular mechanisms in the auditory and vestibular systems of the inner ear.

\section{B. Perception of sound and movement}

The acousticolateralis systems of the inner ear are responsible for our senses of hearing and balance. Sensations detected by these systems begin as physical forces that 
are detected by specialized organs and then translated to a synaptic signal that is processed by the brain (reviewed in Hudspeth, 1989). In the auditory system, sound transmission begins as sinusoidal waves that are filtered by the outer ear, the pinnae, and directed through the middle ear canal where they make contact with the surface of the tympanic membrane (ear drum; Fig 1A). This physical force is translated to three small bones, the ossicles, and then to the oval window of the cochlea (reviewed in Hudspeth, 1989). In the vestibular system, gravity and directional accelerations act to move the auxiliary structures of the inner ear that stimulate the end organs: the utricle, sacculus and semicircular canals (reviewed in Hudspeth, 1989). Both the auditory and vestibular organs share a common mechanoreceptor, the hair cell.

Mammalian auditory detection occurs within the cochlea. Encased in the temporal bone, this assembly, $150 \mu \mathrm{m}$ wide by $35 \mathrm{~mm}$ long, wraps around the modiolus forming a shape analogous to a snail shell (measurement of the human cochlea; von Bekesy, 1960). The cochlea is separated into three spiral ducts; the tympanic, vestibular, and the cochlear canals (Fig 1A, green, pink and yellow respectively). The tympanic and vestibular canals are filled with perilymph, a fluid analogous to cerebral spinal fluid that has a high concentration of sodium and a low concentration of potassium (reviewed in Dallos, 1992). The cochlear canal is filled with endolymph and, like cellular cytosol, has a high concentration of potassium and a low concentration of sodium (reviewed in Dallos, 1992). These differences in ionic concentrations create an electrochemical gradient that is crucial to auditory signal transduction (Offner et al., 1987; reviewed in Dallos, 1992).

In the cochlear canal, the organ of Corti rests on the basilar membrane and contains four parallel rows of sensory hair cells (Fig 1B). The inner hair cells (IHCs) are poised closest to the modiolus and sit directly upon the basilar membrane. The remaining three rows of sensory cells are referred to as the outer hair cells (OHC). The OHCs rest upon an underlying collection of cells called the Dieter cells (Fig 1B; DC). Each hair cell detects a specific frequency of sound relative to its position along the basilar membrane (reviewed in Hudspeth, 1989). Those hair cells posited at the apex of the cochlea detect 
low frequency sound, while those at its base detect high frequency sound (reviewed in Hudspeth, 1989). Additional cochlear supporting cells, pillar cells, separate the IHCs from one another and form a partition between the IHCs and the OHCs (Fig 1B; PC). The remainder of the cochlear epithelium is made up of Henson cells (Fig 1B; HC).

In the vestibular organs, hair cells lie on sensory epithelial sheets in hexagonal arrays separated by supporting cells. In the semicircular canals these sheets occur at the ampule, a bulbaceous region of each canal, and are called crista. In the sacculus and utricle, these sheets are called maculae. Positioned directly above both the crista and maculae is a thin gelatinous layer, referred to as the cupula and otolithic membrane respectively, upon which resides a large mass of carbonate crystals called the otoconia (reviewed in Hudspeth, 1989).

\section{The hair cell}

The hair cell is a polarized epithelial cell. At its apical surface, a sensing organelle, the hair bundle, projects into the endolymph where it is poised to detect stimuli. The OHCs of the cochlea make contact with the tectorial membrane. In the cochlea, the tectorial membrane remains stationary as the basilar membrane oscillates in response to sound waves, creating a shearing movement that acts to deflect the hair bundles of the OHCs (reviewed in Hudspeth, 1989). IHC bundles do not directly contact a structural surface in the cochlea, but instead are deflected solely the fluid displaced by the basilar membrane's movement through the surrounding endolymph (Dallos et al., 1972; Lim, 1986). The hair bundles of vestibular hair cells make direct contact with the otolithic membrane in the sacculus and the cupula in the semicircular canals. The adjacent otoconia move in response to head movements, linear and angular accelerations, and gravity, shifting the underlying cupula and otolithic membranes, resulting in the deflection of the hair bundle (reviewed in Hudspeth, 1989). 
In the cochlea, IHCs are innervated by $95 \%$ of the all the afferent nerve fibers extending from the cochlear nuclei, clearly establishing the IHCs as the primary sensory transmitters of the auditory system (Fig 1B; reviewed in Spoendlin, 1985). In contrast, the OHCs have only a few afferent nerve fibers, and instead have efferent synaptic connections from the superior olivary complex (reviewed in Spoendlin, 1985). This asymmetrical pattern of innervation left the role of the OHCs unclear for many years (reviewed in Dallos, 1988). However, it is now known that OHCs serve in a positive feedback loop that amplifies the sensitivity of stimuli detection (reviewed in Dallos, 1992). This cochlear amplification is proposed to occur as the result of two processes: somatic electromotility and stereociliary amplification (reviewed in Fettiplace, 2006). Together these movements are proposed to occur in phase with the shearing motion of the basilar and tectorial membranes and act to increase the flow of fluid that deflects the hair bundles of the IHC. Somatic electromotility describes the expansion and contraction of the OHC body in response to stimuli and subsequent intracellular depolarization (Brownell et al., 1985; Kachar et al., 1986; Ashmore, 1987). Recent data indicate that this phenomenon is mediated by the motor protein prestin (Zheng et al., 2000a; reviewed in Dallos et al., 2006). Immunolocalization experiments indicate that prestin is present at very high concentrations in the somatic membrane of the OHC (Oliver et al., 2001). In response to intracellular depolarization, prestin is postulated to undergo a conformational change that decreases its surface area, thereby causing the $\mathrm{OHC}$ to contract (reviewed in Dallos et al., 2006). As evidence of prestin's role as the OHC motor, the OHCs of prestin knockout mice do not undergo somatic electromotility (Liberman et al., 2002). As well, the frequency selectivity of the cochlea is greatly reduced in prestin $\mathrm{KO}$ mice despite normal mechanotransduction (Liberman et al., 2002; Cheatham et al., 2004; reviewed in Dallos et al., 2006).

Acoustic emissions manifesting from acousticolateral amplification have also been measured in non-mammalian invertebrates that do not have OHCs (reviewed in Hudspeth, 1989). This led to investigation and the subsequent theory of stereociliary amplification, which describes the negative movement of the hair bundle in response to calcium (Choe et al., 1998; Chan and Hudspeth, 2005). This process has been shown to 
occur in mammals as well as non-mammalian invertebrates and is believed to work in conjunction with the somatic contractility of the OHCs (Chan and Hudspeth, 2005; reviewed in Fettiplace, 2006). Together, both processes clearly provide explanation for the discrepancies noted between the predicted and measured threshold limits of the cochlea (Dallos, 1988). By acting as amplifiers of stimuli, especially at higher frequencies, the OHCs are able to significantly increase the sensitivity of the cochlea. As expected, when OHCs are damaged, hearing persists, but with a limited frequency range (Ryan and Dallos, 1975).

\section{The hair bundle}

Each hair bundle is composed of a single process called the kinocilium and a collection of many elongated actin-filled processes called stereocilia (Fig 2). The kinocilium is the only true cilium of the hair cell. As such, the core of the kinocilium is composed of microtubules arranged in the $9+2$ pattern that is common to all cilia structures (Flock and Duvall, 1965). Despite the localization of numerous hair bundle proteins to the kinocilium, its function is unknown (Hudspeth and Jacobs, 1979; Goodyear et al., 2005; Leibovici et al., 2005; Michel et al., 2005; Shin et al., 2005). Upon its discovery, it was postulated to be the site of mechanotransduction in the hair cell (Hillman, 1969). However, mechanotransduction in the hair cell persists following kinocilium micro-dissection (Hudspeth and Jacobs, 1979). Moreover, the kinocilium degenerates as auditory hair cells mature (reviewed in Eatock, 2000). Current hypotheses predict that the kinocilium acts to tether hair bundles to proximate membranes or, alternatively, contributes to the orientation of the hair bundle in the surrounding sensory epithelium and its resulting axis of sensitivity (Hudspeth and Jacobs, 1979; reviewed in Kelley, 2006).

The mature stereocilium is shaped like a pencil, having a constant diameter along its length and tapering at its point of insertion into the apical surface of the cell. The narrow portion of the stereocilium is referred to as the stereociliary rootlet (Fig 2C). The 
rootlet has decreased rigidity, allowing stereocilia to pivot in response to stimuli (Flock et al., 1977). The predominant protein of stereocilia, comprising 50-75\% of the total protein, is actin (Flock and Cheung, 1977; Tilney et al., 1980; Shepherd et al., 1989). Stereociliary actin, comprised of both beta and gamma monomers, is organized in parallel hexagonal arrays with the positive, or barbed end, of the actin filament oriented at the tips of the stereocilia (Flock and Cheung, 1977; Tilney et al., 1980).

The development of the hair bundle has been explored extensively in avian models (Tilney and DeRosier, 1986; Tilney et al., 1986; Tilney et al., 1988). During early embryonic chick development, the kinocilium and stereocilia are unable to be distinguished from the short microvillia present on the hair cells apical surface (reviewed in Tilney et al., 1992). However, beginning at approximately embryonic day 10 (E10) in avian models, the kinocilium and stereocilia become thicker and more robust than the surrounding microvilliar processes (Tilney and DeRosier, 1986). Shortly thereafter, the kinocilum migrates to an eccentric position at the abneural edge of the hair cell (Tilney and DeRosier, 1986). During this time, stereocilia continue to elongate sequentially, with those stereocilia closest to the kinocilium growing first (reviewed in Tilney et al., 1992). The rate of growth and length of each stereocilium can be correlated to its positioning relative to the kinocilium. Those nearest the kinocilium are taller and have a faster rate of growth when compared to those furthest away. As a result, the stereocilia of a hair bundle form a staircase pattern (reviewed in Tilney et al., 1992). In the adult cochlea, this staircase pattern forms a crescent, with the kinocilium located at the crescent's vertex (Fig 2B). In vestibular organs, the bundle is spherical and the staircase pattern gives the bundle a beveled appearance, with the kinocilium at its tallest point (Fig 2A \& D). In the cochlea, the kinocilium degrades as the hair bundle matures, while in vestibular organs it remains for the life of the hair bundle.

Stereocilia are often compared to the microvilli that extend from the brush border regions of enterocyte cells in the lumen of the small intestine (Flock and Cheung, 1977). Both processes result from a very similar arrangement of parallel actin bundles (PABs) and consequently the two structures share many of the same proteins (discussed below, 
reviewed in Tilney et al., 1980; reviewed in Bartles, 2000). However, stereocilia and microvilli function at different levels within their sub-cellular hierarchies. Microvillar PABs act as a scaffolding for the enterocyte membrane. The increased surface area created by microvillar PABs allow for enhanced nutrient adsorption in the lumen of the small intestine. Mutations in microvillar PAB proteins only moderately affect gut function (Tyska et al., 2005). In contrast, the structure of each stereocilia directly affects the process of signal transduction. Mutations that alter stereocilia structure often lead to complete acousticolateralis dysfunction, making the role of the stereocilia increasingly elaborate when compared to that of the microvilli.

The PABs that make up each stereocilium directly influence the physical properties of the hair bundle. The stereociliary membrane is tightly coupled to the PABs and lies only 100 angstroms away (Tilney et al., 1980). As a result, the length and width of each stereocilium is directly proportional to the hundreds of actin filaments of which it is composed. It is interesting to note that while the height of the hair bundle varies in relation to the hair cells position along the cochlea and the frequency that it is tuned to detect, the total amount of actin utilized in each hair bundle is identical (Tilney and Tilney, 1988). A hair cell with a longer bundle has fewer, thinner stereocilia and a hair cell with a shorter bundle has an increased number of stereocilia with larger girth.

In a stereocilium, approximately $90 \%$ of the actin filaments terminate prior to the rootlet (Tilney et al., 1980). The remaining actin filaments are arranged in a donut-like pattern and extend into the cuticular plate, a dense cytoskeletal network that covers most of the apical surface of the hair-cell body (Tilney et al., 1980). This domain has a high concentration of randomly oriented actin filaments that are cross-linked by the actin bundling protein, spectrin (Tilney et al., 1989; Drenckhahn et al., 1991). In addition, the proteins tropomyosin and radixin have been identified in the cuticular plate and are postulated to play a role in stabilizing and anchoring the stereociliary rootlet (Drenckhahn et al., 1991; Pataky et al., 2004). As a result of the cuticular plate's dense structure, all vesicular traffic appears to be directed around its periphery. This area, referred to as the 
pericuticular necklace, consequently maintains a high concentration of vesicles and hair bundle proteins (Kachar et al., 1997).

Stereociliary actin filaments are predicted to undergo a steady-state process of actin renewal called actin treadmilling (Schneider et al., 2002; Rzadzinska et al., 2004; reviewed in Lin et al., 2005). Actin filaments polymerize at the tip of the stereocilia while simultaneously degrading at the base (Schneider et al., 2002). The details of this process were observed in cochlear cultures, subsequent to the over-expression of GFPactin (Schneider et al., 2002; Rzadzinska et al., 2004). Incorporation of the GFP-actin revealed the identical rates of elongation and degradation of PABs in the stereocilia (Rzadzinska et al., 2004). The rate of actin turnover was shown to adjust according to the height of the stereocilia, allowing the entire hair bundle to renew uniformly; this process takes 48 hours in cochlear hair cells and 72 hours in vestibular hair cells (Schneider et al., 2002; Rzadzinska et al., 2004). Recent evidence also implicates the adjacent stereociliary membrane in the treadmilling process (Grati et al., 2006). One of the most abundant proteins of the hair bundle, plasma membrane $\mathrm{Ca}^{2+}$ ATPase (PMCA), was over-expressed using the same technique used by Schneider et al. (2002). Like actin, PMCA turned over quite rapidly, on the order of 5-7 hours (Grati et al., 2006).

The regulation of actin filament polymerization at the stereociliary tip is only beginning to be elucidated (Mburu et al., 2006). To date, the PSD-95/SAP90 DISCSlargeZ0-1 homologous (PDZ) domain protein whirlin, the membrane associated guanlyate kinase (MAGUK) protein $\mathrm{p} 55$, and the protein 4.1R have all been implicated in this process (Mburu et al., 2003; Kikkawa et al., 2005; Mburu et al., 2006). These proteins are all localized to the tips of stereocilia in the developing hair bundle, and have been shown to interact with one another in vitro (Mburu et al., 2006). In addition, the interactions of these proteins in the process of actin microfilament assembly is well established in erythrocytes (Marfatia et al., 1995).

Of the identified proteins involved in actin polymerization, the role of whirlin has been explored in the greatest detail (Mburu et al., 2003; Kikkawa et al., 2005). Whirlin is 
postulated to be an essential structural protein that acts to organize proteins at the stereocilliary tip by virtue of its multiple PDZ domains (Mburu et al., 2003). Null mutations of whirlin, as modeled in the whirler mouse, result in dramatically shortened stereocilia in IHCs and malformed OHC bundles (Holme et al., 2002). Two isoforms of whirlin are expressed in the hair cell (Mburu et al., 2003). The long isoform of whirlin contains three PDZ domains (one C-terminal and two N-terminal) and a proline rich domain. Short whirlin lacks the two N-terminal PDZ domains (Mburu et al., 2003). While both isoforms of whirlin are expressed in the hair bundle, experiments using a BAC transgene to express only the short isoform in the whirler mouse, show a complete rescue of the mutant phenotype (Mburu et al., 2003).

Antibodies that recognize the short isoform of whirlin have been used to characterize its expression in the developing hair bundles of both IHCs and OHCs in the cochlea (Kikkawa et al., 2005). At murine age P0, whirlin is observed only in the tallest row of stereocilia of all cochlear hair cells (Kikkawa et al., 2005). In OHCs its expression is next detected in each sequentially growing row of stereocilia (Kikkawa et al., 2005). In IHCs, where rows of stereocilia are less defined, a similar pattern of expression is also detected (Kikkawa et al., 2005). In each stereocilium, whirlin's expression is restricted to the actin-free zone at the tip of the stereocilia where actin polymerization is postulated to occur (Schneider et al., 2002; Kikkawa et al., 2005). The expression of whirlin can no longer be detected in OHCs after murine age P14 or in the IHCs after age P11 (Kikkawa et al., 2005). Conversely, whirlin is expressed throughout adulthood in all stereocilia of vestibular hair cells (Kikkawa et al., 2005).

\section{E. Actin cross-linkers}

The actin filaments that make up the cytoskeletal core of each stereocilium are extensively crosslinked. The first identified actin crosslinking protein of the hair bundle was fimbrin (Tilney et al., 1989; reviewed in Tilney et al., 1992). Fimbrin is located with regular periodicity along the entire length of the stereocilium and can easily be observed 
using light microscopy as transverse stripes crossing the actin filament core (Tilney et al., 1989). As the result of two-tandem actin-binding calponin homology domains, fimbrin acts to densely pack the parallel arrays of actin filaments (Banuelos et al., 1998; Hanein et al., 1998). The crosslinks that fimbrin makes with actin are unique, having a degree of flexibility that allows the stereocilia to bend slightly in response to stimuli (Volkmann et al., 2001).

Fimbrin's interactions with actin are sensitive to high calcium $\left(\mathrm{Ca}^{2+}\right)$. In the absence of the fimbrin-actin interaction, actin bundles lose their reported ordered hexagonal packing, but still remain intact (Tilney et al., 1989). Accordingly, early research focused on the identification of other actin crosslinking proteins in the hair bundle (Tilney et al., 1989). Villin, which works in conjunction with fimbrin in the microvillus of the brush border intestinal cells, was thought to be an obvious candidate. However, early experiments indicated that villin was not expressed in hair cells (Flock et al., 1982; Shepherd et al., 1989). Over a decade later, a second protein that works in unison with fimbrin in the intestine, espin, was found to also be an actin-bundling protein of the hair bundle (Zheng et al., 2000b).

Espin was first identified in the PABs of the Sertoli cells lining the seminiferous epithelium (Bartles et al., 1996; Chen et al., 1999). Since then espin has also been characterized in a variety of sensory cells including taste cells, Merkel cells, hair cells, and the microvilli domains of the enterocyte (Bartles et al., 1998; Sekerkova et al., 2004). Each espin isoforms has like $\mathrm{C}$-terminal actin binding modules and unique $\mathrm{N}$-terminal domains that are postulated to modulate espin's specific protein-protein interactions (Bartles, 2000). Espin's affinity for actin is 10 to 100 fold higher than other identified actin-bundling proteins (Chen et al., 1999). As well, in contrast to fimbrin, espin interactions with actin are not modulated by $\mathrm{Ca}^{2+}$ concentrations (Bartles, 2000). In avian cochlear and vestibular hair cells, espin expression is concurrent with stereociliary elongation and is localized along the length of the stereocilium ( $\mathrm{Li}$ et al., 2004). The concentration of espin in each stereocilium increases with stereociliary height (Rzadzinska et al., 2005), and the over-expression of espin in tissue culture cells results 
in microvilliar structures with increased rates of growth (Loomis et al., 2003). In addition, a mutation in the $\mathrm{C}$-terminal actin-binding domain of espin has been identified as the causal mutation of the Jerker mouse (Zheng et al., 2000b). The absence of espin in the stereocilia of these mice results in thin, short stereocilia leading to deafness and vestibular dysfunction (Zheng et al., 2000b; Karolyi et al., 2003). Collectively, data suggest that espin acts to maintain the association of actin filaments, initiate their elongation and regulate the growth required to maintain the hair bundle structure utilizing a concentration-dependent mechanism (Rzadzinska et al., 2005).

\section{F. Mechanotransduction and the tip link}

\section{The tip link}

Stereocilia positioned in the tallest row of the hair bundle have oblate tips, while shorter ones have tips described as prolate. This observed tenting that occurs on shorter stereocilia is thought to be the result of mechanical tension on the stereociliary membrane caused by the presence of an extracellular linkage commonly referred to as the tip link (Fig 2E \& F: Pickles et al., 1984; Kachar et al., 2000). The tip link, visible in transmission electron micrographs from murine hair cells beginning at E17.5, spans the distance between each stereocilia and its next tallest neighbor (Denman-Johnson and Forge, 1999; Geleoc et al., 2004). The tip-link structure is predicted to be composed of a complex of proteins: up to four helical proteins that span the $150-300 \mathrm{~nm}$ between stereocilia and up to three anchoring filamentous proteins at each end that act to secure the structure to the stereociliary membrane (Kachar et al., 2000; Tsuprun et al., 2004).

The intgerity of the tip link structure is $\mathrm{Ca}^{2+}$ dependent. When hair cells are exposed to the classical calcium chelating agents, 1,2-bis( $O$-aminophenoxy)ethane$N, N, N 9, N 9$-tetraacetic acid (BAPTA) or Ethylene glycol-bis(beta-aminoethyl ether)$\mathrm{N}, \mathrm{N}, \mathrm{N}^{\prime}, \mathrm{N}^{\prime}-\mathrm{t}$ etraacetic acid (EGTA), the tip-link structures are immediately obliterated (Assad et al., 1991; Zhao et al., 1996; Marquis and Hudspeth, 1997). Following such 
treatments tip links reform in approximately 4 hours, imperfectly and independent of protein synthesis (Zhao et al., 1996). Additionally, tip links are unaffected by the protease subtilisin, but they are broken by an excess of the trivalent cation lanthanum $\left(\mathrm{La}^{3+}\right)$ (Kachar et al., 2000; Goodyear and Richardson, 2003).

\section{Potential components of the tip link}

Investigators have focused on the identification of the tip-link components since the structure was discovered in 1984 (Pickles et al., 1984). Recently, cadherin-23 (Cdh23) has become a strong candidate for a component of the tip link (Siemens et al., 2004; Sollner et al., 2004; reviewed in Gillespie et al., 2005). Cdh23 is a transmembrane protein that engages in $\mathrm{Ca}^{2+}$ dependent extracellular interactions that mediate cell-cell adhesion (Di Palma et al., 2001a). Its extracellular domain is predicted to contain 27 calcium-binding ectodomain (EC) repeats that form homophilic interactions that are common to many transmembrane adhesion glycoproteins (Nollet et al., 2000; Di Palma et al., 2001a). Two alternatively spiced isoforms of $\operatorname{Cdh} 23\left(\mathrm{Cdh} 23^{+ \text {exon68 }}\right.$ and $\left.\operatorname{Cdh} 23^{\text {-exon68 }}\right)$ are expressed in the inner ear. However, only the expression of $\mathrm{Cdh} 23^{\text {+exon68 }}$ is restricted to the hair bundle.

The short intracellular domain of Cdh23 contains two PDZ-binding interfaces (PBIs); one internal and one at the protein's C-terminus. These domains mediate the interaction of Cdh23 with the structural hair bundle PDZ protein, harmonin-b (Boeda et al., 2002). Harmonin-b contains three PDZ domains (one C-terminal and two Nterminal) and an actin-binding domain at its C-terminus (Bitner-Glindzicz et al., 2000; Verpy et al., 2000). The first PDZ domain of harmonin-b interacts with the internal PBI domain of Cdh23, while its second PDZ domain interacts with the Cdh23 C-terminal PBI (Siemens et al., 2002). The inclusion of exon 68 in $\mathrm{Cdh} 23^{\text {exon68 }}$ isoform disrupts its internal PBI domain and is proposed to specifically direct harmonin-b to interact with only the C-terminal PBI of Cdh23 (Siemens et al., 2002). Mutations in both harmonin-b and Cdh23 have been linked to the human disease Usher's Syndrome type I, subtypes C and D respectively (Verpy et al., 2000; Di Palma et al., 2001b). This disease is an 
autosomal recessive syndromic disorder that results in congenital deafness and concurrent retinitis pigmentosa (reviewed in Petit, 2001). The remaining subtypes of Usher's syndrome type I are linked to mutations in additional hair bundle proteins and will be discussed below.

The phenotypes of the waltzer mouse and sputnik zebrafish have been linked to mutations that cause the null-expression of Cdh23 (Di Palma et al., 2001b; Sollner et al., 2004). The waltzer mouse is affected by early-onset hearing-loss. This is attributed to the abnormal development of their hair bundles; in most cases the kinocilium is mislocalized, cochlear bundles do not form crescent shapes and mature hair bundles are splayed (Di Palma et al., 2001b). This severe bundle disorganization provides evidence of Cdh23's crucial role in stereociliary linkages (Bolz et al., 2001; Bork et al., 2001; Di Palma et al., 2001b). A similar dysfunctional morphology is described in the zebrafish Cdh23 mutant sputnik. Moreover, in this model, no discernible tip-link structures are detected. While the absence of tip links could be a secondary effect of the Cdh23 deficiency, the investigators feel that this observation strongly implicates $\mathrm{Cdh} 23$ as a tiplink component (Sollner et al., 2004; reviewed in Gillespie et al., 2005).

Immunolocalization data has shown Cdh23 expression in the transient lateral links that traverse the length of the developing hair bundle, in kinociliary links, and in close proximity to the tip-link structure (Siemens et al., 2004; Lagziel et al., 2005; Michel et al., 2005). Investigators reason that if $\mathrm{Ch} 23$ is a component of the tip-link complex its localization, detected by fluorescent antibodies, will be identical to that of the tip-link structure observed using electron microscopy (Siemens et al., 2004; Lagziel et al., 2005; Michel et al., 2005). In bullfrog, investigators have found just that; the localization of Cdh23 mirrors that of the tip link. Extracellular exposure to $\mathrm{La}^{3+}$ and EGTA results in the apparent disruption of the tip-link structure and eliminates Cdh23 immunoreactivity at stereociliary tips (Siemens et al., 2004; Phillips et al., 2006). However, the correlation between Cdh23 localization and tip-link integrity does not extend to murine cochlear hair cells. In these cells, despite the identical sensitivities of the tip link to BAPTA, EGTA, and $\mathrm{La}^{3+}$, the immunolocalization of $\mathrm{Cdh} 23$ persists following these treatments (Michel et 
al., 2005; Phillips et al., 2006). As well, the expression of $\mathrm{Cdh} 23$ in adult ( $>\mathrm{P} 30)$ murine hair cells is controversial (Boeda et al., 2002; Siemens et al., 2004; Sollner et al., 2004; Lagziel et al., 2005; Michel et al., 2005, Rzadzinska et al., 2005). Investigators unable to detect $\mathrm{Cdh} 23$ in mature hair bundles discount its predicted role as a principal tip-link component (Lagziel et al., 2005; Michel et al., 2005). However, late onset hearing-loss resulting from $\mathrm{Cdh} 23$ mutations has been reported, giving credence to a vital role of Cdh23 in the mature hair cell (Noben-Trauth et al., 2003).

Two models have been proposed assuming Cdh23's role as the tip link (Corey and Sotomayor, 2004; Tsuprun et al., 2004; reviewed in Gillespie et al., 2005). The first model predicts that $\mathrm{Cdh} 23$ forms a dimer of dimers (one dimer originating from each stereocilium to be connected) creating a linkage between stereocilia whose length is dependent upon the extent of dimer overlap (Corey and Sotomayor, 2004). The second model, suggested by Tsuprun et al. (2004), also predicts that Cdh23 molecules form two dimers that extend from each stereocilium, but these molecules only contact at their $\mathrm{N}$ termini. Both models have trouble fitting seamlessly with the high-resolution measurements of the tip link (reviewed in Gillespie et al., 2005). The first predicts a molecular conformation that falls short of the 100-250 nm tip link length (Kachar et al., 2000), and the second predicts a structure that may be too weak to mediate mechanotransduction forces (reviewed in Gillespie et al., 2005).

In addition to Cdh23, the CD1 and 3 isoforms of protocadherin-15 (Pcdh15), referenced for many years as the tip-link antigen (TLA), have been shown to be associated with the tip-link complex (Goodyear and Richardson, 2003; Ahmed et al., 2006). Because the extracellular domains of the Pcdh15 isoforms are much shorter $(\sim 47.3 \mathrm{~nm})$ than the estimated length of the central helical tip-link protein, it is predicted to be one of the observed filamentous anchoring proteins (Kachar et al., 2000). Pcdh15 expression was shown to persist in the mature hair bundle at the stereociliary tips and its immunolocalization is sensitive to BAPTA, EGTA, and $\mathrm{La}^{3+}$. These data, however, are controversial; other investigators show localization of Pcdh15 at the base of the stereocilia and provide evidence for its interaction with harmonin and Myo7a (Senften et 
al., 2006). Mutations in Pcdh15, as modeled in the orbiter zebrafish and Ames waltzer mouse, result in hair cells that do not transduce (Alagramam et al., 2001; Hampton et al., 2003; Seiler et al., 2005; Haywood-Watson et al., 2006). As well, mutations in human Pcdh15 have been shown to be the cause of Usher's syndrome type IF (Ahmed et al., 2003).

\section{Mechanotransduction and adaptation in the hair cell}

Tip links connect each stereocilium to its next taller neighbor. They exist in the same 3-dimensional plane as the kinocilium and create the axis of mechanical sensitivity for the hair bundle. When stereocilia deflect, along this axis towards the tall end of the hair bundle as a result of sensory stimuli, the space between congruent points on neighboring stereocilia increases and puts tension on this extracellular filamentous structure. This tension is postulated to physically open a single mechanoelectrical transduction (MET) channel that is located in conjunction with each tip-link complex in the stereociliary membrane (Holton and Hudspeth, 1986; Howard and Hudspeth, 1988). Mechanotransduction can be detected in murine vestibular hair cells at E17, concurrently with the observation of tip links at stereociliary tips, long before the hair bundle is fully mature (Geleoc et al., 2004). As well, when tip links are broken following treatment with BAPTA, EGTA or $\mathrm{La}^{3+}$, mechanotransduction is also ablated (Zhao et al., 1996; Marquis and Hudspeth, 1997).

In the absence of stimuli, the open probability of the transduction channel $\left(\mathrm{P}_{\mathrm{O}}\right)$ is 0.1-0.2 and the resting potential of the hair cell is $-60 \mathrm{mV}$ (Hudspeth, 1989; Fettiplace et al., 1992). A stimulus in the positive direction, deflecting the hair bundle toward the kinocilium and increasing tension at the tip link, causes the open probability of the transduction channels to increase $\left(\mathrm{P}_{\mathrm{O}}\right.$ approaches 1$)$, allowing the positively charged potassium $\left(\mathrm{K}^{+}\right)$and $\mathrm{Ca}^{2+}$ ions from the surrounding endolymph to enter the cell. The subsequent cellular depolarization (with maximum receptor potentials equaling tens of millivolts) causes increased synaptic release and consequent neuronal signaling (Hudspeth and Corey, 1977; Fettiplace and Crawford, 1978). Early kinetic experiments performed to develop transduction models indicated that hair-bundle transduction 
kinetics would not fit a traditional Z-state model. Instead, it was proposed that a third, closed state must be added to the traditional two-state model. This added state was referred to as

the "spring" element and became the crux of the "gating spring model" (Corey and Hudspeth, 1983). Initially, the tip link was proposed to be this spring element (Assad et al., 1991; Pickles et al., 1991). However, a recent alternative model suggests that the gating spring may not be the tip link, which appears in high-resolution images to be inelastic, but instead an extension of the MET channel (Kachar et al., 2000; Howard and Bechstedt, 2004; Tsuprun et al., 2004).

Electrophysiological recordings from vestibular hair cells have provided substantial data detailing the process of mechanotransduction. An representative electrophysiological trace that depicts the ion flux in a hair cell following a sustained stimulus is shown in Fig 3. The immediate sharp downward spike is indicative of the positive flow of current into the cell. This current then deteriorates as the result of the process of adaptation (Eatock et al., 1987). This process can be separated into two components (Wu et al., 1999; Holt and Corey, 2000). The first, fast adaptation, occurs in a few milliseconds and results from $\mathrm{Ca}^{2+}$ binding to proximal intracellular sites, perhaps located on the channel, causing its rapid closure (Ricci et al., 1998; Wu et al., 1999). The second component, slow adaptation, is believed to occur as the result of the tip link, MET channel, and associated molecules relocating to a lower position on the stereocilia, thereby decreasing tension in the tip link and allowing for the MET channel's gradual reclosure. Slow adaptation occurs on a timescale of tens of milliseconds following a stimulus (Fig 3: O Eatock et al., 1987; Assad and Corey, 1992). Approximately 60-80\% of the MET channel sensitivity is regained following slow adaptation (Fig 3: $\mathbf{\square}$; reviewed in Eatock, 2000). When the bundle stimulus is removed or when the bundle is deflected in the negative direction, the tip link becomes lax and transduction channels completely close, $\left(\mathrm{P}_{\mathrm{O}}=0\right.$; Fig 3: $\left.\mathbf{\Delta}\right)$. To reset tip-link tension and maintain maximum bundle sensitivity, the transduction channel complex relocates to a position higher on the stereocilia. This returns the MET channel open probability to $\mathrm{P}_{\mathrm{O}}=0.1$ (reviewed in Eatock, 2000). Both the initial slipping of the MET channel complex in response to 
sustained stimuli and the relocation of the complex to a higher point on the stereocilium following the cessation of the stimulus is regulated by the hair cell's adaptation motor (to be discussed below, Howard and Hudspeth, 1987; Assad et al., 1989).

Many experiments have been done to characterize the physiological properties of the MET channel. It is predicted to be a cation channel that boasts a large, non-selective pore that is sensitive to $\mathrm{Ca}^{2+}$ (Corey and Hudspeth, 1979; reviewed in Corey, 2006; reviewed in Ricci et al., 2006). However, to date, the identity of the MET channel is still unknown. Recent advances made using an invertebrate model indicate that TRP family ion channels have a strong role in mechanotransduction. In Drosophilia both NOMPC (TRPN1) and TRPV have been implicated in mechanosensory transduction (Walker et al., 2000; Kim et al., 2003; Gong et al., 2004). As well, these channels are attractive candidates for hair-cell mechanotransduction in mammals (reviewed in Corey, 2006). They have a conductance amplitude and a low ion selectivity that are similar to those predicted for the MET channel (Owsianik et al., 2006). Furthermore, they possess a series of elastic ankryin repeats (Corey et al., 2004; Howard and Bechstedt, 2004). These repeated domains may have the flexibility needed to act as the gating spring of the MET channel complex (Sotomayor et al., 2005). However, TRPN1 is not expressed in mammals. Alternate research has focused on another gene of the TRP family, TRPA1. This isoform has 17 ankyrin repeats, the largest number reported in mammalian TRP family channels (reviewed in Gillespie et al., 2005). Investigators have examined the characteristics of this channel in the hair bundle extensively (Corey et al., 2004; Nagata et al., 2005). The expression of TRPA1 mRNA levels correlate with the onset of mechanotransduction (Corey et al., 2004). As well, siRNA experiments directed against TRPA1 reduce transduction in murine vestibular hair cells (Corey et al., 2004). However, TRPA1 is localized robustly along the length of the stereocilium, at a much higher concentration than one would expect if TRPA1 was acting as the MET channel, which is postulated to be present only one or two times per stereocilium (Corey et al., 2004; Nagata et al., 2005). In addition, TRPA1 knockout mice maintain auditory function (Kwan et al., 2006). Thus continuing research focuses on identifying the MET channel (reviewed in Corey, 2006). 
The phospholipid phosphatidylinositol 4,5-bisphosphate $\left(\mathrm{PIP}_{2}\right)$ has previously been shown to regulate TRP channels (Hilgemann et al., 2001). Consequently, investigators were interested in the potential role $\mathrm{PIP}_{2}$ may have in the regulation of the MET channel in hair cells. $\mathrm{PIP}_{2}$ was shown to be localized to the upper two-thirds of the hair bundle, and absent from the stereociliary base where phosphatidylinositol lipid phosphatase (Ptprq) is expressed (Hirono et al., 2004). Most interesting, electrophysiological recordings show that the depletion of $\mathrm{PIP}_{2}$ decreases the rates of both fast and slow adaptation (Hirono et al., 2004). As well, PIP $_{2}$ has been shown to interact with the slow adaptation motor, Myosin-1c (Myo1c), in vitro (Hirono et al., 2004; Hokanson and Ostap, 2006). These data support the hypothesis that the MET channel may be a member of the TRP channel family and illustrate the complexity of MET regulation.

\section{G. Additional lateral links of the hair bundle}

In addition to the cluster of proteins referred to collectively as the tip link, multiple other lateral links connect adjacent stereocilia at different positions along the length of stereocilia during bundle development. In the avian hair bundle, discrete antibodies label shaft connectors, horizontal top connecting links, ankle links, tectorial membrane (TM) attachment crowns and kinociliary links, providing evidence of each structure's unique biochemical composition (Goodyear and Richardson, 1992, 1999; Goodyear and Richardson, 2003). As well, each observed link has a unique expression pattern during development and differing sensitivities to $\mathrm{Ca}^{2+}$ chelators and proteases (Goodyear et al., 2005). Shaft connectors, which are present along the entire length of the developing hair bundle are first detected at murine age E17.5 and persist until P19 (Goodyear et al., 2005). Shaft connectors are predicted to be composed of Ptprq and are not sensitive to $\mathrm{Ca}^{2+}$ chelators or proteases (Goodyear et al., 2003; Goodyear et al., 2005). Horizontal top connectors, first observed at P9, are also insensitive to both BAPTA and subtilisin, and remain present in the adult hair bundle (Goodyear et al., 2005). Ankle 
links, present transiently from P2-9, are predicted to be composed of very large Gprotein-coupled receptor 1 (Vlgr1) and usherin proteins (Adato et al., 2005; McGee et al., 2006). These have been shown to be sensitive to both $\mathrm{Ca}^{2+}$ chelation and subtilisin treatment and crucial to bundle development (Goodyear et al., 2005; McGee et al., 2006). TM crowns, first observed at P2, are also present in adult hair bundle and degraded by subtilisin, but are unaffected by BAPTA (Goodyear et al., 2005). Kinociliary links, as suggested, connect the kinocilium to the tallest row of stereocilia. These structures are observed in concurrence with the kinocilium, transiently in the cochlea where the kinocilium degrades, and for the lifetime of the hair bundle in vestibular organs where the kinocilium remains (Goodyear et al., 2005). Although the kinocilium is believed to have no direct role in mechanotransduction, antibodies against both Cdh23 and Pcdh15 recognize kinociliary links and investigators postulate that kinociliary links and tip links must be closely related (Siemens et al., 2004; Lagziel et al., 2005; Michel et al., 2005; Ahmed et al., 2006).

\section{H. Myosins of the hair bundle}

In addition to providing structural support for stereocilia, the high concentrations of actin in the hair cell also enable the directed transport of molecules to the distal tips of the hair bundle. As such, unconventional myosin proteins, a class of actin-based motor molecules, have been determined to be vital for proper hair cell function. Unconventional myosin molecules are a large sub-class of the myosin motor proteins that consist of a single heavy chain, in contrast to the dual self-associating heavy chains of traditional myosins (reviewed in Cheney and Mooseker, 1992). The head domain of the myosin molecule binds to and moves along actin filaments, through an actin-binding region, using the traditional myosin power-stroke movement (Spudich and Watt, 1971). Energy consumed during this movement results from adenosine triphosphate (ATP) hydrolysis by the head domain. The mid-section of the unconventional myosin, the neck domain, is composed of multiple (up to six), tandem calmodulin (CaM)-binding sequences referred to as IQ domains, named as such for the first two amino acids, 
isoleucine and glutamine, that make up the CaM-binding consensus sequence: $\mathrm{IQX}_{3} \mathrm{RGX}_{3} \mathrm{R}$ (single amino acid code, where $\mathrm{X}=$ any residue; Rhoads and Friedberg, 1997; reviewed in Bahler and Rhoads, 2002). The rate of actin hydrolysis and the resulting step size of the power-stroke is often regulated by the CaM occupancy of this neck region, which in turn, is regulated by $\mathrm{Ca}^{2+}$ (reviewed in Bahler and Rhoads, 2002). $\mathrm{CaM}$ is able to bind four $\mathrm{Ca}^{2+}$ molecules (reviewed in Chin and Means, 2000). When these binding sites are filled, CaM adopts a conformation that is generally unfavorable for its interaction with the IQ domains of myosin molecules (reviewed in Chin and Means, 2000; reviewed in Bahler and Rhoads, 2002). Conversely, when $\mathrm{Ca}^{2+}$ concentrations are low, CaM binds the IQ consensus sequences tightly. Each IQ domain has its own specific affinity along this spectrum, allowing for the precise regulation of myosin activity in response to $\mathrm{Ca}^{2+}$ flux. A tail domain, the most variable region among myosin molecules, completes the C-terminus of the unconventional myosin (reviewed in Cheney and Mooseker, 1992).

Since the origin of the motor model of adaptation, the hair-cell adaptation motor has been postulated to be a myosin molecule (Howard and Hudspeth, 1987). To test this hypothesis, investigators focused on interrupting general myosin function in the hair bundle by applying saturating concentrations of adenosine diphosphate (ADP) during sustained mechanical stimuli (Gillespie and Hudspeth, 1993). Excess amounts of ADP were predicted to saturate the active site of any myosin molecules present in the bundle and hold them in a state of rigor, thereby preventing both slipping and climbing adaptation (Gillespie and Hudspeth, 1993). Because ADP can be modified to form ATP in vivo, an analog of ADP that can not be phosphorylated, adenosine $5^{\prime}-[\beta$ thio]diphosphate (ADP[ $\beta S]$ ), was used (Goody et al., 1972). Following a sustained stimulus given in conjunction with $\mathrm{ADP}[\beta \mathrm{S}]$, the transduction current in bullfrog saccular hair cells ceased to adapt, and the resting $\mathrm{P}_{\mathrm{O}}$ value increased from 0.1 to 0.8 (Gillespie and Hudspeth, 1993). These data indicated that essentially all MET channels remained open following the stimulus and adaptation was completely blocked (Gillespie and Hudspeth, 1993). It also provided strong evidence that the adaptation motor was in fact a 
myosin isozyme, and investigators began to focus on its identification (Gillespie and Hudspeth, 1993).

\section{Myosin-1c}

Myo1c, $120 \mathrm{kDa}$, was the first myosin identified in the hair cell bundle and an early candidate for the adaptation motor (Gillespie et al., 1993; Gillespie and Corey, 1997). Myo1c's neck domain is composed of four tandem IQ motifs and a highly basic tail domain that has been shown to bind to $\mathrm{PIP}_{2}$ in vitro (Hirono et al., 2004; Hokanson and Ostap, 2006). Myo1c mRNA can first be detected in the murine vestibular hair cell at E17, the same time as the developmental acquisition of mechanotransduction (Geleoc and Holt, 2003). Initial studies in the bullfrog sacculus showed a distinct immunolocalization of Myo1c to the distal two-thirds of the stereociliary shaft, in the pericuticular necklace, and diffusely throughout the hair cell body (Gillespie et al., 1993). Further ultra-structural localization experiments showed the highest density of Myo1c immunoreactivity around the base of the tip-link insertion plaque (Metcalf et al., 1994; Garcia et al., 1998; Steyger et al., 1998).

To directly implicate Myo1c in mechanotransduction, investigators developed a mutant Myo1c by replacing a key tyrosine residue of the ATP-binding pocket with glycine (Y61G; Gillespie et al., 1999). Because glycine is small, Y61G has a larger binding pocket when compared to wild-type Myo1c. This enables larger molecules like $\mathrm{N}^{6}$-modified (NMB)-ADP analogs to interact with the Y61G catalytic components. Because NMB-ADP can not be hydrolyzed, its interaction with Y61G results in the complete inhibition of myosin ATPase activity and the arrest of myosin motility (Gillespie et al., 1999). Despite the mutation, the motility and activity of Y61G remains similar to wild-type Myo1c in the absence of NMB-ADP analogs (Gillespie et al., 1999). Y61G, when expressed in transgenic mice, provides an ideal model to assess Myo1c's contribution to mechanotransduction and adaptation (Holt et al., 2002). Because it is completely functional in the absence of NMB-ADP analogs, investigators were able test for Myo1c function in a targeted manner by perfusing NMB-ADP into vestibular hair bundles during a sustained mechanical stimulus. Under these conditions, the Y61G 
mouse showed no adaptative response (Holt et al., 2002). Investigators postulate that the mutant Myo1c molecules, acting as part of a large grouping of Myo1c molecules that function as the adaptation motor, arrest on the actin cytoskeleton and prevent the sliding and climbing of the MET channel complex (Holt et al., 2002; Stauffer et al., 2005).

Myo1c's role as the slow adaptation motor in vestibular hair cells is a wellestablished hypothesis. However, the localization of Myo1c in the murine cochlear hair cell is not limited to the stereociliary tips. As a result, the role of Myolc in auditory hair cells is not as clear, and other myosin molecules have been posited as adaptation motor candidates (Kros et al., 2002). Nevertheless, because of its early identification and interesting localization, Myo1c has been the focus of intense research. Unfortunately, a mouse model for Myo1c mutations, perhaps the most powerful tool in protein characterization, does not yet exist; attempts to develop a Myo1c knockout mouse have been unsuccessful (personal communication, P. Gillespie). Alternately, in situ binding assays using recombinant Myo1c fragments consisting of combinations of its neck and tail domains have been used to characterize Myo1c's interactions with other constituents of the hair cell (Cyr et al., 2002). Myo1c's distinct localization at the tip of the stereocilia was shown to be dependent upon only its neck domain and consequently is regulated by CaM occupancy at these domains (Cyr et al., 2002). Excess CaM abolishes all interactions of Myo1c and hair bundle constituents observed using the in situ binding assay. It is proposed that interactions of Myo1c and hair bundle constituents are disrupted as the result of $\mathrm{CaM}$ masking an interaction domain present in the neck sequence (Cyr et al., 2002). Of particular focus is the second IQ domain of Myo1c, which shows a level of sequence conservation across species that surpasses that needed for CaM interaction (Cyr et al., 2002).

In addition, Myo1c has recently been shown to interact with Cdh23 when overexpressed together in tissue culture cell lines (Siemens et al., 2004). If Cdh23 is a component of the tip link, as suggested, its interaction with Myo1c might be expected (Siemens et al., 2004). These data, along with its proposed in vivo interaction with $\mathrm{PIP}_{2}$, 
may begin to elucidate the molecular components that regulate hair-cell mechanotransduction (Hirono et al., 2004; Hokanson and Ostap, 2006).

\section{Myosin-7a}

Myo7a is composed of a head domain, five IQ domains, a coiled-coil domain that enables the formation of homodimers, and a tail domain (Weil et al., 1997). The tail of Myo7a has a myosin tail homology 4 (MyTH4) domain, a SH3 domain, and a FERM domain, which is a region of high sequence homology to that of the 4.1 protein family which associates with integral membrane proteins (Chen et al., 1996). By virtue of its tail, Myo7a interacts directly with the N-terminal PDZ domains of harmonin-b, and this interaction is believed essential to localization of harmonin-b in the hair bundle (Boeda et al., 2002). Mice that do not express Myo7a (shaker1 mutants) express harmonin-b only in the hair-cell pericuticular necklace, as opposed to the stereociliary tips as seen in wildtype animals. These data, along with evidence of Cdh23 and harmonin-b interactions, has led to the hypothesis that the three proteins interact in a complex that acts to regulate bundle formation and shape (Boeda et al., 2002). However, Cdh23 localization in the shaker 1 mouse is normal, and therefore, the stereociliary transport of $\operatorname{Cdh} 23$ is not dependant upon Myo7a. In addition to its interaction with harmonin-b, Myo7a also interacts with vezatin, a protein associated closely with the ankle links of stereocilia and the hair-cell adherens junctions (Kussel-Andermann et al., 2000).

Myosin-7a (Myo7a) mutants have been modeled in seven allelic variations of the shaker 1 mouse. Five of these mutations occur in the head domain of Myo7a, presumably disrupting Myo7a motor function and two occur in the tail domain. All mutations disrupt normal cochlear electrophysiology and only one shakerl variant has normal hair-bundle development (Mburu et al., 1997). Shaker 1 mice demonstrate very poor hair-cell mechanotransduction, only transducing following very large mechanical bundle deflections of more than $100 \mathrm{~nm}$ (Kros et al., 2002).

In addition to the allelic variations in the shakerl mouse family, the mutant mouse, headbanger, also harbors mutations that map to the same locus as Myo7a (Rhodes 
et al., 2004). However, the phenotype of these hair cells, an "O" shaped bundle, does not coincide with the shakerl bundle morphology (Rhodes et al., 2004). As well, headbanger mice are not profoundly deaf and exhibit reduced levels of Myo7a (Rhodes et al., 2004). Myo7a mutations have also been linked to the human disease, Usher's syndrome type I B (Liu et al., 1997).

Myo7a has been postulated to regulate the function of the MET channel (Kros et al., 2002). However, as is the case for Myo1c, Myo7a is localized along the entire length of the stereocilia of murine cochlea (Hasson et al., 1995). This arrangement suggests that if Myo7a does directly regulate the MET channel at the tips of stereocilia, it must do so by regulating the tension applied to the entire stereociliary membrane, and consequently affect the MET channel function (Kros et al., 2002). Other hypotheses propose that Myo7a may maintain the environment necessary for MET channel function by transporting molecules essential for MET channel regulation to their proper location in the stereocilia (Boeda et al., 2002).

\section{Myosin-6}

Myosin-6 (Myo6) is the only unconventional myosin protein reported in association with the hair bundle whose actin motility is directed toward the base of the stereocilia (Wells et al., 1999). In addition to its catalytic head domain, Myo6 has only one IQ domain, a coiled-coil domain, and a short tail region with no identifiable binding domains. Myo6, specific to the hair cell, is localized to the rootlet of the stereocilium and is observed most clearly in the cuticular plate (Hasson et al., 1997) (Avraham et al., 1995). It has been postulated to anchor the apical membrane of the stereocilia to the cuticular plate region (Hasson et al., 1997; Kappler et al., 2004).

Mutations in Myo6 cause auditory and vestibular dysfunction that define the Snell's waltzer mouse phenotype (Melchionda et al., 2001). In early development, normal hair bundle morphology is observed in these mice, but as the hair cell matures, the stereocilia begin to fuse and the hair cell eventually degrades (Seiler et al., 2004). Cochlear hair cells are completely degraded in these mice by 6 weeks of age (Avraham et 
al., 1995). In addition to the murine model, mutations to Myo6 or species homologues have been identified in both humans and zebrafish, concurrently with deafness and vestibular dysfunction (Melchionda et al., 2001; Kappler et al., 2004).

\section{Myosin-15a}

Myosin-15a (Myo15a) is located exclusively at stereociliary tips, concentrated at the space between the end of the actin core (positive-end) and the stereociliary plasma membrane (Belyantseva et al., 2003). It contains two IQ domains in its neck region, followed by a long proline/tyrosine rich region of unknown function, and a tail containing MyTH4, SH3, and FERM domains in a pattern identical to that of Myo7a (Chen et al., 1996; Mburu et al., 1997; Liang et al., 1999). Myo15a transports whirlin to its position at the tips of stereocilia, and without its expression, whirlin remains in a pool in the cuticular plate region, and stereociliary elongation is disrupted (Kikkawa et al., 2005). Mice with mutations in Myo15a (shaker2), much like the whirler mouse, which does not express whirlin, have dramatically shortened stereocilia and are profoundly deaf (Wang et al., 1998; Liang et al., 1999). As hair cells mature (>P9) in mutant animals the links between stereocilia disappear and the hair bundle morphology degrades (Anderson et al., 2000). As well, extended actin filaments can be observed in the basal region of the hair cell indicating an actin organizational deficiency (Anderson et al., 2000). However, prior to bundle degradation, both the shaker 2 and whirler mice have normal mechanotransduction following a mechanical stimulus in vitro (Stepanyan et al., 2006). This provides evidence that neither Myo15 or whirlin plays a direct role in MET channel function (Stepanyan et al., 2006).

\section{Myosin-3a}

In addition to the head and neck domains observed in other unconventional myosins, myosin-3a (Myo3a) has a N-terminal kinase domain that undergoes autophosphorylation ( $\mathrm{Ng}$ et al., 1996; Komaba et al., 2003), and two unique motifs termed myosin III tail homology domains (3THDI and 3THDII; Dose et al., 2003). Myo3a expression in the stereocilia is localized to the crown of the stereocilia forming a

thimble-like compartment at the stereociliary tip (Schneider et al., 2006). This 
localization occurs even in the absence of the 3THD domains, and the over-expression of Myo3a at stereociliary tips causes abnormal elongation of the stereocilium (Schneider et al., 2006).

\section{Myosin-1a}

Myosin-1a (Myo1a) is the predominant myosin motor protein found in the enterocyte, the specialized epithelial cell that lines the gut (Fig 5). The MYO1A gene may give rise to multiple Myo1a isoforms; in the gut, full-length Myo1a mRNA transcript is detected, along with a short isoform that is predicted to code for the proteins C-terminus (unpublished data, M. Tyska). Like other unconventional myosins, full length Myo1a is composed of the actin-binding head domain, the neck domain made up of three IQ-binding motifs, and tail domain (reviewed in Mooseker and Cheney, 1995). The tail domain of Myo1a has a highly basic region, the TH1 domain, which binds directly to cellular membranes and has been shown to be involved in Myola localization (reviewed in Mooseker and Cheney, 1995). High concentrations of Myola exist in the gut as part of the arrays of microvilli that form the brush border domains of the enterocyte (Mooseker, 1985). Here, Myo1a function is unclear, although it is predicted to anchor the enterocyte actin cytoskeleton to extracellular membranes, regulate microvillar organization and packing, or facilitate vesicle release in microvilli. Myo1a function in the brush borders of the gut has been studied using a genetically engineered Myola knockout (KO) mouse (Tyska et al., 2005). Extensively characterized, this mouse does not express full-length Myo1a mRNA transcripts or protein in the gut tissue (Tyska et al., 2005). Careful comparison between Myo1a KO mice and wild-type mice reveal that despite the lack of an overt phenotype, Myola KO mice have cellular perturbations in the organization and packing of both the brush border domains and microvillar arrays. In addition, the localization of Myo1c at the membrane region of the enterocyte is increased, suggesting potential myosin compensation and functional redundancy (Tyska et al., 2005). 
Recently, Myo1a has been linked to auditory dysfunction. Multiple mutations in Myo1a have been identified as a result of broad genetic screening in patients with sensorineural bilateral hearing loss, although the pathogenesis of this hearing loss has not yet been elucidated (Donaudy et al., 2003). As well, Myo1a maps to the newly identified non-syndromic autosomal dominant chromosomal locus DFNA48 (D'Adamo et al., 2003). Despite the detection of Myo1a mRNA transcripts in the cochlea, Myola protein expression or localization in the auditory/vestibular systems is unknown, and the Myo1a KO mouse shows no overt auditory or hearing deficits, although careful analysis of auditory function has not been performed (Donaudy et al., 2003, K. Phillips \& M. Tyska unpublished data, and unpublished observation, M. Tyska).

\section{Hurdles of hair-cell research}

\section{Hair-cell biochemistry}

Humans have approximately 32,000 hair cells in their cochlea and 134,000 total (reviewed in Hudspeth, 1989). Compared to the 131 million photoreceptors present in one human retina, it is clear that those studying the acousticolateralis systems are at a severe disadvantage with respect to experimental sample size. In addition, hair cells are unable to survive in a cell culture environment for longer than a few days, they do not divide, and there are no hair-cell tissue culture lines. As a result, it becomes very challenging to conduct biochemical research. Therefore, out of necessity, hair-cell research requires innovative laboratory techniques. Initial experiments focused on isolating the cytoskeletal core of the hair bundle and its associated proteins (Tilney et al., 1989). This enabled the early identification of both actin and fimbrin (Flock and Cheung, 1977; Tilney et al., 1989). However, because the membrane was sheared away during these procedures, many low abundant, soluble and membrane-associated proteins were lost.

In an attempt to examine constituents specific to the hair bundle more closely, the "bundle blot" and "twist off" methods were developed in 1989 and 1991, respectively 
(Shepherd et al., 1989; Gillespie and Hudspeth, 1991). Each of these methods entailed mechanically separating the bullfrog saccular hair bundle from the hair cell body while it was secured in the macula. In the bundle-blot method, stereocilia were pressed against nitrocellulose sheets, to which they adhered. When the nitrocellulose was pulled away from the macula, the bundles broke at the stereociliary taper. The bundles were then extracted from the nitrocellulose membrane and used as experimental samples. The bundle blot method uses approximately 30 saccular equivalents per silver-stained SDSPAGE gel lane (Shepherd et al., 1989). Using this method, the high concentrations of actin and fimbrin in the hair bundle were confirmed, as was the absence of villin. In addition, a small number of other unidentifiable proteins were observed. In a similar technique, hair bundles were embedded in warm agarose in the twist-off method (Gillespie and Hudspeth, 1991). After cooling, the hardened agarose was sharply twisted, and the bundles isolated (Gillespie and Hudspeth, 1991). The twist-off method yielded approximately $<40 \mathrm{ng}$ of purified protein per saccular equivalent, $50-75 \%$ being actin, and as many as 50 saccular equivalents were used per SDS-PAGE gel lane (Gillespie and Hudspeth, 1991). Both experiments were ingenious and technically challenging, but neither provided a complete complement of hair bundle proteins or a way to identify the proteins isolated. Thus, for decades the identification of hair bundle constituents using biochemical techniques was a difficult and unrewarding process.

\section{Genetic screening and mass spectrometry}

Hair cell research of the $21^{\text {st }}$ century has been increasingly successful as genetically-based research has flourished (Nicolson, 2005a). Many of the recently identified proteins of the hair bundle have been the result of a zebrafish, mouse or human models of deafness. Because zebrafish can be systematically mutated and screened for hearing deficits en masse, they have proven to be powerful genetic tools. Myo6 was shown to be essential to mechanotransduction in this manner (Kappler et al., 2004). As well, mice strains that show acousticolateralis dysfunction have been instrumental to recent advances. Currently there are 40 mouse models that have mutations in genes implicated in non-syndromic deafness (hearing-loss not associated with other disorders; 
Www.jax.org). Of these mouse models, 26 correlate with non-syndromic deafness disorders identified in humans (http://ghr.nlm.nih.gov/ghr/page/BrowseConditions), and 15 directly relate to the hair bundle. From these models, researchers have been able to identify those genes essential to hearing and predict their specific function based on the diseased phenotype.

Supplementing strong genetic tools are the advances in the sensitivities of massspectrometry. Proteins isolated from hair cells can now be identified despite their low abundances. As a result, researchers have been able to identify the previously unknown antigens of antibodies created against hair bundle proteins. VLGR1 was identified in such manner (McGee et al., 2006). Known as the ankle link antigen (ALA) for seven years, VLGR1 was immunoprecipitated from avian retina, digested with trypsin, and identified by comparison to proteins catalogued in the National Center for Biotechnology Information human and mouse databases (McGee et al., 2006).

\section{J. Significance of hair-cell research}

The precise detection abilities of the auditory and vestibular systems occur as a result of hair cell physiology and consequent mechanical signaling pathways. These fragile mechanics are susceptible to both genetic and environmental stresses that can result in partial hearing loss or deafness. Moreover, the hair cells of higher vertebrates are never replaced by mitotic turnover. Thus the only hair cells we have are the ones we begin life with. Insult to hair bundle structure resulting from sudden loud noises or prolonged stimuli can manifest in temporary hearing loss which has been shown to occur on the same time scale as tip link regeneration and actin turnover in the hair bundle (Zhao et al., 1996; Schneider et al., 2002).

Congenital deafness, as a result of hair-cell loss, affects 1 in every 1000 children (Hudspeth, 1997). Additionally, as the United States population's life expectancy increases, the number of older adults with age-onset hearing loss will also increase. 
Hearing loss, related to hair cell damage due to over stimulation, infections, and phamaceutical agents, is becoming increasingly prevalent. Approximately $33.2 \%$ of the adult population over 70yrs of age report deafness or hearing-loss and the resulting problems in daily life (Campbell et al., 1999). Overall, 28 million people in the US are affected by hearing loss, and over 50 billion dollars are spent annually compensating for these deficits (http://ghr.nlm.nih.gov/condition=nonsyndromicdeafness and Hudspeth, 1997).

Despite intensive research, much about the molecular details of auditory and vestibular mechanotransduction is unknown. To date, only a few key proteins have been identified and much about the molecular components comprising the gating spring model is unknown. The long-term goal of our research is to detail the mechanisms and participating proteins of the MET complex in the hair bundle, the site of auditory and vestibular transduction. Identification of these proteins is the first step towards developing genetic therapies and repair.

\section{K. Summary and research goals}

The hair bundle, an apical protrusion of the hair cell, is the site of mechanotransduction in the acousticolateralis systems. It is composed of numerous stereocilia and a single kinocilium that is lost as the cochlear bundle matures (reviewed in Hudspeth and Jacobs, 1979). The main constituent of the stereocilia is actin. In the hair bundle actin forms unidirectional filamentous arrays that are oriented with the barbed end of the actin pointing towards the tip of the stereocilia (Tilney et al., 1980). These arrays are held together by the crosslinking proteins fimbrin and espin and provide a cytoskeletal structure that shapes the hair bundle (Shepherd et al., 1989; Tilney et al., 1989; Zheng et al., 2000b). The actin filaments are dynamic and undergo constant renewal by a process referred to as treadmilling (Schneider et al., 2002; Rzadzinska et al., 2004). Structural proteins, such as whirlin and harmonin-b, bind to the cytoskeleton and 
organize proteins of the hair bundle involved in mechanotransduction (Verpy et al., 2000; Holme et al., 2002).

Mechanotransduction refers to the physical opening of a MET channel, in response to the physical force provided by a stimulus, that results in the transmission of synaptic signal. The tip link, a complex of proteins that connects each stereocilia to its next tallest neighbor, is the sensor for this physical force (Pickles et al., 1984; Assad et al., 1991). While the identity of the tip link is controversial (Michel et al., 2005), much evidence has been published that supports the roles of both $\operatorname{Cdh} 23$ and Pcdh15 in the tiplink complex (Siemens et al., 2004; Sollner et al., 2004; Ahmed et al., 2006). Following a stimulus, the components of the MET channel move to a lower position on the stereocilia; this relieves the force applied to the tip link and closes the channel (Eatock et al., 1987). This process, adaptation, allows the hair bundle to be sensitive to new stimuli.

Unconventional myosins, molecular motors that move along filamentous actin, play important roles in proper hair bundle development and function (reviewed in Friedman et al., 1999). Adaptation is believed to be mediated by Myo1c (Holt et al., 2002; Stauffer et al., 2005). In vestibular organs Myo1c localizes in association with tip link insertional plaques and is essential to MET (Garcia et al., 1998; Steyger et al., 1998).

The goal of this research is to describe the interaction of Myo1c with the other unknown components associated with the MET channel. As well, we would like to use the characterization of this interaction to identify these unknown components. In-situ binding assays using recombinant fragments of Myo1c show an identical localization pattern as endogenous Myo1c (Cyr et al., 2002). These interactions are dependent upon only the neck region of Myolc and are modulated by $\mathrm{CaM}$; excess $\mathrm{CaM}$ added to the in situ binding reaction eliminates all Myo1c localization (Cyr et al., 2002). In addition, the sequence conservation across species of the second IQ domain far exceeds that necessary to confer CaM interaction (Cyr et al., 2002). It is our hypothesis that the second IQ domain of Myo1c is important to its interactions with components of the MET channel complex, and when in excess, CaM masks this domain. As well, Myo1c has also been 
shown to interact with $\mathrm{PIP}_{2}$ and Cdh23 in vitro (Hirono et al., 2004) (Siemens et al., 2004). We wish to explore these potential interactions in the hair bundle using the in-situ binding assay.

Finally, there has been recent evidence of Myo1a's association with hearing disorders in humans (Donaudy et al., 2003). Despite the detection of Myo1a mRNA transcript in the cochlea, the role of Myola in hearing is unknown (Donaudy et al., 2003). Moreover, previous studies that have examined the expression of Myola protein in vestibular hair cells have been negative (Hasson et al., 1997). To address these questions, we have developed a collaboration with Dr. Matthew Tyska at Vanderbilt University. Using antibodies against Myola and Myola mutant mice provided by his laboratory, we wish to characterize Myo1a's expression in the cochlea. 


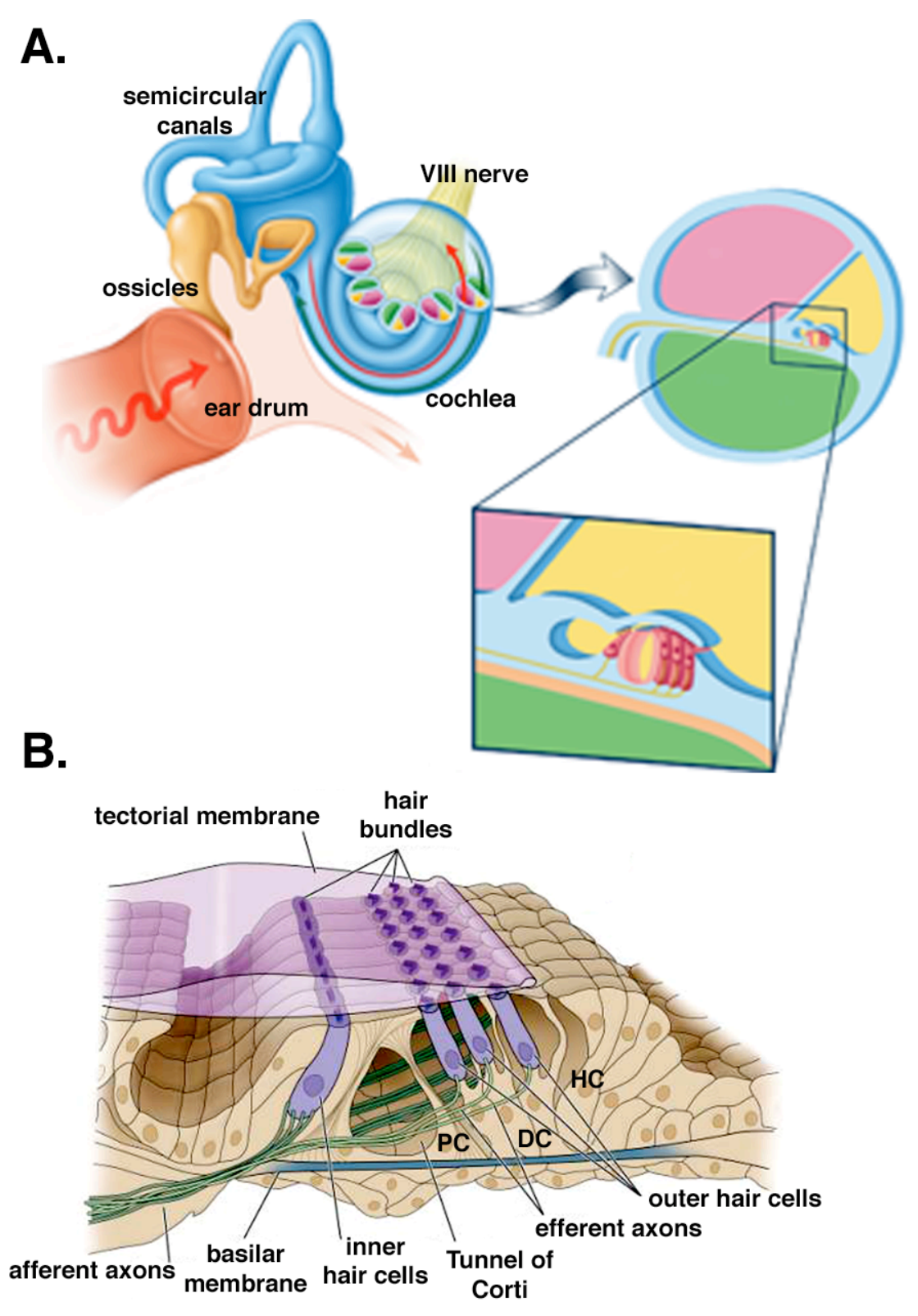

Figure 1. Inner ear morphology A) Cartoon schematic of the inner ear. A soundwave is shown in red. Gray arrow points to longitudinal cross-section of cochlear labyrinth. The tympanic, vestibular, and cochlear canals are colored green, pink and yellow respectively. Boxed inset shows the organ of Corti and hair cells. Image, without labels, is used with permission from www.brainconnection.com, copyright 1999, Scientific Learning Corportation $B$ ) Detailed cartoon of the Organ of Corti. Supporting cells are labeled as follows: $P C$, pillar cell; $D C$, Dieter cell; and $H C$, Henson cell. 

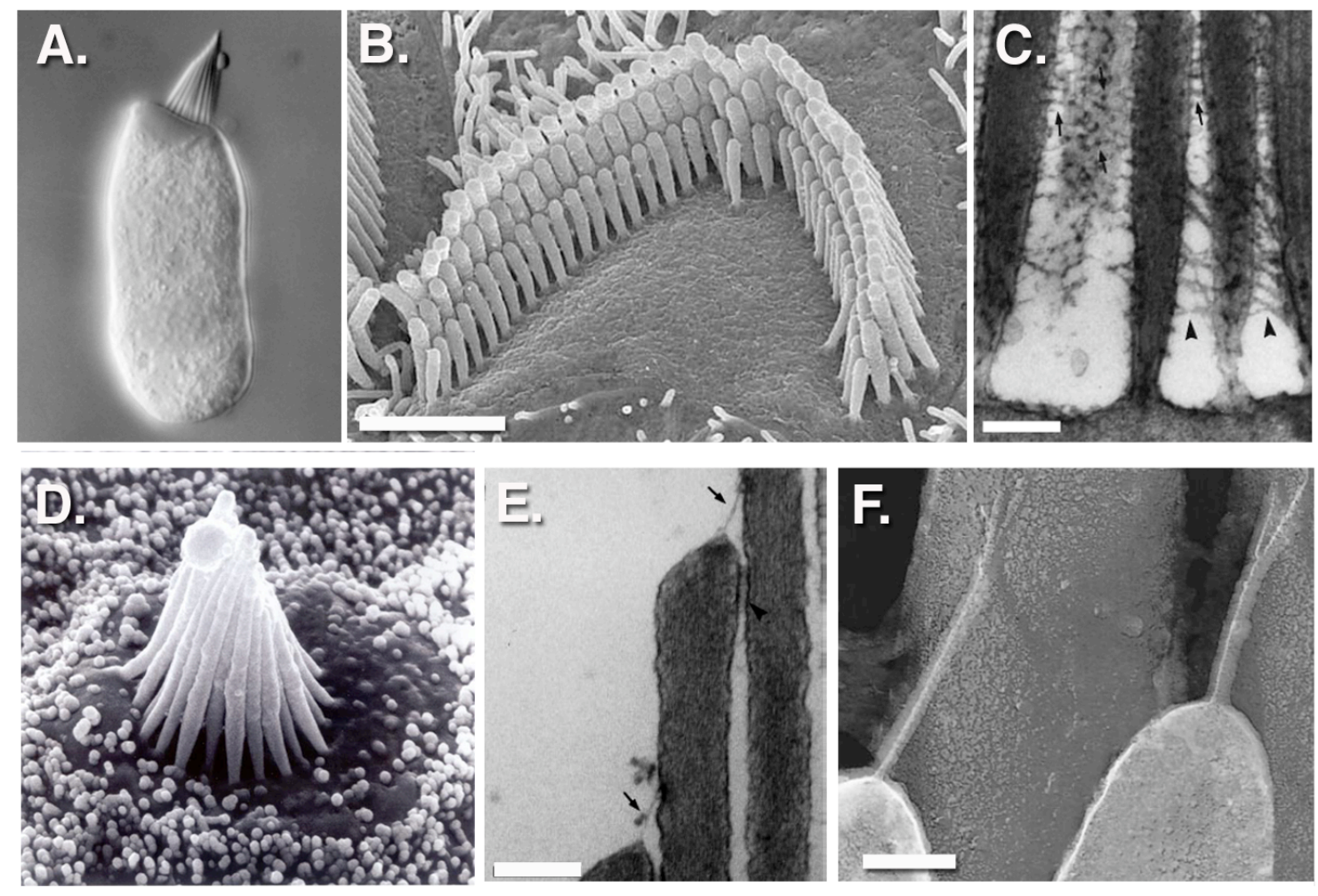

Figure 2. Hair-bundle morphology A) Bright-field image of an isolated bullfrog saccular hair cell. B) Electron micrograph (EM) of a mature murine cochlear hair cell $C$ ) TEM longitudinal section of avian vestibular stereociliary base stained with ruthedium red. Arrows point to shaft connectors. Arrowheads point to ankle links. D) SEM of a mature frog saccular hair cell. E) TEM longitudinal cross-section of avian vestibular stereocilia tips stained with tannic acid. Arrows point to tip links. Arrowhead point to top connectors. F) High-resolution freeze-etch image of the tip link from guinea pig cochlear hair cells. Scale bars: $B \& F, 100 \mathrm{~nm} ; E, 300 \mathrm{~nm}$. Image $B$ is courtesy of David Furness, Keele University, UK. Image $C$ was reproduced from Goodyear and Richardson, The Journal of Neuroscience, 2003, 23(12):4878-87; copyright 2003 The Journal of Neuroscience. Images A \& $D$ are courtesy of A.J. Hudspeth, Rockefeller University, NY. Image $E$ was reproduced from Goodyear and Richardson, The Journal of Neuroscience, 1999, 19(10):3761-72; copyright 1999 The Journal of Neuroscience. Image $F$ was reproduced from Kachar et al., PNAS, 97(24):13336-41; copyright 2000, The National Academy of Sciences. 
A.

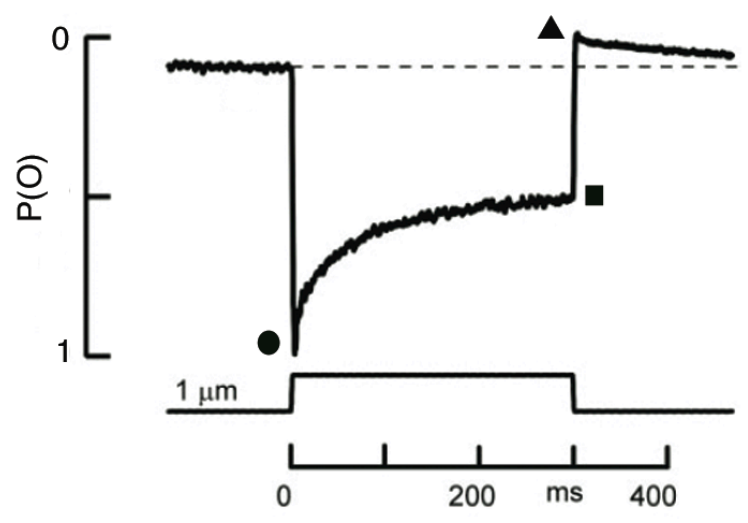

B.

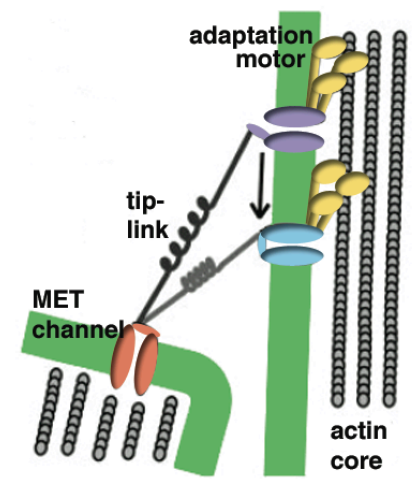

Figure 3. Hair cell transduction and adaptation. A) Transduction current measured from a bullfrog saccular hair cell following mechanical displacement. Prior to stimulation the open probability of the channel $\mathrm{P}(\mathrm{O})=0.1$, indicating that at rest a few channels remain open and current is slightly negative. Following the $1 \mu \mathrm{m}$ positive displacement the maximum inward rectifying current is reached immediately and $P(O)=1, \bullet$. The transduction current adapts over time to approximately $60-80 \%$ of baseline, $\boldsymbol{\square}$. Following a negative displacement, $\boldsymbol{\Lambda}$, the current overshoots its resting state briefly, $\mathrm{P}(\mathrm{O})=0$, and then returns to baseline. B) Cartoon of adaptation in the hair cell. Immediately following a positive deflection, tension on the tip link increases and the MET channel is mechanically opened (purple channel). As a result of tension the MET channel slips down the length of the stereocilia (see arrow). The space between the tip of the shorter stereocilia and the tip link attachment on the taller stereocilia is thus decreased, tension on the tip link is reduced, and the MET channel closes (blue channel). Adaptation motor is shown in yellow. Stereociliary membrane is green. Mechanotradsduction trace and adaptation cartoon modified from Holt \& Corey, PNAS, 2000, 97(22):11730-5; copyright 2000 National Academy of Sciences. 


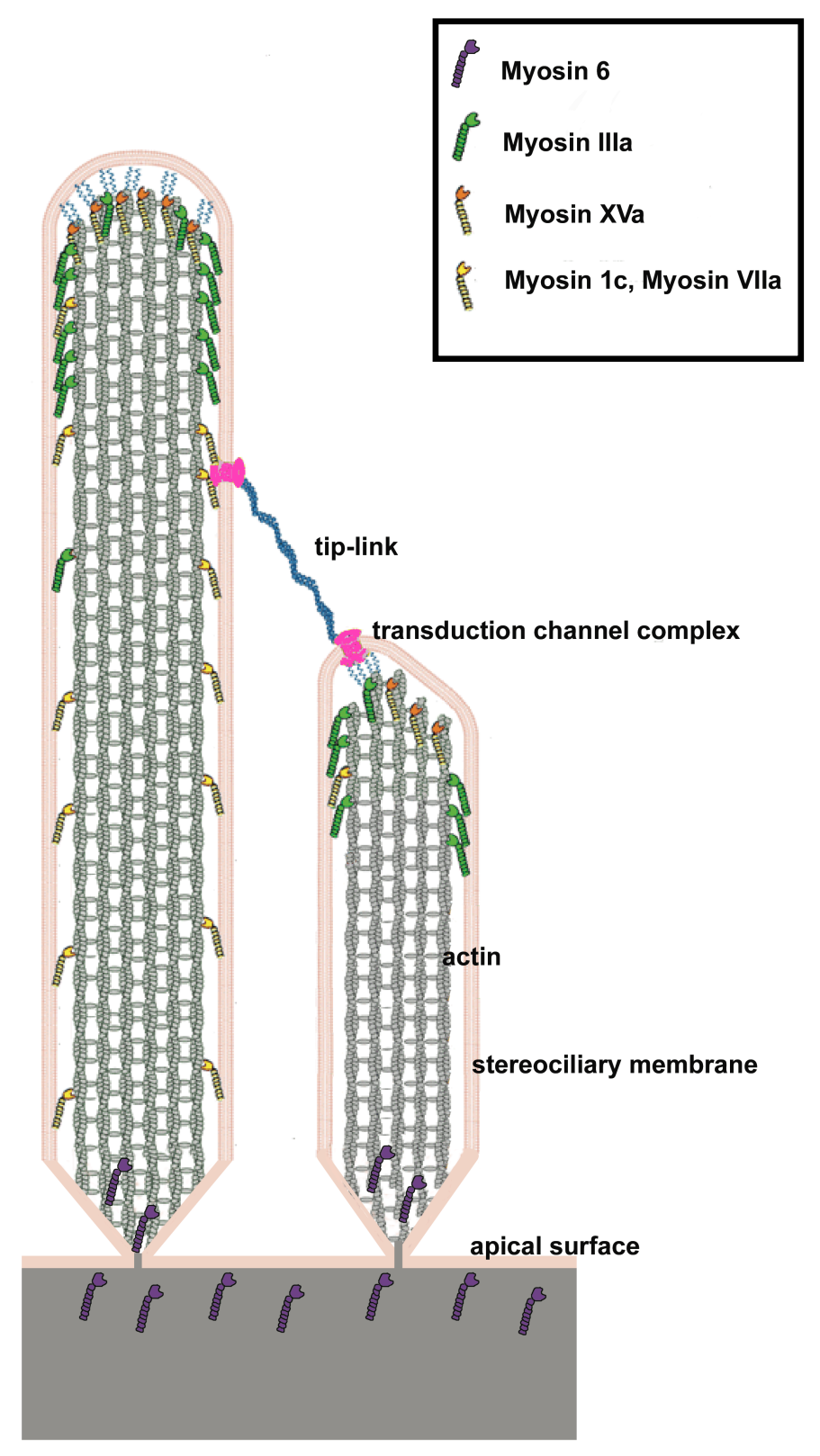

Figure 4. Myosins of the cochlear hair bundle. Cartoon of two adjacent stereocilia connected by the tip link, shown in blue (other stereociliary links are not shown for simplicity). MET channel is shown in pink. Myosin key is shown in top right corner. Briefly, Myosin-6 (purple) is located in the stereociliary taper region and in cuticular plate; Myosin-3a (green) caps the stereocilia akin to a thimble; Myosin-15a (orange and yellow) is exclusively at the stereociliary tip; Myosins 7 and 1C (yellow) are distributed along the length of the stereocilia. Stereociliary membrane is shown in pink, the transduction channel in bright pink, the tip-link in blue, and filamentous actin in gray. Figure is not drawn to scale. 

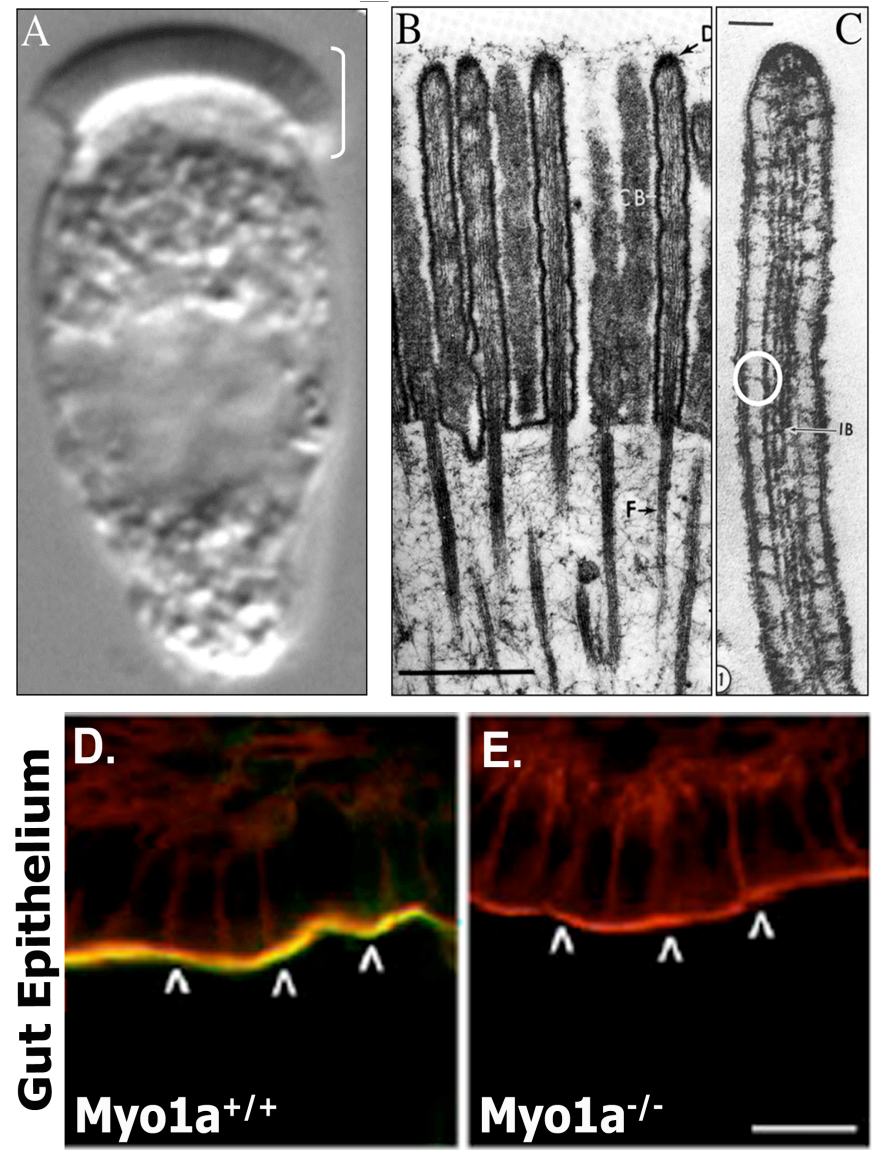

Figure 5. Myo1a in enterocyte of the gut A) Bright-field image of an enterocyte cell. Bracket indicates the enterocyte microvilli; actin-filled structures analogous to hair cell stereocilia. B) SEM of microvilli. C) Magnification of an SEM of microvilli. An example of a Myola cross-link is circled. D) Confocal image of gut epithelium of Myo1 $\mathrm{a}^{+/+}$mouse immunolabeled with the Myo1a antibody, $\alpha \mathrm{BBI}$, which recognizes the tail domain of Myola (green). Filamentous actin is labeled with phalloidin (red). Yellow labeling indicates the overlap of the two fluorophores. E) Myo1 $^{-/-}$sample; labeling conditions are the same as in panel $D$. Scale bars: $\mathrm{B}, 0.5 \mu \mathrm{m} ; \mathrm{C}, 0.05 \mu \mathrm{m}$; and $E, 10 \mu \mathrm{m}$, which applies to $D \& E$. Image in $A$ is courtesy of Matthew Tyska, Vanderbilt University, TN. Images in $B$ \& $C$ were adapted from Mooseker and Tilney, Journal of Cell Biology, 1975, 67:725-743; copyright 1975 Rockefeller University Press. Images in $D \& E$ were adapted from Tyska et. al., Molecular Biology of the Cell, 2005, 16: 2443-2457, copyright 2005 American Society for Cell Biology, 


\section{References}

Adato A, Lefevre G, Delprat B, Michel V, Michalski N, Chardenoux S, Weil D, ElAmraoui A, Petit C (2005) Usherin, the defective protein in Usher syndrome type IIA, is likely to be a component of interstereocilia ankle links in the inner ear sensory cells. Hum Mol Genet 14:3921-3932.

Ahmed ZM, Riazuddin S, Ahmad J, Bernstein SL, Guo Y, Sabar MF, Sieving P, Riazuddin S, Griffith AJ, Friedman TB, Belyantseva IA, Wilcox ER (2003) PCDH15 is expressed in the neurosensory epithelium of the eye and ear and mutant alleles are responsible for both USH1F and DFNB23. Hum Mol Genet 12:3215-3223.

Ahmed ZM, Goodyear R, Riazuddin S, Lagziel A, Legan PK, Behra M, Burgess SM, Lilley KS, Wilcox ER, Riazuddin S, Griffith AJ, Frolenkov GI, Belyantseva IA, Richardson GP, Friedman TB (2006) The tip-link antigen, a protein associated with the transduction complex of sensory hair cells, is protocadherin-15. J Neurosci 26:7022-7034.

Alagramam KN, Murcia CL, Kwon HY, Pawlowski KS, Wright CG, Woychik RP (2001) The mouse Ames waltzer hearing-loss mutant is caused by mutation of Pcdh15, a novel protocadherin gene. Nat Genet 27:99-102.

Anderson DW, Probst FJ, Belyantseva IA, Fridell RA, Beyer L, Martin DM, Wu D, Kachar B, Friedman TB, Raphael Y, Camper SA (2000) The motor and tail regions of myosin $\mathrm{XV}$ are critical for normal structure and function of auditory and vestibular hair cells. Hum Mol Genet 9:1729-1738.

Ashmore JF (1987) A fast motile response in guinea-pig outer hair cells: the cellular basis of the cochlear amplifier. J Physiol 388:323-347.

Assad JA, Corey DP (1992) An active motor model for adaptation by vertebrate hair cells. J Neurosci 12:3291-3309.

Assad JA, Hacohen N, Corey DP (1989) Voltage dependence of adaptation and active bundle movement in bullfrog saccular hair cells. Proc Natl Acad Sci U S A 86:2918-2922.

Assad JA, Shepherd GM, Corey DP (1991) Tip-link integrity and mechanical transduction in vertebrate hair cells. Neuron 7:985-994.

Avraham KB, Hasson T, Steel KP, Kingsley DM, Russell LB, Mooseker MS, Copeland NG, Jenkins NA (1995) The mouse Snell's waltzer deafness gene encodes an unconventional myosin required for structural integrity of inner ear hair cells. Nat Genet 11:369-375.

Bahler M, Rhoads A (2002) Calmodulin signaling via the IQ motif. FEBS Lett 513:107113.

Banuelos S, Saraste M, Carugo KD (1998) Structural comparisons of calponin homology domains: implications for actin binding. Structure 6:1419-1431.

Bartles JR (2000) Parallel actin bundles and their multiple actin-bundling proteins. Curr Opin Cell Biol 12:72-78.

Bartles JR, Wierda A, Zheng L (1996) Identification and characterization of espin, an actin-binding protein localized to the F-actin-rich junctional plaques of Sertoli cell ectoplasmic specializations. J Cell Sci 109 ( Pt 6):1229-1239. 
Bartles JR, Zheng L, Li A, Wierda A, Chen B (1998) Small espin: a third actin-bundling protein and potential forked protein ortholog in brush border microvilli. J Cell Biol 143:107-119.

Belyantseva IA, Boger ET, Friedman TB (2003) Myosin XVa localizes to the tips of inner ear sensory cell stereocilia and is essential for staircase formation of the hair bundle. Proc Natl Acad Sci U S A 100:13958-13963.

Bitner-Glindzicz M, Lindley KJ, Rutland P, Blaydon D, Smith VV, Milla PJ, Hussain K, Furth-Lavi J, Cosgrove KE, Shepherd RM, Barnes PD, O'Brien RE, Farndon PA, Sowden J, Liu XZ, Scanlan MJ, Malcolm S, Dunne MJ, Aynsley-Green A, Glaser B (2000) A recessive contiguous gene deletion causing infantile hyperinsulinism, enteropathy and deafness identifies the Usher type 1C gene. Nat Genet 26:56-60.

Boeda B, El-Amraoui A, Bahloul A, Goodyear R, Daviet L, Blanchard S, Perfettini I, Fath KR, Shorte S, Reiners J, Houdusse A, Legrain P, Wolfrum U, Richardson G, Petit C (2002) Myosin VIIa, harmonin and cadherin 23, three Usher I gene products that cooperate to shape the sensory hair cell bundle. Embo J 21:66896699.

Bolz H, von Brederlow B, Ramirez A, Bryda EC, Kutsche K, Nothwang HG, Seeliger M, del CSCM, Vila MC, Molina OP, Gal A, Kubisch C (2001) Mutation of CDH23, encoding a new member of the cadherin gene family, causes Usher syndrome type 1D. Nat Genet 27:108-112.

Bork JM, Peters LM, Riazuddin S, Bernstein SL, Ahmed ZM, Ness SL, Polomeno R, Ramesh A, Schloss M, Srisailpathy CR, Wayne S, Bellman S, Desmukh D, Ahmed Z, Khan SN, Kaloustian VM, Li XC, Lalwani A, Riazuddin S, BitnerGlindzicz M, Nance WE, Liu XZ, Wistow G, Smith RJ, Griffith AJ, Wilcox ER, Friedman TB, Morell RJ (2001) Usher syndrome 1D and nonsyndromic autosomal recessive deafness DFNB12 are caused by allelic mutations of the novel cadherin-like gene CDH23. Am J Hum Genet 68:26-37.

Brownell WE, Bader CR, Bertrand D, de Ribaupierre Y (1985) Evoked mechanical responses of isolated cochlear outer hair cells. Science 227:194-196.

Campbell VA, Crews JE, Moriarty DG, Zack MM, Blackman DK (1999) Surveillance for sensory impairment, activity limitation, and health-related quality of life among older adults--United States, 1993-1997. MMWR CDC Surveill Summ 48:131156.

Chalfie M, Sulston J (1981) Developmental genetics of the mechanosensory neurons of Caenorhabditis elegans. Dev Biol 82:358-370.

Chalfie M, Au M (1989) Genetic control of differentiation of the Caenorhabditis elegans touch receptor neurons. Science 243:1027-1033.

Chan DK, Hudspeth AJ (2005) Ca2+ current-driven nonlinear amplification by the mammalian cochlea in vitro. Nat Neurosci 8:149-155.

Cheatham MA, Huynh KH, Gao J, Zuo J, Dallos P (2004) Cochlear function in Prestin knockout mice. J Physiol 560:821-830.

Chen B, Li A, Wang D, Wang M, Zheng L, Bartles JR (1999) Espin contains an additional actin-binding site in its $\mathrm{N}$ terminus and is a major actin-bundling protein of the Sertoli cell-spermatid ectoplasmic specialization junctional plaque. Mol Biol Cell 10:4327-4339. 
Chen ZY, Hasson T, Kelley PM, Schwender BJ, Schwartz MF, Ramakrishnan M, Kimberling WJ, Mooseker MS, Corey DP (1996) Molecular cloning and domain structure of human myosin-VIIa, the gene product defective in Usher syndrome 1B. Genomics 36:440-448.

Cheney RE, Mooseker MS (1992) Unconventional myosins. Curr Opin Cell Biol 4:27-35. Cheung EL, Corey DP (2006) Ca2+ changes the force sensitivity of the hair-cell transduction channel. Biophys J 90:124-139.

Chin D, Means AR (2000) Calmodulin: a prototypical calcium sensor. Trends Cell Biol 10:322-328.

Choe Y, Magnasco MO, Hudspeth AJ (1998) A model for amplification of hair-bundle motion by cyclical binding of $\mathrm{Ca} 2+$ to mechanoelectrical-transduction channels. Proc Natl Acad Sci U S A 95:15321-15326.

Corey DP (2006) What is the hair cell transduction channel? J Physiol 576:23-28.

Corey DP, Hudspeth AJ (1979) Ionic basis of the receptor potential in a vertebrate hair cell. Nature 281:675-677.

Corey DP, Hudspeth AJ (1983) Kinetics of the receptor current in bullfrog saccular hair cells. J Neurosci 3:962-976.

Corey DP, Sotomayor M (2004) Hearing: tightrope act. Nature 428:901-903.

Corey DP, Garcia-Anoveros J, Holt JR, Kwan KY, Lin SY, Vollrath MA, Amalfitano A, Cheung EL, Derfler BH, Duggan A, Geleoc GS, Gray PA, Hoffman MP, Rehm HL, Tamasauskas D, Zhang DS (2004) TRPA1 is a candidate for the mechanosensitive transduction channel of vertebrate hair cells. Nature 432:723730.

Cyr JL, Dumont RA, Gillespie PG (2002) Myosin-1c interacts with hair-cell receptors through its calmodulin-binding IQ domains. J Neurosci 22:2487-2495.

D'Adamo P, Donaudy F, D'Eustacchio A, Di Iorio E, Melchionda S, Gasparini P (2003) A new locus (DFNA47) for autosomal dominant non-syndromic inherited hearing loss maps to 9p21-22 in a large Italian family. Eur J Hum Genet 11:121-124.

Dallos P (1988) Cochlear neurobiology: revolutionary developments. Asha 30:50-56.

Dallos P (1992) The active cochlea. J Neurosci 12:4575-4585.

Dallos P, Zheng J, Cheatham MA (2006) Prestin and the cochlear amplifier. J Physiol 576:37-42.

Dallos P, Billone MC, Durrant JD, Wang C, Raynor S (1972) Cochlear inner and outer hair cells: functional differences. Science 177:356-358.

Denman-Johnson K, Forge A (1999) Establishment of hair bundle polarity and orientation in the developing vestibular system of the mouse. J Neurocytol 28:821-835.

Di Palma F, Pellegrino R, Noben-Trauth K (2001a) Genomic structure, alternative splice forms and normal and mutant alleles of cadherin 23 (Cdh23). Gene 281:31-41.

Di Palma F, Holme RH, Bryda EC, Belyantseva IA, Pellegrino R, Kachar B, Steel KP, Noben-Trauth K (2001b) Mutations in Cdh23, encoding a new type of cadherin, cause stereocilia disorganization in waltzer, the mouse model for Usher syndrome type 1D. Nat Genet 27:103-107.

Donaudy F, Ferrara A, Esposito L, Hertzano R, Ben-David O, Bell RE, Melchionda S, Zelante L, Avraham KB, Gasparini P (2003) Multiple mutations of MYO1A, a 
cochlear-expressed gene, in sensorineural hearing loss. Am J Hum Genet 72:1571-1577.

Dose AC, Hillman DW, Wong C, Sohlberg L, Lin-Jones J, Burnside B (2003) Myo3A, one of two class III myosin genes expressed in vertebrate retina, is localized to the calycal processes of rod and cone photoreceptors and is expressed in the sacculus. Mol Biol Cell 14:1058-1073.

Drenckhahn D, Engel K, Hofer D, Merte C, Tilney L, Tilney M (1991) Three different actin filament assemblies occur in every hair cell: each contains a specific actin crosslinking protein. J Cell Biol 112:641-651.

Eatock RA (2000) Adaptation in hair cells. Annu Rev Neurosci 23:285-314.

Eatock RA, Corey DP, Hudspeth AJ (1987) Adaptation of mechanoelectrical transduction in hair cells of the bullfrog's sacculus. J Neurosci 7:2821-2836.

Fettiplace R (2006) Active hair bundle movements in auditory hair cells. J Physiol 576:29-36.

Fettiplace R, Crawford AC (1978) The coding of sound pressure and frequency in cochlear hair cells of the terrapin. Proc R Soc Lond B Biol Sci 203:209-218.

Fettiplace R, Crawford AC, Evans MG (1992) The hair cell's mechanoelectrical transducer channel. Ann N Y Acad Sci 656:1-11.

Flock A, Duvall AJ, 3rd (1965) The Ultrastructure of the Kinocilium of the Sensory Cells in the Inner Ear and Lateral Line Organs. J Cell Biol 25:1-8.

Flock A, Cheung HC (1977) Actin filaments in sensory hairs of inner ear receptor cells. J Cell Biol 75:339-343.

Flock A, Flock B, Murray E (1977) Studies on the sensory hairs of receptor cells in the inner ear. Acta Otolaryngol 83:85-91.

Flock A, Bretscher A, Weber K (1982) Immunohistochemical localization of several cytoskeletal proteins in inner ear sensory and supporting cells. Hear Res 7:75-89.

Friedman TB, Sellers JR, Avraham KB (1999) Unconventional myosins and the genetics of hearing loss. Am J Med Genet 89:147-157.

Garcia JA, Yee AG, Gillespie PG, Corey DP (1998) Localization of myosin-Ibeta near both ends of tip links in frog saccular hair cells. J Neurosci 18:8637-8647.

Geleoc GS, Holt JR (2003) Developmental acquisition of sensory transduction in hair cells of the mouse inner ear. Nat Neurosci 6:1019-1020.

Geleoc GS, Risner JR, Holt JR (2004) Developmental acquisition of voltage-dependent conductances and sensory signaling in hair cells of the embryonic mouse inner ear. J Neurosci 24:11148-11159.

Gillespie PG, Hudspeth AJ (1991) High-purity isolation of bullfrog hair bundles and subcellular and topological localization of constituent proteins. J Cell Biol 112:625-640.

Gillespie PG, Hudspeth AJ (1993) Adenine nucleoside diphosphates block adaptation of mechanoelectrical transduction in hair cells. Proc Natl Acad Sci U S A 90:27102714.

Gillespie PG, Corey DP (1997) Myosin and adaptation by hair cells. Neuron 19:955-958.

Gillespie PG, Walker RG (2001) Molecular basis of mechanosensory transduction. Nature 413:194-202.

Gillespie PG, Wagner MC, Hudspeth AJ (1993) Identification of a 120 kd hair-bundle myosin located near stereociliary tips. Neuron 11:581-594. 
Gillespie PG, Dumont RA, Kachar B (2005) Have we found the tip link, transduction channel, and gating spring of the hair cell? Curr Opin Neurobiol 15:389-396.

Gillespie PG, Gillespie SK, Mercer JA, Shah K, Shokat KM (1999) Engineering of the myosin-ibeta nucleotide-binding pocket to create selective sensitivity to N(6)modified ADP analogs. J Biol Chem 274:31373-31381.

Gong Z, Son W, Chung YD, Kim J, Shin DW, McClung CA, Lee Y, Lee HW, Chang DJ, Kaang BK, Cho H, Oh U, Hirsh J, Kernan MJ, Kim C (2004) Two interdependent TRPV channel subunits, inactive and Nanchung, mediate hearing in Drosophila. J Neurosci 24:9059-9066.

Goody RS, Eckstein F, Schirmer RH (1972) The enzymatic synthesis of thiophosphate analogs of nucleotides. Biochim Biophys Acta 276:155-161.

Goodyear R, Richardson G (1992) Distribution of the $275 \mathrm{kD}$ hair cell antigen and cell surface specialisations on auditory and vestibular hair bundles in the chicken inner ear. J Comp Neurol 325:243-256.

Goodyear R, Richardson G (1999) The ankle-link antigen: an epitope sensitive to calcium chelation associated with the hair-cell surface and the calycal processes of photoreceptors. J Neurosci 19:3761-3772.

Goodyear RJ, Richardson GP (2003) A novel antigen sensitive to calcium chelation that is associated with the tip links and kinocilial links of sensory hair bundles. $\mathbf{J}$ Neurosci 23:4878-4887.

Goodyear RJ, Marcotti W, Kros CJ, Richardson GP (2005) Development and properties of stereociliary link types in hair cells of the mouse cochlea. J Comp Neurol 485:75-85.

Goodyear RJ, Legan PK, Wright MB, Marcotti W, Oganesian A, Coats SA, Booth CJ, Kros CJ, Seifert RA, Bowen-Pope DF, Richardson GP (2003) A receptor-like inositol lipid phosphatase is required for the maturation of developing cochlear hair bundles. J Neurosci 23:9208-9219.

Grati M, Schneider ME, Lipkow K, Strehler EE, Wenthold RJ, Kachar B (2006) Rapid turnover of stereocilia membrane proteins: evidence from the trafficking and mobility of plasma membrane $\mathrm{Ca}(2+)$-ATPase 2. J Neurosci 26:6386-6395.

Haeberle H, Fujiwara M, Chuang J, Medina MM, Panditrao MV, Bechstedt S, Howard J, Lumpkin EA (2004) Molecular profiling reveals synaptic release machinery in Merkel cells. Proc Natl Acad Sci U S A 101:14503-14508.

Hamill OP, Martinac B (2001) Molecular basis of mechanotransduction in living cells. Physiol Rev 81:685-740.

Hampton LL, Wright CG, Alagramam KN, Battey JF, Noben-Trauth K (2003) A new spontaneous mutation in the mouse Ames waltzer gene, Pcdh15. Hear Res 180:67-75.

Hanein D, Volkmann N, Goldsmith S, Michon AM, Lehman W, Craig R, DeRosier D, Almo S, Matsudaira P (1998) An atomic model of fimbrin binding to F-actin and its implications for filament crosslinking and regulation. Nat Struct Biol 5:787792.

Hasson T, Heintzelman MB, Santos-Sacchi J, Corey DP, Mooseker MS (1995) Expression in cochlea and retina of myosin VIIa, the gene product defective in Usher syndrome type 1B. Proc Natl Acad Sci U S A 92:9815-9819. 
Hasson T, Gillespie PG, Garcia JA, MacDonald RB, Zhao Y, Yee AG, Mooseker MS, Corey DP (1997) Unconventional myosins in inner-ear sensory epithelia. J Cell Biol 137:1287-1307.

Haywood-Watson RJ, 2nd, Ahmed ZM, Kjellstrom S, Bush RA, Takada Y, Hampton LL, Battey JF, Sieving PA, Friedman TB (2006) Ames Waltzer deaf mice have reduced electroretinogram amplitudes and complex alternative splicing of Pcdh15 transcripts. Invest Ophthalmol Vis Sci 47:3074-3084.

Hilgemann DW, Feng S, Nasuhoglu C (2001) The complex and intriguing lives of PIP2 with ion channels and transporters. Sci STKE 2001:RE19.

Hillman DE (1969) New ultrastructural findings regarding a vestibular ciliary apparatus and its possible functional significance. Brain Res 13:407-412.

Hirono M, Denis CS, Richardson GP, Gillespie PG (2004) Hair cells require phosphatidylinositol 4,5-bisphosphate for mechanical transduction and adaptation. Neuron 44:309-320.

Hokanson DE, Ostap EM (2006) Myo1c binds tightly and specifically to phosphatidylinositol 4,5-bisphosphate and inositol 1,4,5-trisphosphate. Proc Natl Acad Sci U S A 103:3118-3123.

Holme RH, Kiernan BW, Brown SD, Steel KP (2002) Elongation of hair cell stereocilia is defective in the mouse mutant whirler. J Comp Neurol 450:94-102.

Holt JR, Corey DP (2000) Two mechanisms for transducer adaptation in vertebrate hair cells. Proc Natl Acad Sci U S A 97:11730-11735.

Holt JR, Gillespie SK, Provance DW, Shah K, Shokat KM, Corey DP, Mercer JA, Gillespie PG (2002) A chemical-genetic strategy implicates myosin-1c in adaptation by hair cells. Cell 108:371-381.

Holton T, Hudspeth AJ (1986) The transduction channel of hair cells from the bull-frog characterized by noise analysis. J Physiol 375:195-227.

Howard J, Hudspeth AJ (1987) Mechanical relaxation of the hair bundle mediates adaptation in mechanoelectrical transduction by the bullfrog's saccular hair cell. Proc Natl Acad Sci U S A 84:3064-3068.

Howard J, Hudspeth AJ (1988) Compliance of the hair bundle associated with gating of mechanoelectrical transduction channels in the bullfrog's saccular hair cell. Neuron 1:189-199.

Howard J, Bechstedt S (2004) Hypothesis: a helix of ankyrin repeats of the NOMPC-TRP ion channel is the gating spring of mechanoreceptors. Curr Biol 14:R224-226.

Huang M, Chalfie M (1994) Gene interactions affecting mechanosensory transduction in Caenorhabditis elegans. Nature 367:467-470.

Hudspeth AJ (1989) How the ear's works work. Nature 341:397-404.

Hudspeth AJ (1997) How hearing happens. Neuron 19:947-950.

Hudspeth AJ, Corey DP (1977) Sensitivity, polarity, and conductance change in the response of vertebrate hair cells to controlled mechanical stimuli. Proc Natl Acad Sci U S A 74:2407-2411.

Hudspeth AJ, Jacobs R (1979) Stereocilia mediate transduction in vertebrate hair cells (auditory system/cilium/vestibular system). Proc Natl Acad Sci U S A 76:15061509.

Kachar B, Battaglia A, Fex J (1997) Compartmentalized vesicular traffic around the hair cell cuticular plate. Hear Res 107:102-112. 
Kachar B, Brownell WE, Altschuler R, Fex J (1986) Electrokinetic shape changes of cochlear outer hair cells. Nature 322:365-368.

Kachar B, Parakkal M, Kurc M, Zhao Y, Gillespie PG (2000) High-resolution structure of hair-cell tip links. Proc Natl Acad Sci U S A 97:13336-13341.

Kappler JA, Starr CJ, Chan DK, Kollmar R, Hudspeth AJ (2004) A nonsense mutation in the gene encoding a zebrafish myosin VI isoform causes defects in hair-cell mechanotransduction. Proc Natl Acad Sci U S A 101:13056-13061.

Karolyi IJ, Probst FJ, Beyer L, Odeh H, Dootz G, Cha KB, Martin DM, Avraham KB, Kohrman D, Dolan DF, Raphael Y, Camper SA (2003) Myo15 function is distinct from Myo6, Myo7a and pirouette genes in development of cochlear stereocilia. Hum Mol Genet 12:2797-2805.

Kelley MW (2006) Hair cell development: commitment through differentiation. Brain Res 1091:172-185.

Kernan M, Cowan D, Zuker C (1994) Genetic dissection of mechanosensory transduction: mechanoreception-defective mutations of Drosophila. Neuron 12:1195-1206.

Kikkawa Y, Mburu P, Morse S, Kominami R, Townsend S, Brown SD (2005) Mutant analysis reveals whirlin as a dynamic organizer in the growing hair cell stereocilium. Hum Mol Genet 14:391-400.

Kim J, Chung YD, Park DY, Choi S, Shin DW, Soh H, Lee HW, Son W, Yim J, Park CS, Kernan MJ, Kim C (2003) A TRPV family ion channel required for hearing in Drosophila. Nature 424:81-84.

Komaba S, Inoue A, Maruta S, Hosoya H, Ikebe M (2003) Determination of human myosin III as a motor protein having a protein kinase activity. J Biol Chem 278:21352-21360.

Kros CJ, Marcotti W, van Netten SM, Self TJ, Libby RT, Brown SD, Richardson GP, Steel KP (2002) Reduced climbing and increased slipping adaptation in cochlear hair cells of mice with Myo7a mutations. Nat Neurosci 5:41-47.

Kussel-Andermann P, El-Amraoui A, Safieddine S, Nouaille S, Perfettini I, Lecuit M, Cossart P, Wolfrum U, Petit C (2000) Vezatin, a novel transmembrane protein, bridges myosin VIIA to the cadherin-catenins complex. Embo J 19:6020-6029.

Kwan KY, Allchorne AJ, Vollrath MA, Christensen AP, Zhang DS, Woolf CJ, Corey DP (2006) TRPA1 contributes to cold, mechanical, and chemical nociception but is not essential for hair-cell transduction. Neuron 50:277-289.

Lagziel A, Ahmed ZM, Schultz JM, Morell RJ, Belyantseva IA, Friedman TB (2005) Spatiotemporal pattern and isoforms of cadherin 23 in wild type and waltzer mice during inner ear hair cell development. Dev Biol 280:295-306.

Leibovici M, Verpy E, Goodyear RJ, Zwaenepoel I, Blanchard S, Laine S, Richardson GP, Petit C (2005) Initial characterization of kinocilin, a protein of the hair cell kinocilium. Hear Res 203:144-153.

Li H, Liu H, Balt S, Mann S, Corrales CE, Heller S (2004) Correlation of expression of the actin filament-bundling protein espin with stereociliary bundle formation in the developing inner ear. J Comp Neurol 468:125-134.

Liang Y, Wang A, Belyantseva IA, Anderson DW, Probst FJ, Barber TD, Miller W, Touchman JW, Jin L, Sullivan SL, Sellers JR, Camper SA, Lloyd RV, Kachar B, Friedman TB, Fridell RA (1999) Characterization of the human and mouse 
unconventional myosin XV genes responsible for hereditary deafness DFNB3 and shaker 2. Genomics 61:243-258.

Liberman MC, Gao J, He DZ, Wu X, Jia S, Zuo J (2002) Prestin is required for electromotility of the outer hair cell and for the cochlear amplifier. Nature 419:300-304.

Lim DJ (1986) Functional structure of the organ of Corti: a review. Hear Res 22:117-146.

Lin HW, Schneider ME, Kachar B (2005) When size matters: the dynamic regulation of stereocilia lengths. Curr Opin Cell Biol 17:55-61.

Liu XZ, Walsh J, Mburu P, Kendrick-Jones J, Cope MJ, Steel KP, Brown SD (1997) Mutations in the myosin VIIA gene cause non-syndromic recessive deafness. Nat Genet 16:188-190.

Loomis PA, Zheng L, Sekerkova G, Changyaleket B, Mugnaini E, Bartles JR (2003) Espin cross-links cause the elongation of microvillus-type parallel actin bundles in vivo. J Cell Biol 163:1045-1055.

Marfatia SM, Leu RA, Branton D, Chishti AH (1995) Identification of the protein 4.1 binding interface on glycophorin $\mathrm{C}$ and p55, a homologue of the Drosophila discs-large tumor suppressor protein. J Biol Chem 270:715-719.

Marquis RE, Hudspeth AJ (1997) Effects of extracellular Ca2+ concentration on hairbundle stiffness and gating-spring integrity in hair cells. Proc Natl Acad Sci U S A 94:11923-11928.

Mburu P, Kikkawa Y, Townsend S, Romero R, Yonekawa H, Brown SD (2006) Whirlin complexes with p55 at the stereocilia tip during hair cell development. Proc Natl Acad Sci U S A 103:10973-10978.

Mburu P, Liu XZ, Walsh J, Saw D, Jr., Cope MJ, Gibson F, Kendrick-Jones J, Steel KP, Brown SD (1997) Mutation analysis of the mouse myosin VIIA deafness gene. Genes Funct 1:191-203.

Mburu P, Mustapha M, Varela A, Weil D, El-Amraoui A, Holme RH, Rump A, Hardisty RE, Blanchard S, Coimbra RS, Perfettini I, Parkinson N, Mallon AM, Glenister P, Rogers MJ, Paige AJ, Moir L, Clay J, Rosenthal A, Liu XZ, Blanco G, Steel KP, Petit C, Brown SD (2003) Defects in whirlin, a PDZ domain molecule involved in stereocilia elongation, cause deafness in the whirler mouse and families with DFNB31. Nat Genet 34:421-428.

McGee J, Goodyear RJ, McMillan DR, Stauffer EA, Holt JR, Locke KG, Birch DG, Legan PK, White PC, Walsh EJ, Richardson GP (2006) The very large G-proteincoupled receptor VLGR1: a component of the ankle link complex required for the normal development of auditory hair bundles. J Neurosci 26:6543-6553.

Melchionda S, Ahituv N, Bisceglia L, Sobe T, Glaser F, Rabionet R, Arbones ML, Notarangelo A, Di Iorio E, Carella M, Zelante L, Estivill X, Avraham KB, Gasparini P (2001) MYO6, the human homologue of the gene responsible for deafness in Snell's waltzer mice, is mutated in autosomal dominant nonsyndromic hearing loss. Am J Hum Genet 69:635-640.

Metcalf AB, Chelliah Y, Hudspeth AJ (1994) Molecular cloning of a myosin I beta isozyme that may mediate adaptation by hair cells of the bullfrog's internal ear. Proc Natl Acad Sci U S A 91:11821-11825.

Michel V, Goodyear RJ, Weil D, Marcotti W, Perfettini I, Wolfrum U, Kros CJ, Richardson GP, Petit C (2005) Cadherin 23 is a component of the transient lateral 
links in the developing hair bundles of cochlear sensory cells. Dev Biol 280:281294.

Mooseker MS (1985) Organization, chemistry, and assembly of the cytoskeletal apparatus of the intestinal brush border. Annu Rev Cell Biol 1:209-241.

Mooseker MS, Cheney RE (1995) Unconventional myosins. Annu Rev Cell Dev Biol 11:633-675.

Nagata K, Duggan A, Kumar G, Garcia-Anoveros J (2005) Nociceptor and hair cell transducer properties of TRPA1, a channel for pain and hearing. J Neurosci 25:4052-4061.

Ng KP, Kambara T, Matsuura M, Burke M, Ikebe M (1996) Identification of myosin III as a protein kinase. Biochemistry 35:9392-9399.

Nicolson T (2005a) The genetics of hearing and balance in zebrafish. Annu Rev Genet $39: 9-22$.

Nicolson T (2005b) Fishing for key players in mechanotransduction. Trends Neurosci 28:140-144.

Noben-Trauth K, Zheng QY, Johnson KR (2003) Association of cadherin 23 with polygenic inheritance and genetic modification of sensorineural hearing loss. Nat Genet 35:21-23.

Nollet F, Kools P, van Roy F (2000) Phylogenetic analysis of the cadherin superfamily allows identification of six major subfamilies besides several solitary members. $\mathbf{J}$ Mol Biol 299:551-572.

Offner FF, Dallos P, Cheatham MA (1987) Positive endocochlear potential: mechanism of production by marginal cells of stria vascularis. Hear Res 29:117-124.

Oliver D, He DZ, Klocker N, Ludwig J, Schulte U, Waldegger S, Ruppersberg JP, Dallos P, Fakler B (2001) Intracellular anions as the voltage sensor of prestin, the outer hair cell motor protein. Science 292:2340-2343.

Owsianik G, Talavera K, Voets T, Nilius B (2006) Permeation and selectivity of TRP channels. Annu Rev Physiol 68:685-717.

Pataky F, Pironkova R, Hudspeth AJ (2004) Radixin is a constituent of stereocilia in hair cells. Proc Natl Acad Sci U S A 101:2601-2606.

Petit C (2001) Usher syndrome: from genetics to pathogenesis. Annu Rev Genomics Hum Genet 2:271-297.

Phillips KR, Tong S, Goodyear R, Richardson GP, Cyr JL (2006) Stereociliary myosin$1 \mathrm{c}$ receptors are sensitive to calcium chelation and absent from cadherin 23 mutant mice. J Neurosci 26:10777-10788.

Pickles JO, Comis SD, Osborne MP (1984) Cross-links between stereocilia in the guinea pig organ of Corti, and their possible relation to sensory transduction. Hear Res 15:103-112.

Pickles JO, von Perger M, Rouse GW, Brix J (1991) The development of links between stereocilia in hair cells of the chick basilar papilla. Hear Res 54:153-163.

Rhoads AR, Friedberg F (1997) Sequence motifs for calmodulin recognition. Faseb J 11:331-340.

Rhodes CR, Hertzano R, Fuchs H, Bell RE, de Angelis MH, Steel KP, Avraham KB (2004) A Myo7a mutation cosegregates with stereocilia defects and lowfrequency hearing impairment. Mamm Genome 15:686-697. 
Ricci AJ, Wu YC, Fettiplace R (1998) The endogenous calcium buffer and the time course of transducer adaptation in auditory hair cells. J Neurosci 18:8261-8277.

Ricci AJ, Kachar B, Gale J, Van Netten SM (2006) Mechano-electrical transduction: new insights into old ideas. J Membr Biol 209:71-88.

Rusch A, Hummler E (1999) Mechano-electrical transduction in mice lacking the alphasubunit of the epithelial sodium channel. Hear Res 131:170-176.

Ryan A, Dallos P (1975) Effect of absence of cochlear outer hair cells on behavioural auditory threshold. Nature 253:44-46.

Rzadzinska AK, Derr, A, Kachar, B, Noben-Trauth K (2005) Sustained cadherin 23 expression in young and adult cochlea of normal and hearing-impaired mice. Hear Res 208(1-2):114-21.

Rzadzinska AK, Schneider M, Noben-Trauth K, Bartles JR, Kachar B (2005) Balanced levels of Espin are critical for stereociliary growth and length maintenance. Cell Motil Cytoskeleton 62:157-165.

Rzadzinska AK, Schneider ME, Davies C, Riordan GP, Kachar B (2004) An actin molecular treadmill and myosins maintain stereocilia functional architecture and self-renewal. J Cell Biol 164:887-897.

Schneider ME, Belyantseva IA, Azevedo RB, Kachar B (2002) Rapid renewal of auditory hair bundles. Nature 418:837-838.

Schneider ME, Dose AC, Salles FT, Chang W, Erickson FL, Burnside B, Kachar B (2006) A new compartment at stereocilia tips defined by spatial and temporal patterns of myosin IIIa expression. J Neurosci 26:10243-10252.

Seiler C, Finger-Baier KC, Rinner O, Makhankov YV, Schwarz H, Neuhauss SC, Nicolson T (2005) Duplicated genes with split functions: independent roles of protocadherin 15 orthologues in zebrafish hearing and vision. Development 132:615-623.

Seiler C, Ben-David O, Sidi S, Hendrich O, Rusch A, Burnside B, Avraham KB, Nicolson T (2004) Myosin VI is required for structural integrity of the apical surface of sensory hair cells in zebrafish. Dev Biol 272:328-338.

Sekerkova G, Zheng L, Loomis PA, Changyaleket B, Whitlon DS, Mugnaini E, Bartles JR (2004) Espins are multifunctional actin cytoskeletal regulatory proteins in the microvilli of chemosensory and mechanosensory cells. J Neurosci 24:5445-5456.

Senften M, Schwander M, Kazmierczak P, Lillo C, Shin JB, Hasson T, Geleoc GS, Gillespie PG, Williams D, Holt JR, Muller U (2006) Physical and functional interaction between protocadherin 15 and myosin VIIa in mechanosensory hair cells. J Neurosci 26:2060-2071.

Shepherd GM, Barres BA, Corey DP (1989) "Bundle blot" purification and initial protein characterization of hair cell stereocilia. Proc Natl Acad Sci U S A 86:4973-4977.

Shin JB, Adams D, Paukert M, Siba M, Sidi S, Levin M, Gillespie PG, Grunder S (2005) Xenopus TRPN1 (NOMPC) localizes to microtubule-based cilia in epithelial cells, including inner-ear hair cells. Proc Natl Acad Sci U S A 102:12572-12577.

Siemens J, Kazmierczak P, Reynolds A, Sticker M, Littlewood-Evans A, Muller U (2002) The Usher syndrome proteins cadherin 23 and harmonin form a complex by means of PDZ-domain interactions. Proc Natl Acad Sci U S A 99:1494614951. 
Siemens J, Lillo C, Dumont RA, Reynolds A, Williams DS, Gillespie PG, Muller U (2004) Cadherin 23 is a component of the tip link in hair-cell stereocilia. Nature 428:950-955.

Sollner C, Rauch GJ, Siemens J, Geisler R, Schuster SC, Muller U, Nicolson T (2004) Mutations in cadherin 23 affect tip links in zebrafish sensory hair cells. Nature 428:955-959.

Sotomayor M, Corey DP, Schulten K (2005) In search of the hair-cell gating spring elastic properties of ankyrin and cadherin repeats. Structure 13:669-682.

Spoendlin H (1985) Anatomy of cochlear innervation. Am J Otolaryngol 6:453-467.

Spudich JA, Watt S (1971) The regulation of rabbit skeletal muscle contraction. I. Biochemical studies of the interaction of the tropomyosin-troponin complex with actin and the proteolytic fragments of myosin. J Biol Chem 246:4866-4871.

Stauffer EA, Scarborough JD, Hirono M, Miller ED, Shah K, Mercer JA, Holt JR, Gillespie PG (2005) Fast adaptation in vestibular hair cells requires myosin-1c activity. Neuron 47:541-553.

Stepanyan R, Belyantseva IA, Griffith AJ, Friedman TB, Frolenkov GI (2006) Auditory mechanotransduction in the absence of functional myosin-XVa. J Physiol 576:801-808.

Steyger PS, Gillespie PG, Baird RA (1998) Myosin Ibeta is located at tip link anchors in vestibular hair bundles. J Neurosci 18:4603-4615.

Tilney LG, DeRosier DJ (1986) Actin filaments, stereocilia, and hair cells of the bird cochlea. IV. How the actin filaments become organized in developing stereocilia and in the cuticular plate. Dev Biol 116:119-129.

Tilney LG, Tilney MS (1988) The actin filament content of hair cells of the bird cochlea is nearly constant even though the length, width, and number of stereocilia vary depending on the hair cell location. J Cell Biol 107:2563-2574.

Tilney LG, Derosier DJ, Mulroy MJ (1980) The organization of actin filaments in the stereocilia of cochlear hair cells. J Cell Biol 86:244-259.

Tilney LG, Tilney MS, Cotanche DA (1988) Actin filaments, stereocilia, and hair cells of the bird cochlea. V. How the staircase pattern of stereociliary lengths is generated. J Cell Biol 106:355-365.

Tilney LG, Tilney MS, DeRosier DJ (1992) Actin filaments, stereocilia, and hair cells: how cells count and measure. Annu Rev Cell Biol 8:257-274.

Tilney LG, Tilney MS, Saunders JS, DeRosier DJ (1986) Actin filaments, stereocilia, and hair cells of the bird cochlea. III. The development and differentiation of hair cells and stereocilia. Dev Biol 116:100-118.

Tilney MS, Tilney LG, Stephens RE, Merte C, Drenckhahn D, Cotanche DA, Bretscher A (1989) Preliminary biochemical characterization of the stereocilia and cuticular plate of hair cells of the chick cochlea. J Cell Biol 109:1711-1723.

Tsuprun V, Goodyear RJ, Richardson GP (2004) The structure of tip links and kinocilial links in avian sensory hair bundles. Biophys J 87:4106-4112.

Tyska MJ, Mackey AT, Huang JD, Copeland NG, Jenkins NA, Mooseker MS (2005) Myosin-1a is critical for normal brush border structure and composition. Mol Biol Cell 16:2443-2457.

Verpy E, Leibovici M, Zwaenepoel I, Liu XZ, Gal A, Salem N, Mansour A, Blanchard S, Kobayashi I, Keats BJ, Slim R, Petit C (2000) A defect in harmonin, a PDZ 
domain-containing protein expressed in the inner ear sensory hair cells, underlies Usher syndrome type 1C. Nat Genet 26:51-55.

Volkmann N, DeRosier D, Matsudaira P, Hanein D (2001) An atomic model of actin filaments cross-linked by fimbrin and its implications for bundle assembly and function. J Cell Biol 153:947-956.

von Bekesy G (1960) Experiments in Hearing. McGraw Hill, New York:485-510.

Walker RG, Willingham AT, Zuker CS (2000) A Drosophila mechanosensory transduction channel. Science 287:2229-2234.

Wang A, Liang Y, Fridell RA, Probst FJ, Wilcox ER, Touchman JW, Morton CC, Morell RJ, Noben-Trauth K, Camper SA, Friedman TB (1998) Association of unconventional myosin MYO15 mutations with human nonsyndromic deafness DFNB3. Science 280:1447-1451.

Weil D, Kussel P, Blanchard S, Levy G, Levi-Acobas F, Drira M, Ayadi H, Petit C (1997) The autosomal recessive isolated deafness, DFNB2, and the Usher 1B syndrome are allelic defects of the myosin-VIIA gene. Nat Genet 16:191-193.

Wells AL, Lin AW, Chen LQ, Safer D, Cain SM, Hasson T, Carragher BO, Milligan RA, Sweeney HL (1999) Myosin VI is an actin-based motor that moves backwards. Nature 401:505-508.

Wu YC, Ricci AJ, Fettiplace R (1999) Two components of transducer adaptation in auditory hair cells. J Neurophysiol 82:2171-2181.

Zhao Y, Yamoah EN, Gillespie PG (1996) Regeneration of broken tip links and restoration of mechanical transduction in hair cells. Proc Natl Acad Sci U S A 93:15469-15474.

Zheng J, Shen W, He DZ, Long KB, Madison LD, Dallos P (2000a) Prestin is the motor protein of cochlear outer hair cells. Nature 405:149-155.

Zheng L, Sekerkova G, Vranich K, Tilney LG, Mugnaini E, Bartles JR (2000b) The deaf jerker mouse has a mutation in the gene encoding the espin actin-bundling proteins of hair cell stereocilia and lacks espins. Cell 102:377-385. 


\section{Stereociliary Myosin-1c Receptors are Sensitive to Calcium Chelation and Absent from Cadherin 23 Mutant Mice}

This chapter has been published in $J$ Neurosci. 2006 Oct 18;26(42):10777-88. (C) 2006 by The Society for Neuroscience

Kelli R. Phillips ${ }^{1,2}$, Song Tong ${ }^{1,3}$, Richard Goodyear ${ }^{4}$, Guy P. Richardson ${ }^{4}$, and Janet L. $\mathrm{Cyr}^{1,2,3}$

${ }^{1}$ Sensory Neuroscience Research Center and Departments of ${ }^{2}$ Biochemistry \& Molecular Pharmacology and ${ }^{3}$ Otolaryngology, West Virginia University School of Medicine, Morgantown, WV 26506-9303, and ${ }^{4}$ School of Life Sciences, University of Sussex, Falmer, Brighton, BN1 9QG, United Kingdom

Corresponding Author:

Janet L. Cyr, Ph.D.

West Virginia University School of Medicine

Sensory Neuroscience Research Center

One Medical Center Drive

PO Box 9303

Morgantown, WV 26506-9303

Email: jcyr@hsc.wvu.edu

Phone: 304-293-5255

Keywords: myosin 1c, hair cell, calmodulin, cadherin 23, phosphatidylinositol 4,5bisphosphate, IQ domain

\section{Acknowledgements:}

We thank Gwenaelle Geleoc, Jeffrey Holt, and Eric Stauffer for tutorials on cochlear dissections; Peter Gillespie for the anti-Myo1c antibody; Thomas Freidman for the antiCdh23 antibody, Peter Downes for the PLC81PH-GFP construct; Corné Kros for mutant mice; Bill Wonderlin and Paul Fuchs for experimental suggestions; Matt Roberts for technical help; and George Spirou and Peter Mathers for critical reading of the manuscript. This work was supported by the NIH/NIDCD grants R01DC006402 (JLC) and F31DC007558 (KRP), American Hearing Research Foundation (JLC), NIH/NCRR COBRE grant P20RR015574-06 to the Sensory Neuroscience Research Center, and The Wellcome Trust (Grant 071394/Z/03/Z to GPR). 


\section{Abstract}

The identities of some of the constituents of the hair-cell transduction apparatus have only recently been elucidated. The molecular motor myosin-1c (Myo1c) functions in adaptation of the hair cell response to sustained mechanical stimuli and is therefore an integral part of the transduction complex. Recent data indicate that Myolc interacts in vitro with two other molecules proposed to be important for transduction: cadherin 23 (Cdh23), a candidate for the stereociliary tip link, and phosphatidylinositol 4,5bisphosphate $\left(\mathrm{PIP}_{2}\right)$, which is abundant in the membranes of hair-cell stereocilia. It is not known, however, whether these interactions occur in hair cells. Using an in situ binding assay on saccular hair cells, we previously demonstrated that Myo1c interacts with molecules at stereociliary tips, the site of transduction, through sequences contained within its calmodulin (CaM)-binding neck domain, which can bind up to four $\mathrm{CaM}$ molecules. In the current study, we identify the second CaM-binding IQ domain (IQ2) as a region of Myo1c that mediates CaM-sensitive binding to stereociliary tips and to $\mathrm{PIP}_{2}$ immobilized on a solid support. Binding of Myolc to stereociliary tips of cochlear and vestibular hair cells is disrupted by treatments that break tip links. In addition, Myo1c does not bind to stereocilia from mice whose hair cells lack $\mathrm{Cdh} 23$ protein despite the presence of $\mathrm{PIP}_{2}$ in the stereociliary membranes. Collectively our data suggest that Myo1c and Cdh23 interact at the tips of hair-cell stereocilia and that this interaction is modulated by $\mathrm{CaM}$. 
In auditory and vestibular end organs, transduction of physical stimuli into electrical signals occurs in hair cells and is critically dependent upon the hair bundle, which protrudes from the hair-cell apical surface and is comprised of actin-filled stereocilia arranged in rows by ascending height (Hudspeth, 1989). Stereocilia are interconnected by several types of extracellular linkages (Goodyear et al., 2005) including the tip link, which connects the top of a shorter stereocilium to the side of its tallest neighbor (Pickles et al., 1984). Cadherin 23 (Cdh23) has been proposed to be a tip-link component (Siemens et al., 2004; Sollner et al., 2004), however this designation is controversial (Lagziel et al., 2005; Michel et al., 2005; Rzadzinska et al., 2005). In the prevailing model of hair-cell transduction, bundle deflection tenses tip links and opens mechanically-gated, cation-selective transduction channels (Pickles et al., 1984) (Howard and Hudspeth, 1987). During prolonged stimuli, transduction-current magnitude reduces within tens of microseconds (for review; Gillespie and Cyr, 2004). This adaptation occurs at two rates (Wu et al., 1999; Holt et al., 2002; Stauffer et al., 2005) and involves the motor protein myosin-1c (Myo1c; Holt et al., 2002; Stauffer et al., 2005), an unconventional myosin comprised of three domains: a mechanochemical head, a neck containing 3-4 calmodulin (CaM)-binding IQ domains, and a tail (Fig. 1A). CaM binding to Myo1c IQ domains is favored in low $\mathrm{Ca}^{2+}$ and modulates both motor activity and binding to intracellular components (for review; Gillespie and Cyr, 2004).

Slow adaptation is predicted to require, at a minimum, the transduction channel; the tip link, which may, in part, be comprised of (Siemens et al., 2004; Sollner et al., 2004); the adaptation motor, Myolc (Holt et al., 2002); and phosphatidylinositol 4,5bisphosphate (PIP2; Hirono et al., 2004). To generate a functional transduction complex, these molecules are expected to interact with one another and perhaps other unidentified transduction-apparatus constituents. To date, Myolc has been shown to bind, in vitro, to both $\mathrm{PIP}_{2}$ and Cdh23 (Hirono et al., 2004; Siemens et al., 2004; Hokanson and Ostap, 2006), however, such interactions have not been demonstrated in hair cells. 
To examine Myo1c interactions with transduction components, we developed an in situ binding assay to visualize Myo1c binding to hair-cell constituents, which we term "Myo1c receptors" (Cyr et al., 2002). Using this assay, we demonstrated that the Myo1c neck region binds to available receptors at stereociliary tips, the site of transduction; in the pericuticular necklace, a vesicle-rich region encircling the cuticular plate; in the kinocilium, a cilium located at the tall edge of the hair bundle, and also within the haircell soma (Cyr et al., 2002). With the exception of the kinocilium, Myo1c binding is modulated by $\mathrm{CaM}$, which implicated the CaM-binding IQ domains in receptor interactions (Cyr et al., 2002). In the current study, we determine that the second IQ domain (IQ2) of Myolc mediates interactions with stereociliary receptors. In addition, these interactions are sensitive to $\mathrm{Ca}^{2+}$ chelation, a procedure that breaks tip links, and do not occur in hair cells lacking Cdh23.

\section{Materials and Methods}

Animals. All animal procedures followed NIH guidelines and were approved by either the Animal Care and Use Committee at West Virginia University School of Medicine or the United Kingdom Home Office and local ethical committee.

Myo1c constructs. To generate Myo1c-T701 $1_{\mathrm{IQ} 2 \mathrm{Mut}}$ (Fig. 1A), a construct with mutations in conserved residues in the second consensus IQ domain of Myo1c, the first two amino acids, Ile728 and Gln729, were each mutated to Ala in the context of the bullfrog MyolcT701 construct (Cyr et al., 2002), using the Quick-Change site-directed mutagenesis system (Stratagene, La Jolla, CA) and the oligonucleotides 5'-ATTCCGCGGTAGAGGCCGCGTCGTGGTGGCGTGG-3' and 5'-CCACGCCACCA CGACGCGGCCTCTACCGCGGAAAT-3'. A construct with mutations in the first IQ domain of bullfrog Myo1c (IQ1), Myo1c-T701 $1_{\text {IQ1RG1Mut, was generated by site-directed }}$ mutagenesis using the oligonucleotide primers 5'-GGGTAGCAT AGCAACATTCGCCGCGGCTAGGTGGAGAGG-3' and 5'-CCTCTCCACCTAG CCGCGGCGAATGTTGCTATGCTACCC-3' to mutate Leu706 and Gln707 to Ala residues. The residues Arg711 and Gly712 were each also mutated to Ala using the 
primers

5 '-GCAACATTCCTCCAGGCTAGGTGGGCGGCCTATCATCAA

CGACAG-3' and 5'-CTGTCGTTGATGATAGGCCGCCCACCTAGCCTGGAGGA ATGTTGC-3' resulting in a construct in which four of the five residues of the IQ consensus sequence of IQ1 were altered. The mutated Myo1c sequences were ligated into the pFastbacI expression vector (Invitrogen, Carlsbad, CA) and sequenced. A construct encoding the second IQ domain of Myo1c, Myo1c-N2 (bullfrog Myo1c amino acids 721-744), was generated by the polymerase chain reaction (PCR) using pGus-T701 (Cyr et al., 2002) as the template and the oligonucleotides 5'-CATGCCATGGGTCACATGAAACATTCCGCGGTAG-3' and 5'-CCGGAATTC TCACTACTCATTCTCAGTGCAACGGGG-3'. The amplified product was ligated into the EcoR I and Nco I sites of pBBHis2A-N123 (Cyr et al., 2002) and re-amplified using the primers 5'-TTGGCGCGCCTATAAATTGCCGCGGGGTTC-3' and 5'-CCGGAATTCTCACTACTCATTCTCAGTGCAACGGGG-3'. The PCR product was ligated into the BssH I and EcoR I sites of the pFastBacI vector and sequenced.

Recombinant Myo1c protein purification. Recombinant bullfrog Myolc protein fragments were co-expressed with $\mathrm{CaM}$ in Sf9 insect cells using baculovirus infection as previously described (Gillespie et al., 1999). Sf9 cells expressing recombinant protein were sedimented and stored at $-80^{\circ} \mathrm{C}$. Protein was purified from the frozen pellets using a $\mathrm{Ni}^{2+}$-nitrilotriacetic acid chromatography column (Qiagen, Valencia, CA) as outlined in Cyr et al., 2002. Eluted fractions exhibiting a high protein concentration were pooled and stored on ice at $4^{\circ} \mathrm{C}$. Eluates were analyzed by SDS-PAGE and gel-filtration chromatography on a 25-ml Superdex 200 HR 10/30 or Superdex 200 10/300 GL column (Amersham Biosciences, Piscataway, New Jersey) in $400 \mathrm{mM} \mathrm{KCl}, 0.1 \mathrm{mM}$ ethylene glycol bis(2-aminoethyl ether)-N,N,N'N'-tetraacetic acid (EGTA), 15 mM HEPES, $\mathrm{pH} 7.5$ at room temperature. Protein concentrations were determined using the Bradford assay with bovine serum albumin (BSA) as a standard (Bradford, 1976).

CaM purification. Bovine $\mathrm{CaM}$ was purified from brain tissue using a phenylsepharose affinity column (Gopalakrishna and Anderson, 1982) and was quantified assuming $330 \mu \mathrm{M} / \mathrm{A}_{276 \mathrm{~nm}}$. 
Myo1c fragment:CaM stoichiometry. Gel filtration-purified Myo1c-T701, Myo1cT701 $1_{\mathrm{IQ} 2 \mathrm{Mut}}$, and Myo1c-T701 $1_{\mathrm{IQ} 1 \mathrm{RG} 1 \mathrm{Mut}}$ protein fragments were each concentrated by trichloroacetic acid (TCA) precipitation $(8 \% \mathrm{v} / \mathrm{v})$ and resuspended in NuPage LDS sample buffer (Invitrogen). Resuspended TCA precipitates were separated by electrophoresis on $12 \%$ Bis-Tris NuPage gels in NuPage MOPS SDS running buffer (Invitrogen) and stained with colloidal blue (Invitrogen). Destained gels were scanned using a flatbed scanner and analyzed with Scion Image Beta software (v4.03, Scion Corporation, Frederick, MD). The ratio of mutated Myolc heavy-chain fragments to $\mathrm{CaM}$ was calculated using the wild-type Myo1c-T701 protein complex as a standard. Under our purification conditions, Myo1c-T701 binds $1.8 \pm 0.2 \mathrm{CaM}$ molecules per Myo1c polypeptide (Gillespie and Cyr, 2002). Three separate preparations of each purified recombinant protein were analyzed in duplicate on two separate gels. Values are represented as the mean $\underline{ \pm}$ standard deviation.

Cochlear cultures. Cochlear cultures were prepared from postnatal day 0 (P0)-P2 $C d h 23^{v 2 J}$ and $M y o 7 a^{6 J}$ mice as previously described (Russell and Richardson, 1987). Briefly, cochleas were dissected in Hanks' balanced salt solution buffered with $10 \mathrm{mM}$ HEPES, pH 7.2. (HBHBSS). Cochlear coils were plated onto a hydrated collagen gel on a glass coverslip and maintained in sealed Maximow slide assemblies containing $\sim 50 \mathrm{ml}$ of medium (93\% DMEM/F12, 7\% fetal calf serum, $10 \mathrm{mg} / \mathrm{ml}$ ampicillin). Cultures were grown for 1-2 days in vitro at $37^{\circ} \mathrm{C}$ after which they were fixed in $3 \%$ paraformaldehyde (Agar Scientific, Essex, UK) and stored in phosphate buffered saline (PBS; $137 \mathrm{mM}$ $\mathrm{NaCl}, 2.7 \mathrm{mM} \mathrm{KCl}, 4.3 \mathrm{mM} \mathrm{Na}_{2} \mathrm{HPO}_{4}$, and $1.5 \mathrm{mM} \mathrm{KH}_{2} \mathrm{PO}_{4}, \mathrm{pH}$ 7.4) at $4^{\circ} \mathrm{C}$. To assess the dependence of Myo1c binding on intact tip links, tips links were broken in a subset of the cultures prior to fixation by incubation for 15-30 $\mathrm{min}$ at room temperature in either a solution containing $5 \mathrm{mM}$ EGTA or $5 \mathrm{mM}$ 1,2-bis(2-aminophenoxy)ethane-N,N,N',N'tetraacetic acid (BAPTA) in HBHBSS supplemented with $0.5 \mathrm{mM} \mathrm{MgCl}_{2}$ and $0.4 \mathrm{mM} \mathrm{MgSO}_{4}$ or a solution containing $5 \mathrm{mM} \mathrm{LaCl}_{3}$ in $155 \mathrm{mM} \mathrm{NaCl}, 6 \mathrm{mM} \mathrm{KCl}$, $3 \mathrm{mM}$ glucose, $4 \mathrm{mM} \mathrm{CaCl}$, $10 \mathrm{mM}$ HEPES, $\mathrm{pH}$ 7.2. 
In situ binding assay. In situ binding assays were performed as described (Cyr et al., 2002) on bullfrog (Rana catesbeina) sacculi or mouse cochlear cultures. Briefly, the samples were fixed in 3\% paraformaldehyde in PBS, washed in PBS, and permeabilized with $0.1 \%(\mathrm{w} / \mathrm{v})$ Sarkosyl for 1 hour. Following a PBS wash, nonspecific binding sites were blocked with $5 \mathrm{mg} / \mathrm{ml}$ BSA (fraction V, Calbiochem, La Jolla, CA) in $25 \mathrm{mM}$ HEPES, $\mathrm{pH}$ 7.5, and the samples were incubated overnight at room temperature with purified Myo1c fragments at $20 \mathrm{mg} / \mathrm{ml}$ [corresponding to either $230 \mathrm{nM}$ for MyolcT701, Myo1c-T701 $1_{\text {IQ2Mut }}(\mathrm{n}=10)$, and Myo1c-T701 $1_{\mathrm{IQ} 1 R \mathrm{R} 1 \mathrm{Mut}}(\mathrm{n}=9)$ or $1.65 \mathrm{mM}$ for Myo1c$\mathrm{N} 2(\mathrm{n}=4)]$ in $5 \mathrm{mg} / \mathrm{ml} \mathrm{BSA}, 25 \mathrm{mM}$ HEPES, $\mathrm{pH}$ 7.5, $1 \mathrm{mM}$ EGTA, and $400 \mathrm{mM} \mathrm{NaCl}$. Following washing, bound Myolc fragments were detected by virtue of the Xpress tag located at the amino terminus of the Myolc constructs, using the anti-Xpress antibody ( $5 \mu \mathrm{g} / \mathrm{ml}$; Invitrogen). Following three washes, bound antibody was detected with Alexa488 goat-anti-mouse secondary antibody ( $13 \mu \mathrm{g} / \mathrm{ml}$; Invitrogen) in $25 \mathrm{mM}$ HEPES, $\mathrm{pH} 7.5,1 \mathrm{mM}$ EGTA, and $5 \mathrm{mg} / \mathrm{ml}$ BSA. Filamentous actin was labeled with $33 \mathrm{nM}$ Alexa 568-phalloidin (Invitrogen) present during the secondary antibody incubation. All aforementioned washes were performed using $25 \mathrm{mM}$ HEPES, pH 7.5, $1 \mathrm{mM}$ EGTA, and $0.1 \%$ Tween-20. Samples were then washed in $25 \mathrm{mM}$ HEPES, pH 7.5, 1 mM EGTA, mounted using Vectashield (Vector Laboratories, Burlingame, CA), and imaged on a LSM-510 Meta confocal microscope (Carl Zeiss Inc., Thornwood, NY). In some experiments, $16 \mu \mathrm{M}$ bovine brain CaM was added during the recombinant protein incubation step (for co-incubations with Myo1c-T701 IQ2Mut, $\mathrm{n}=9$; with Myo1cT701 $1_{\text {IQIRGIMut, }} \mathrm{n}=4$ ). To break tips links, bullfrog sacculi were treated for $30 \mathrm{~min}$ at room temperature with either $(\mathrm{n}=8) 5 \mathrm{mM}$ EGTA in low- $\mathrm{Ca}^{2+}$ saline $(110 \mathrm{mM} \mathrm{NaCl}$, $2 \mathrm{mM} \mathrm{KCl}, 2 \mathrm{mM} \mathrm{MgCl}, 0.1 \mathrm{mM} \mathrm{CaCl}_{2}, 3 \mathrm{mM}$ D-glucose, $10 \mathrm{mM}$ HEPES, $\mathrm{pH}$ 7.2) or (n=5) $5 \mathrm{mM} \mathrm{LaCl}_{3}$ in low-Ca ${ }^{2+}$ saline without $\mathrm{MgCl}_{2}$. To assess the efficacy of these treatments, sacculi were subjected in parallel to a 5-sec incubation with $3 \mathrm{mM}$ AM1-43 (Biotium, Inc., Hayward, CA), washed, fixed, mounted, and visualized by confocal microscopy. Images of Myo1c binding to pretreated tissues are gain-matched to control conditions except for Fig. $8 C$ and $8 D$ where the gains for Myo1c-T701 binding are 558 and 565 respectively. 
PIP-strip binding assay. PIP-strips (Invitrogen and Echelon Biosciences, Salt Lake City, UT) were incubated in blocking solution (1:10 dilution of Liquid Block in PBS; Amersham Biosciences) to reduce non-specific binding. This and subsequent steps were performed at room temperature. Purified recombinant Myolc protein was added at a concentration of $1 \mu \mathrm{g} / \mathrm{ml}$ (corresponding to either $11.5 \mathrm{nM}$ for Myo1c-T701 and MyolcT701 $1_{\mathrm{IQ} 2 \mathrm{Mut}}$ or $82.5 \mathrm{nM}$ Myo1c-N2) with or without $460 \mathrm{nM} \mathrm{CaM}$ to blocking solution containing $1 \mathrm{mM}$ EGTA and incubated for 2 hours. Following three 10-min washes with PBS/0.1\%Tween-20 (PBS-T), the membranes were incubated with $1 \mu \mathrm{g} / \mathrm{ml}$ anti-Xpress antibody in blocking solution for 1 hour, washed in PBS-T, and incubated with $170 \mathrm{ng} / \mathrm{ml}$ goat-anti-mouse alkaline phosphatase antibody (Jackson Immunoresearch, West Grove, PA) in blocking solution for 1 hour. The PIP strips were then washed $3 \times 10$ min with PBS-T and $2 \times 5 \mathrm{~min}$ in alkaline phosphatase buffer (100 mM Tris, pH 9.5, $50 \mathrm{mM} \mathrm{MgCl} 2,100 \mathrm{mM} \mathrm{NaCl}$ ), and developed using 1-step NBT/BCIP (Pierce, Rockford, IL) for 5-15 min.

Myolc immunolabeling. Cochlear cultures from $C d h 23^{v 2 J}$ or $M y o 7 a^{6 J}$ mice were fixed with cold 3\% paraformaldehyde in PBS for 25 min. Samples were washed and stored in PBS at $4{ }^{\circ} \mathrm{C}$ until they were processed for immunocytochemistry at which time the tissue was permeabilized with $0.2 \%$ saponin in PBS for 1 hour. This and subsequent steps were performed at room temperature unless otherwise indicated. Non-specific binding sites were blocked using 5\% goat serum, $1 \%$ BSA, and $0.1 \%$ saponin in PBS for 1 hour. The tissue was incubated overnight at $4{ }^{\circ} \mathrm{C}$ with $3.4 \mu \mathrm{g} / \mathrm{ml}$ anti-Myo1c antibody x (R2652; gift from P. Gillespie, Oregon Health \& Science University; Dumont et al., 2002) in blocking solution. Samples were washed $3 \times 10 \mathrm{~min}$ in PBS-T and incubated with $13 \mu \mathrm{g} / \mathrm{ml}$ Alexa 488 goat-anti-rabbit antibody and $33 \mathrm{nM}$ Alexa-568 phalloidin in PBS containing $1 \%$ BSA and $0.1 \%$ saponin for $1.5 \mathrm{hrs}$. Samples were washed $3 \times 10$ min in PBS-T followed by 1 x $10 \mathrm{~min}$ in PBS. Samples were mounted in Vectashield and imaged by confocal microscopy. Immunolabeled images acquired for treated samples are gainmatched to control conditions. Ten apical and 10 basal cochlear coils from 5 
heterozygous $C d h 23^{v 2 J}$ mice were examined, and 16 apical and 16 basal cochlear coils from 8 homozygous $C d h 23^{v 2 J}$ animals were examined. Likewise, 4 apical and 4 basal cochlear coils from 2 heterozygous $M y o 7 a^{6 J}$ mice and 9 apical coils and 10 basal cochlear coils from 5 homozygous $M y o 7 a^{6 J}$ mice were analyzed.

Cdh23 immunolabeling. Cdh23 immunolabeling was performed on cochlear cultures from wild-type mice, acutely dissected vestibular organs (P3 and P6) from wild-type mice, or acutely dissected bullfrog sacculi with anti-Cdh23 antiserum (T8, gift from T. Friedman, NIDCD; Lagziel et al., 2005) as outlined for Myo1c immunolabeling except the tissue was permeabilized for 30 min with $0.5 \%$ Triton X-100 in PBS and the blocking solution was $2 \%$ BSA, $5 \%$ goat serum in PBS. To break tip links, samples were subjected to the designated treatments prior to fixation as indicated above for cochlear cultures or as outlined in the in situ binding assay for bullfrog sacculi. Four apical and 4 basal mouse cochlear turns, 5 mouse utricules, and at least 3 frog sacculi were examined for each treatment. Immunolabeled images acquired for treated samples are gainmatched to control conditions.

$\boldsymbol{P I P}_{2}$ immunolabeling. Mouse cochlear cultures $(\mathrm{P} 0+1$ day in vitro $)$ from $C d h 23^{\text {v2J }}$ animals were fixed in 4\% paraformaldehyde (diluted from ampules of a $16 \%$ stock solution) in $0.1 \mathrm{M}$ sodium phosphate $\mathrm{pH} 7.2$, washed in $\mathrm{PBS}$, and stored at $4{ }^{\circ} \mathrm{C}$ overnight. The tissue was permeabilized with $1 \%(w / v)$ Sarkosyl in PBS for 1 hour, blocked for 1 hour with $5 \mathrm{mg} / \mathrm{ml} \mathrm{BSA}$ in Tris-buffered saline (TBS; $10 \mathrm{mM}$ Tris-HCl $\mathrm{pH} 7.4,150 \mathrm{mM} \mathrm{NaCl}$ ), and incubated with $10 \mu \mathrm{g} / \mathrm{ml}$ anti-PIP ${ }_{2}$ monoclonal antibody (clone 2C11; Invitrogen) in blocking solution overnight at $4^{\circ} \mathrm{C}$. The tissue was washed with $5 \mathrm{mg} / \mathrm{ml} \mathrm{BSA}$ in TBS, incubated with FITC-conjugated goat anti-mouse IgM secondary antibody (1:200 dilution; Sigma Aldrich) and Texas Red-conjugated phalloidin (1 $\mathrm{U} / \mathrm{ml}$, Invitrogen) in blocking solution for 2-3 hours, washed, mounted, and visualized by confocal microscopy. All steps were performed at room temperature unless otherwise noted. The gain setting for the heterozygous image presented in Fig. $9 \mathrm{C}$ is 590 and for the homozygous image in Fig. $9 D$ is 540 . A total of 10 apical and 10 basal cochlear turns 
were examined from 5 homozygous $C d h 23^{22 J}$ mice; 8 apical and 8 basal cochlear coils from 4 heterozygous $C d h 23^{v 2 J}$ mice were examined.

Biolistic transfection of hair cells with the EGFP-tagged pleckstrin homology domain of PLCס1. A mammalian expression vector containing the N-terminal pleckstrin homology (PH) domain of phospholipase C81 (PLC81) ligated in frame with the enhanced green fluorescent protein (PLC81PH-EGFP; Watt et al., 2002) was a kind gift from Peter Downes (University of Dundee, UK). Gold microcarrier particles (1 mm diameter) were coated with plasmid DNA and used to transfect cochlear cultures prepared from 1-2 day old $C d h 23^{v 2 J}$ mouse pups using a Helios Gene Gun (Bio-Rad Laboratories, Hercules, CA; Schneider et al., 2002; Rzadzinska et al., 2004). After a further 20-24 hours in vitro, cultures were fixed with $3.7 \%$ formaldehyde in $0.1 \mathrm{M}$ sodium phosphate buffer $\mathrm{pH} 7.4$ for 1 hour, preblocked and permeabilized with $10 \%$ horse serum in TBS containing $0.1 \%$ Triton $\mathrm{X}-100$, and stained with rabbit anti-GFP antibody ( $4 \mathrm{mg} / \mathrm{ml}$; Invitrogen) followed by FITC-conjugated swine anti-rabbit Ig (4 mg/ml; Dako Ltd, Ely, UK) and Texas Red conjugated phalloidin (1 U/ml; Invitrogen). Samples were mounted and imaged by scanning confocal microscopy. A total of seventeen transfected hair cells from five heterozygous $C d h 23^{v 2 J}$ cultures, and thirtyseven hair cells from nine homozygous $C d h 23^{v 2 J}$ cultures were analyzed.

\section{Results}

The second IQ domain of Myolc is necessary, but not sufficient, for interaction with stereociliary receptors

To evaluate the role of the Myo1c IQ domains in binding to stereociliary receptors we exploited two previous observations: (1) CaM blocks the binding of MyolcT701, a fragment of Myo1c containing the neck and tail regions (Fig. 1A), to the tips of stereocilia (Fig. 2A,B and Cyr et al., 2002) and (2) amino-acid sequences in the second Myo1c IQ domain (IQ2) are highly conserved across species suggesting that this domain 
may be involved in receptor interactions (Cyr et al., 2002). We hypothesized that if IQ2 is the receptor-binding site of Myolc, then mutations that prevent CaM binding to IQ2 would abolish the ability of $\mathrm{CaM}$ to block interactions between Myo1c and its receptors. Because CaM binding to IQ domains critically depends upon the IQ consensus sequence $\mathrm{IQX}_{3} \mathrm{RGX}_{3} \mathrm{R}$ (single amino acid code where $\mathrm{X}$ is any amino acid; Rhoads and Friedberg, 1997), we sought to mutate the Myo1c IQ2 consensus sequence to prevent CaM interaction, but retain the ability of the domain to bind to stereociliary receptors. Accordingly, we changed the first two amino acids of the bullfrog Myo1c IQ2 consensus sequence, isoleucine 728 and glutamine 729 , to alanine residues. These mutations, I728A and Q729A, were made in the context of Myo1c-T701, resulting in a recombinant Myo1c fragment referred to as Myo1c-T701 $1_{\text {IQ2Mut }}$ (Fig. 1A).

Using baculovirus infection, Myo1c-T701 IQ2Mut was co-expressed with CaM and purified by virtue of an N-terminal $\mathrm{His}_{6}$ tag (Fig. 1C). As with the purification of wildtype Myo1c-T701, CaM co-purifies with the Myo1c-T701 $1_{\text {IQ2Mut }}$ protein indicating that $\mathrm{CaM}$ is bound to one or more of the Myolc IQ domains (Fig. 1 B,C). To verify that the mutations made in IQ2 disrupt CaM binding, the complex of Myo1c-T701 ${ }_{\text {IQ2Mut }}$ and CaM was further purified by gel-filtration chromatography and the amount of $\mathrm{CaM}$ copurifying with the mutated Myo1c fragment was compared to that which co-purifies with the wild-type Myolc-T701 fragment using densitometry. Gel-filtration chromatography and sucrose-density centrifugation indicate that an average of $1.8 \pm 0.2 \mathrm{CaM}$ molecules are bound per wild-type Myo1c-T701 under identical purification conditions (Gillespie and Cyr, 2002). However, it is not known which IQ domains are bound by CaM in the wild-type protein. Analysis of Myo1c-T701 $1_{\text {IQ2Mut }}$ reveals that one CaM $(1.0 \pm 0.3, \mathrm{n}=3)$ is bound per Myo1c-T701 $1_{\mathrm{IQ} 2 \mathrm{Mut}}$ molecule, confirming that the mutations in IQ2 were successful in disrupting $\mathrm{CaM}$ interactions.

The ability of Myo1c-T701 $1_{\text {IQ2Mut }}$ to bind to Myo1c receptors in hair cells was confirmed using our in situ binding assay. Like the wild-type Myo1c-T701, Myo1cT701 $1_{\mathrm{IQ} 2 \mathrm{Mut}}$ bound to receptors located at the tips of stereocilia (Fig. $2 A, C$ ), in the vesiclerich pericuticular necklace, and also in the hair-cell soma (data not shown). This 
interaction profile is indistinguishable from that of the wild-type protein (Fig. 2A), demonstrating that the IQ2 mutations did not adversely affect the ability of the molecule to bind to stereociliary receptors. To ascertain whether IQ2 is the site of CaM-sensitive interaction between Myo1c and its receptors, we tested the ability of excess CaM to block the observed interactions. As previously reported, wild-type Myo1c-T701 binding to stereociliary tips is blocked in the presence of excess CaM (Fig. 2B and Cyr et al., 2002). Conversely, Myo1c-T701 $1_{\mathrm{IQ} 2 \mathrm{Mut}}$ binding is not altered despite the presence of excess CaM (Fig. 2D). These data confirm that the second IQ domain comprises a vital component of the interaction site between Myolc and its receptors and that when this domain is occupied by $\mathrm{CaM}$, binding is prevented.

To determine whether the Myo1c IQ2 domain is sufficient for receptor interaction, a protein fragment containing only the second IQ domain of Myolc, termed Myo1c-N2, was generated (Fig. 1A). This Myolc fragment was co-expressed with CaM, purified (Fig. 1D), and tested for its ability to bind stereociliary receptors. If the receptorinteraction domain of Myo1c is composed solely of IQ2, Myo1c-N2 would be expected to bind to stereociliary receptors in a manner similar to Myo1c-T701. However, purified Myo1c-N2 protein did not bind to stereocilia (Fig. 2E) or the pericuticular necklace region (data not shown), suggesting that IQ2 is insufficient for binding. These data support previous results in which the addition of excess IQ2 peptide did not block the interaction of Myo1c-T701 and Myo1c receptors (Cyr et al., 2002).

The presence of one CaM bound to Myo1c-T701 $1_{\text {IQ2Mut }}$ indicated that $\mathrm{CaM}$ is bound to one of the other three Myo1c IQ domains. The weak IQ consensus sequence and low apparent affinity of CaM for IQ4 (Gillespie and Cyr, 2002) suggested that the IQ domain occupied by CaM was either IQ1 or IQ3. To determine whether CaM is bound at IQ1 and if so, whether this CaM is important for receptor interactions, we mutated the IQ1 consensus sequence to prevent CaM binding. The Myo1c-T701 IQ1RG1Mut protein was expressed, purified, and tested for receptor binding in our in situ binding assay (Fig. $1 E$ and supplemental Fig. 1). Despite the simultaneous alteration of four of the five residues 
of the IQ1 consensus sequence (L706A, Q707A, R711A, and G712A), no loss of CaM was detected from the purified protein $(1.5 \pm 0.4 \mathrm{CaMs}$ bound per T701 IQIRG1Mut, $\mathrm{n}=3)$ and binding to stereociliary receptors was only slightly reduced compared to the control (supplemental Fig. 1A,B). In addition, as seen with the wild-type Myo1c-T701, incubation with excess $\mathrm{CaM}$ blocked the interaction of Myo1c-T701 $1_{\mathrm{IQ} 1 \mathrm{RG} 1 \mathrm{Mut}}$ with stereociliary receptors (supplemental Fig. 1C). These data suggest that CaM is not bound to IQ1 in the Myo1c-T701 construct and therefore is likely bound at IQ3.

\section{The second IQ domain of Myolc mediates CaM-sensitive binding to $\mathrm{PIP}_{2}$ in vitro}

Recent data demonstrate that $\mathrm{PIP}_{2}$, which is present in stereociliary membranes and plays a role in hair-cell transduction, binds to Myolc in vitro (Hirono et al., 2004; Hokanson and Ostap, 2006). The region of Myolc that binds to $\mathrm{PIP}_{2}$, however, is not clear; both the Myo1c neck and tail regions have been identified as sites of interaction (Hirono et al., 2004; Hokanson and Ostap, 2006). Using a nitrocellulose membranebased assay and $\mathrm{PIP}_{2}$-containing vesicles, Hirono et al. (2004) determined that the neck region of Myo1c interacts with $\mathrm{PIP}_{2}$. In addition, Myolc interactions with $\mathrm{PIP}_{2}$ vesicles were blocked by CaM in the presence of EGTA or $\mathrm{Ca}^{2+}$ (Hirono et al., 2004). We sought to further characterize Myo1c and $\mathrm{PIP}_{2}$ interactions and to explore the possibility that $\mathrm{PIP}_{2}$ may represent the Myolc receptors observed in our in situ binding assay. To do so we examined whether Myo1c-T701, Myo1c-T701 $1_{\mathrm{IQ} 2 \mathrm{Mut}}$ and Myo1c-N2 bound to $\mathrm{PIP}_{2}$ in a membrane-based assay in a manner similar to their binding to stereociliary receptors. In $1 \mathrm{mM}$ EGTA, Myo1c-T701 bound to PIP $_{2}$ and this binding was blocked by the presence of excess CaM (Fig. $3 A, B$ ). Similar to the results seen in our in situ binding assay, Myo1c-T701 ${ }_{\text {IQ2Mut }}$ bound to $\mathrm{PIP}_{2}$ and this interaction was not blocked by the addition of excess CaM (Fig. 3C,D). In addition, Myo1c-N2, which did not bind to stereociliary receptors in the in situ binding assay (Fig. 2E), did not bind to $\mathrm{PIP}_{2}$ in the membrane-based assay (Fig. 3E). Finally, co-incubation of Myo1c-T701 with an excess amount of a synthetic peptide encoding IQ2 did not block binding to $\mathrm{PIP}_{2}$ (Fig. $3 F$ ). These data demonstrate that, in an in vitro assay, Myolc interacts with $\mathrm{PIP}_{2}$ and the 
stereociliary receptors in a similar manner. Although $\mathrm{PIP}_{2}$ binds to Myolc in a membrane-based assay, further evidence (detailed below) suggests that $\mathrm{PIP}_{2}$ is not the receptor detected in our in situ binding assay.

\section{Tip-link loss abolishes Myolc binding to stereociliary receptors}

Myo1c has been shown to interact with $\mathrm{Cdh} 23$, a proposed component of the tip link, when the proteins are co-expressed in tissue culture cells (Siemens et al., 2004). To examine the requirement for intact tip links on Myo1c interactions with its receptors, we exposed bullfrog saccular hair cells to either lanthanide ions or calcium chelators, agents which break tip links and eradicate mechanotransduction (Baumann and Roth, 1986; Assad et al., 1991; Michel et al., 2005), prior to fixation and Myo1c-T701 binding. Treatment with $5 \mathrm{mM} \mathrm{La}^{3+}$ or $5 \mathrm{mM}$ EGTA successfully broke tip links as assayed by either a complete, or near-complete, loss of AM1-43 loading into hair cells through transduction channels (Fig. 4A,B,E,F). Moreover, pretreatment with either $\mathrm{La}^{3+}$ or EGTA eliminated virtually all Myo1c-T701 binding at both the hair-cell stereociliary tips and pericuticular necklace (Fig. 4D, $H$ and data not shown) in the bullfrog sacculus.

To assess whether intact tip links are also needed for Myo1c binding in the mouse cochlea, we broke tip links with either $5 \mathrm{mM}$ EGTA, BAPTA or $\mathrm{La}^{3+}$ and determined whether Myo1c bound to stereociliary tips following these treatments. In untreated cochlear hair cells, Myolc-T701 bound at the tips of stereocilia as seen in the bullfrog sacculus (Fig. 5A). Pretreatment of cochleas with BAPTA eliminated all binding of Myo1c to stereocilia (Fig. $5 B$ ), while $\mathrm{La}^{3+}$ pretreatment reduced, but did not eliminate, Myo1c binding (Fig. 5D). EGTA pretreatment gave variable results ranging from a slight reduction in binding (data not shown) to a loss of binding (Fig. 5C); this variability could be found within a single cochlea and did not correspond to location of the hair cells along the length of the organ. 


\section{Effects of tip-link loss on Cdh23 immunolocalization in bullfrog sacculi and mouse cochlea}

The elimination of Myo1c binding to stereociliary tips following tip-link loss led us to revisit the question of $\mathrm{Cdh} 23$ localization in stereocilia following such treatments in both bullfrogs and mice. To date, seemingly contradictory results have been reported regarding the effects of tip-link loss on Cdh23 localization in hair cells (Siemens et al., 2004; Michel et al., 2005). Siemens et al. (2004) demonstrate that EGTA treatment results in a loss of Cdh23 immunolocalization in bullfrog saccular hair bundles and an appearance of immunoreactivity observed at the pericuticular necklace, a vesicle-rich region surrounding the cuticular plate. However, in the mouse cochlea, similar treatments result neither in a loss of $\mathrm{Cdh} 23$ immunoreactivity in stereocilia nor the appearance of immunoreactivity in the pericuticular necklace (Michel et al., 2005). These ostensibly disparate results were performed using different antibodies against Cdh23 and may reflect differences in the antibodies used, species, or type of hair cell. To distinguish between these possibilities, we examined the immunolocalization of $\mathrm{Cdh} 23$ in the hair cells of the bullfrog sacculus, mouse utricle, and mouse cochlea following tiplink loss using an antiserum raised against the cytoplasmic domain of $\mathrm{Cdh} 23$ (T8 antiserum; Lagziel et al., 2005). In the bullfrog sacculus, this antibody detects Cdh23 at the tall edge of the hair bundle, presumably between the tallest stereocilia and the kinocilium as previously reported (Fig. 6A and Lagziel et al., 2005). Similar to the results of Siemens et al. (2004) treatment of bullfrog saccular hair cells with $\mathrm{La}^{3+}$ did not abolish immunolabeling (Fig. 6B), however, treatment with BAPTA (Fig. 6C) or EGTA (Fig. 6D) eliminated Cdh23 immunolabeling. The loss of labeling was observed throughout the hair cells of the sacculus including the immature cells located at the periphery of the sensory epithelium (data not shown). Unlike the results of Siemens et al. (2004), we did not detect Cdh23 immunoreactivity in the pericuticular necklace following EGTA treatment (data not shown). Moreover, as reported by Michel et al. (2005) using two different antibodies to the cytoplasmic domain of cadherin 23 , we observed that treatment of mouse cochlear hair cells with $\mathrm{La}^{3+}$, BAPTA, or EGTA or had no detectable 
effect on Cdh23 immunolocalization (Fig. 6E-H). These data suggest that reported differences in Cdh23 immunolocalization following tip-link loss in bullfrog sacculus (Siemens et al., 2004) and mouse cochlea (Michel et al., 2005) are not due to the use of different antibodies.

To determine whether the effects of tip-link loss on $\mathrm{Cdh} 23$ immunolocalization differs in auditory and vestibular hair cells within a single species, we examined $\operatorname{Cdh} 23$ immunolabeling in mouse vestibular hair cells following treatment with EGTA (Fig. 6I,J). In untreated samples, Cdh23 was present in hair bundles (Fig. 6I) and occasionally could be seen at stereociliary tips (Fig. 6I, arrowhead). Smaller utricular hair bundles were much more intensely labeled than larger hair bundles (Fig. 6I, asterisk). In contrast to that observed in bullfrog saccular hair cells, tip-link loss in mouse utricular hair cells did not coincide with a loss of Cdh23 immunoreactivity (Fig. $6 J$ ). Hair bundles remained immunolabeled for $\mathrm{Cdh} 23$ to varying degrees. Noteably, smaller hair bundles remained intensely labeled following EGTA treatment and often the immunolabeling was observed along the length of stereocilia rather than concentrated at stereociliary tips (Fig. $6 J$ and inset). Such a Cdh23 distribution following $\mathrm{Ca}^{2+}$ chelation was observed when the EGTA incubation was done at both room temperature and $4^{\circ} \mathrm{C}$ (Fig. $6 \mathrm{~J}$, inset and data not shown). These data suggest that the differences seen in $\mathrm{Cdh} 23$ immunolocalization following tip-link loss are species dependent and do not reflect a distinction between auditory and vestibular hair cells. We did, however, observe a slight difference in immunolabeling in the mouse utricle in comparison to the sacculus following EGTA treatment. Saccular hair cells exhibited reduced labeling following treatment, although labeling was still apparent (data not shown).

The molecular basis for the observed differences in $\operatorname{Cdh} 23$ immunoreactivity following $\mathrm{Ca}^{2+}$ chelation in the mouse and frog inner ear is unknown, but suggest that the properties of Cdh 23 differ between species or within a given species. It is possible that within a given species, there exist subpopulations of $\mathrm{Cdh} 23$ that differ in their clearance from the stereociliary membrane, their conformational state, or their interaction with 
other molecules following $\mathrm{Ca}^{2+}$ chelation. Indeed, multiple isoforms of $\mathrm{Cdh} 23$ have been reported in the mouse inner ear, which may reflect such $\mathrm{Cdh} 23$ subpopulations (Lagziel et al., 2005).

\section{Interaction of Myo1c-T701 and stereociliary receptors does not occur in Cdh23 ${ }^{\text {v2J }}$ mice}

The loss of Myo1c binding to the tips stereocilia following tip-link loss implicates $\mathrm{Cdh} 23$ as a stereociliary interaction partner for Myolc. Although mouse cochlear hair cells retain Cdh23 immunoreactivity following tip-link loss, we are unable to determine whether a small fraction of the Cdh 23 immunoreactivity, perhaps that located at very the tips of stereocilia which binds to Myolc, is eliminated by treatment with EGTA, BAPTA or $\mathrm{La}^{3+}$ (Fig. $\left.6 E-H\right)$. We, therefore, further explored whether the Myo1c receptors detected in our in situ binding assay are Cdh23. To do so, we examined the binding of Myo1c-T701 to stereocilia of mice lacking the $\mathrm{Cdh} 23$ protein. Immunolocalization studies using antibodies directed against the $\mathrm{N}$-terminal and $\mathrm{C}$-terminal domains of $\mathrm{Cdh} 23$ show that $C d h 23^{\text {v2J }}$ homozygous mice have no $\mathrm{Cdh} 23$ protein present in stereocilia (Michel et al., 2005; A. Lagziel and T. Friedman, personal communication). Moreover, other antibodies against the C-terminus do not detect $\mathrm{Cdh} 23$ protein in cochleas of $C d h 23^{v 2 J}$ homozygous mice by immunoblotting (Rzadzinska et al., 2005). To further characterize the hair bundles of the $C d h 23^{22 J}$, we first examined the localization of endogenous Myolc in cochleas of both $C d h 23^{v 2 J}$ heterozygous and homozygous mice. In heterozygous mice, which have normal hair-bundle morphology, Myolc was located along the length of stereocilia in both inner and outer hair cells, however, immunolabeling was more prevalent in the outer hair cells (Fig. $7 A$ and inset). Although the hair bundles of $C d h 23^{v 2 J}$ homozygous mice are drastically malformed, Myolc is also present in the mutant hair bundles of both inner and outer hair cells (Fig. $7 B$ and inset). As seen with bullfrog saccular hair cells (Cyr et al., 2002), Myo1c-T701 binds to the tips of stereocilia and to the kinocilium in cochlear hair cells from heterozygous $C d h 23^{\text {v2J }}$ mice (Fig. $7 C$ and inset). In contrast, no binding was detected in hair cells of homozygous $C d h 23^{v 2 J}$ animals (Fig. $7 D$ and inset). 


\section{Interaction of Myo1c-T701 and stereociliary receptors occurs in $\mathrm{Myo}^{6 \mathrm{a}^{6 \mathrm{~J}}}$ mice}

The loss of tip links due to exogenous treatments is expected to result in transduction-channel closure, which could alter the available binding sites for our recombinant Myo1c probes. To examine whether transduction-channel closure prevents Myo1c binding in our in situ binding assay, we examined the ability of Myo1c-T701 to bind to the stereocilia in cochleas from $M y o 7 a^{6 J}$ mice which harbor a mutation in myosin VIIa resulting in bundle abnormalities and transduction channels that are closed at rest (Richardson et al., 1997; Self et al., 1998; Gale et al., 2001; Kros et al., 2002). Cochlear hair cells from heterozygous $M y o 7 a^{6 J}$ animals exhibit normal bundle morphology, however those from homozygous $M y o 7 a^{6 J}$ mice have severely disorganized hair bundles that are fragmented into several smaller units each comprised of variable numbers of individual stereocilia (Fig. 8B,D). As demonstrated by immunolabeling, endogenous Myolc is present in the stereocilia of both heterozygous and homozygous animals (Fig. $8 A, B$ and insets). Unlike the $C d h 23^{v 2 J}$ homozygotes (Fig. $7 D$ ), however, Myo1c-T701 binds to receptors in $M y o 7 a^{6 J}$ homozygotes as well as the heterozygotes (Fig. 8C,D). Binding to homozygous hair bundles was often less obvious than that seen in the heterozygous samples, but was above background levels. Collectively, these data suggest that neither aberrant bundle morphology nor channel closure affect the availability of Myolc binding sites in our assay.

\section{$\mathrm{PIP}_{2}$ is present in $\mathrm{Cdh}^{23^{\mathrm{v} 2 \mathrm{~J}} \text { hair bundles }}$}

In bullfrog saccular hair bundles, $\mathrm{PIP}_{2}$ is present in stereociliary membranes and is important for transduction (Hirono et al., 2004). The binding of Myolc fragments to $\mathrm{PIP}_{2}$ in vitro (Fig. 3 and Hirono et al., 2004) and the loss of Myo1c-T701 binding to hair cells in $C d h 23^{v 2 J}$ homozygous animals (Fig. 7) led us to examine whether $C d h 23^{v 2 J}$ homozygous animals have $\mathrm{PIP}_{2}$ within their stereociliary membranes. To examine $\mathrm{PIP}_{2}$ localization, an expression construct comprised of the PLC $\delta 1$ pleckstrin homology domain coupled with EGFP was transiently transfected into cochlear hair cells of 
homozygous and heterozygous $C d h 23^{v 2 J}$ animals. PLC $\delta 1 \mathrm{PH}-\mathrm{EGFP}$ binds to $\mathrm{PIP}_{2}$ providing a fluorescent reporter of $\mathrm{PIP}_{2}$ localization in the membranes of living cells (Downes et al., 2005). Between 20-24 hours after transfection, inner and outer hair cells of both $C d h 23^{v 2 J}$ heterozygous and homozygous mice show robust fluorescence of their stereociliary membranes verifying the presence of $\mathrm{PIP}_{2}$ in the hair bundles of living cells (Fig. 9A,B). We then examined whether $\mathrm{PIP}_{2}$ remains in the stereociliary membrane following fixation and extraction with sarkosyl, the detergent used to permeabilize the tissue in our in situ binding assay. Using a monoclonal antibody against $\mathrm{PIP}_{2}$, we found $\mathrm{PIP}_{2}$ in the stereociliary membrane and concentrated at stereociliary tips in both $C d h 23^{22 J}$ heterozygous and homozygous cochlear hair cells even after extraction of the tissue with $1 \%$ Sarkosyl for one hour (Fig. 9C,D). Similar results were obtained in the wild-type bullfrog sacculus (data not shown). In addition, $\mathrm{PIP}_{2}$ immunolabeling was detected in hair cell microvilli, which are very abundant at the cell's apical surface (Fig. 9C, arrow). Thus, the lack of Myo1c-T701 binding to stereociliary receptors in homozygous $C d h 23^{\text {v2J }}$ hair cells is not due to the absence of stereociliary PIP $_{2}$.

\section{Discussion}

\section{The second IQ domain of Myolc mediates binding to intracellular receptors}

We have previously established the importance of the Myolc neck domain in interactions of the adaptation motor with its receptors stereociliary tips (Cyr et al., 2002). This interaction is blocked by excess $\mathrm{CaM}$, indicating that binding is modulated by the CaM occupancy of the Myo1c IQ domains, which in turn is modulated by $\mathrm{Ca}^{2+}$. In the current study we demonstrate that mutations in IQ2 that are predicted to prevent CaM binding to this IQ domain also prevent the CaM modulation of Myo1c binding to its receptors. The second IQ domain of Myo1c, which is highly conserved across species (Cyr et al., 2002), therefore, mediates CaM-sensitive interactions of the adaptation motor at the site of transduction. 
Although a CaM-free IQ2 domain is necessary for receptor interactions, it may not be not sufficient for binding. Myo1c-N2, which contains only the Myo1c IQ2 domain and detection tags, does not bind to stereociliary components. These data are consistent with previous results showing an excess of the IQ2 peptide does not block Myo1c-T701 binding at stereociliary tips (Cyr et al., 2002) and support our earlier observations that micromolar $\mathrm{Ca}^{2+}$ concentrations, which are expected to remove $\mathrm{CaM}$ from neighboring IQ domains, can prevent Myo1c-T701 binding to stereociliary receptors (Cyr et al., 2002). Collectively these results suggest that additional portions of the Myo1c protein, perhaps CaM molecules bound at neighboring IQ domains, are also required for binding.

Sucrose-density centrifugation and gel-filtration chromatography demonstrates that $\sim 2$ CaMs are bound to Myo1c-T701 following purification (Gillespie and Cyr, 2002). The weak affinity of IQ4 for CaM (Gillespie and Cyr, 2002) suggests that these CaMs are bound at two of the first three IQ domains. Moreover, the loss of a CaM from Myo1cT701 following mutations in IQ2 suggests that one of the two CaMs that co-purify with Myo1c-T701 is bound at IQ2. In order for Myo1c-T701 to bind to receptors, therefore, CaM must be displaced from IQ2 during our assay, perhaps due to competition, thereby unmasking IQ2 and allowing receptor interactions. Simultaneous mutation of four of the five residues comprising the CaM-binding consensus sequence of IQ1, however, did not result in a loss of a CaM molecule from Myolc-T701. These results suggest that the second CaM that co-purifies with Myo1c-T701 is not bound at IQ1 and therefore is likely bound at IQ3.

\section{Myolc binding to PIP}

$\mathrm{PIP}_{2}$, which is abundant in stereociliary membranes, is important for hair-cell transduction and binds to the Myolc neck in vitro (Hirono et al., 2004). Using a nitrocellulose-based assay we determined that CaM occupancy of the second IQ domain of Myo1c also modulates the interaction of the motor protein with $\mathrm{PIP}_{2}$ in vitro. However, as evidenced in cochleas from homozygous $C d h 23^{v 2 J}$ mice, which have 
stereociliary $\mathrm{PIP}_{2}$ but no Myolc binding, our in situ binding assay does not detect Myo1c interactions with $\mathrm{PIP}_{2}$, suggesting that the conditions of the assay are not favorable for detecting this interaction. Nevertheless, the in situ binding assay enables the examination and characterization of Myo1c interactions with other stereociliary components.

\section{Which molecules are the observed Myolc receptors?}

Our results allow us to eliminate several candidate molecules as the receptors visualized in our in situ binding assay. As mentioned above, while Myolc may interact with immobilized $\mathrm{PIP}_{2}$ in vitro, we do not detect Myo1c interactions with $\mathrm{PIP}_{2}$ in our in

situ binding assay. Similarly, because stereocilia of homozygous $C d h 23^{v 2 J}$ mice contain endogenous Myo1c but do not bind recombinant Myo1c probes, the observed Myo1c receptors are not endogenous Myolc molecules. Another candidate Myo1c receptor is PHR1, which binds to a Myolc fragment containing IQ4 and the tail. Because a Myo1c fragment containing only IQs 1-3 is sufficient for binding to stereociliary tips (Cyr et al., 2002), it is unlikely the PHR1 molecules are the receptors observed in our assay unless Myo1c has two independent PHR1 interaction domains. Our data do not preclude the possibility that PHR1 and Myolc interact in hair bundles. Indeed, molecular motors often interact with more than one molecule.

Treatment of bullfrog vestibular or mouse cochlear hair cells with agents that break tip links including EGTA, BAPTA, and $\mathrm{La}^{3+}$ eliminates or greatly reduces Myo1c binding. The effects of tip-link loss on Myolc binding implicate a component of the tiplink complex as the binding partner for Myolc in our assay. As a candidate tip-link molecule, $\mathrm{Cdh} 23$, therefore, became an obvious contender for the Myo1c receptor. To examine the role of Cdh23 in the interactions of Myo1c with its receptors in hair cells, we made use of the homozygous $C d h 23^{v 2 J}$ mouse, which does not express Cdh 23 protein in hair cells, has gross hair-bundle abnormalities, and exhibits both auditory and vestibular defects (Di Palma et al., 2001; Lagziel et al., 2005; Michel et al., 2005; Rzadzinska et al., 2005). Although Myolc binds to the hair bundles from heterozygous $C d h 23^{v 2 J}$ cochleas, no binding is detected in the cochleas from homozygous animals. This lack of binding is 
unlikely to be simply due to hair-bundle disarray or transduction-channel closure because Myolc binds to stereociliary tips of homozygous $M y o 7 a^{6 J}$ cochlear hair cells.

Our data suggest that the lack of Myo1c binding to hair bundles with broken tip links and in homozygous $C d h 23^{v 2 J}$ cochleas reflects a perturbation of molecular interactions that involve both $\mathrm{Cdh} 23$ and Myo1c. It is formally possible that these interactions are not direct and that the loss of tip links and $\mathrm{Cdh} 23$ from hair bundles results in the loss of another molecule, which directly interacts with Myolc. However, the interaction of Cdh23 and Myo1c in tissue culture cells (Siemens et al., 2004) lends support to the conclusion that these molecules also interact in hair cells.

The immunolocalization of Cdh23 in stereocilia of mouse cochlear hair cells following treatment with agents that break tip links is not incongruous with our hypothesis. We propose that the structural alterations of the $\mathrm{Cdh} 23$ ectodomain due to $\mathrm{Ca}^{2+}$ chelation results in a conformational change in the protein's intracellular domain, thereby altering its interaction with other molecules. In support of this hypothesis, in bullfrog saccular hair cells, distinct immunolabeling patterns for Cdh23 following EGTA treatment have been obtained using different antisera raised against the $\operatorname{Cdh} 23$ cytoplasmic domain (this study and Siemens et al., 2004). Specifically, Seimens et al. (2004) report an appearance of $\mathrm{Cdh} 23$ immunoreactivity in the pericuticular necklace following EGTA treatment. However, using a different antibody against the $\operatorname{Cdh} 23$ cytoplasmic domain, we do not detect $\mathrm{Cdh} 23$ in this subcellular domain. These differences in labeling patterns suggest that the cytoplasmic domain of the protein undergoes conformational changes, perhaps by binding to or dissociating from other molecules, which render the epitopes recognized by certain antibodies inaccessible. Similar types of intra- or intermolecular changes in $\mathrm{Cdh} 23$ might also alter the ability of Myo1c probes to interact with this domain in our in situ binding assay. Thus following $\mathrm{Ca}^{2+}$ chelation, Cdh23 may be present, but unable to bind to exogenously applied Myo1c fragments. 


\section{Myolc interactions with transduction components}

Our data demonstrate that the second IQ domain of Myolc is important for Myolc interactions with $\mathrm{PIP}_{2}$ in vitro and at stereociliary tips in situ. In hair cells, the later interaction requires intact tip links and is absent in hair cells lacking Cdh23, a proposed component of the tip link (Siemens et al., 2004; Sollner et al., 2004). The ability of IQ2 to bind CaM, which blocks the interaction, suggests that the local $\mathrm{Ca}^{2+}$ concentration plays a critical role in determining which molecule is bound to the Myo1c neck at a given point in time (supplemental Fig. 2). Due to the high degree of identity of IQ2 across species, the ability of a Myo1c fragment containing only IQs 1-3 to bind to stereociliary tips (Cyr et al., 2002), and the effects of mutations in IQ2 on the ability of $\mathrm{CaM}$ to block stereociliary interactions, we propose that the domain of Myo1c that modulates interactions with stereociliary receptors, which are likely to be Cdh23, is IQ2. We predict, therefore, that interactions of Myo1c and Cdh23 will depend both upon the CaM-occupancy of the Myo1c IQ domains and the conformation of the Cdh23 cytoplasmic domain (supplemental Fig. 2).

Accordingly, large increases in the $\mathrm{Ca}^{2+}$ concentration, perhaps immediately after channel opening and before fast adaptation has occurred to reduce channel open probability, should favor the loss of $\mathrm{CaM}$ from the Myolc IQ domains and reduce the interaction of Myolc with Cdh23. As the stereociliary plasma membrane $\mathrm{Ca}^{2+}$-ATPase begins to reduce the $\mathrm{Ca}^{2+}$ concentration, $\mathrm{CaM}$ would re-associate with the high-affinity IQ domains (IQ3 and perhaps IQ1) and Cdh23 binding would be favored. It would be predicted that interactions with $\mathrm{Cdh} 23$ would be maintained unless both the local $\mathrm{Ca}^{2+}$ concentration and the relative affinity for $\mathrm{CaM}$ favors $\mathrm{CaM}$ re-association at IQ2 in vivo or hair cells are exposed to $\mathrm{Ca}^{2+}$ chelators in vitro (supplemental Fig. 2). 
A. Wild-type Myo1c (amino acid residues 1-1028)

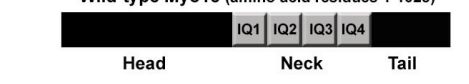

B.

B. T701 (amino acid residues 701-1028)

C.

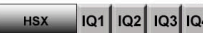

IQ2M (amino acid residues 701-1028)

D.

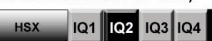

N2 (amino acid residues 721-749) \begin{tabular}{lll} 
HSXS & IO2 \\
\hline
\end{tabular}

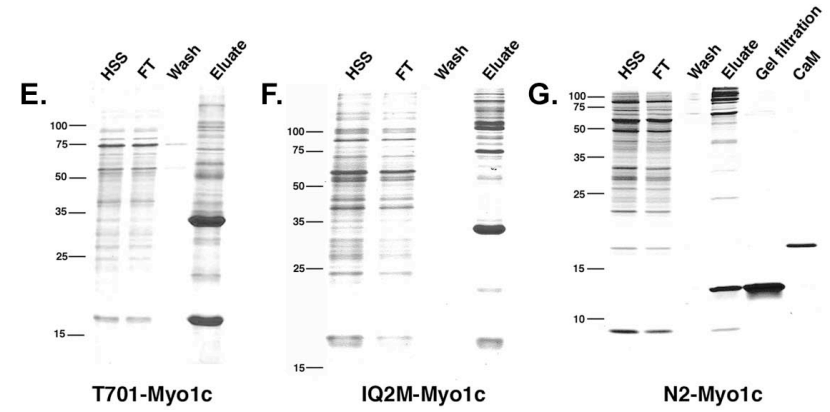

Figure 1. Recombinant Myo1c proteins. A) Construct maps. Wild-type Myo1c includes a catalytic head domain, a neck composed of four tandem IQ domains that bind $\mathrm{CaM}$, and a tail region. The recombinant protein Myo1c-T701 encompasses the Myo1c neck and tail domains. Myo1c-T701IQ2Mut is identical to Myo1c-T701, with the exception of mutations made to the first two amino acids of the IQ consensus sequence of the second IQ domain: I728A and Q729A. Myo1c-N2 consists of only IQ2. Purification and detection tags $\left(H, \mathrm{His}_{6}\right.$-tag; $S$, S-tag; $X$, Xpress-tag) have been appended to the N-terminus of all recombinant constructs and are indicated by the light gray box. Myo1c-T701IQ1RG1Mut is identical to Myo1c-T701, with the exception of mutations that made four amino acids of the IQ consensus sequence of the first IQ domain: L706A, Q707A, R711A, and G712A. The diagram is not drawn to scale. B \& C) Coomassie blue-stained SDS-PAGE gels of recombinant Myo1c protein fragments Myo1c-T701 and Myo1c-T701IQ2Mut purification. HSS, High-speed supernatant; FT, flow through from $\mathrm{Ni}^{+2}$-NTA column; Wash, $\mathrm{Ni}^{+2}$-NTA column wash; Eluate, protein eluted from $\mathrm{Ni}^{+2}$-NTA column. Myo1c-T701 and Myo1c-T701IQ2Mut migrate at 34 $\mathrm{kDa}(*)$. CaM (\#) copurifies with each Myo1c fragment and migrates at $16 \mathrm{kDa}$. D) Purification of recombinant Myo1c protein fragment N2. Lanes are labeled as in $B$. In addition, Gel filtration shows the Myolc-N2 protein further purified by size-exclusion chromatography. CaM is purified bovine CaM. Note that although CaM is coexpressed with Myo1c-N2, CaM does not co-purify with the Myo1c-N2 protein. E) Coomassie blue-stained SDS-PAGE gel of Myolc-T701IQ1RG1Mut protein purification. Lanes are labeled as indicated in $B$. Molecular weight markers (kDa) are indicated to the left of each gel. 

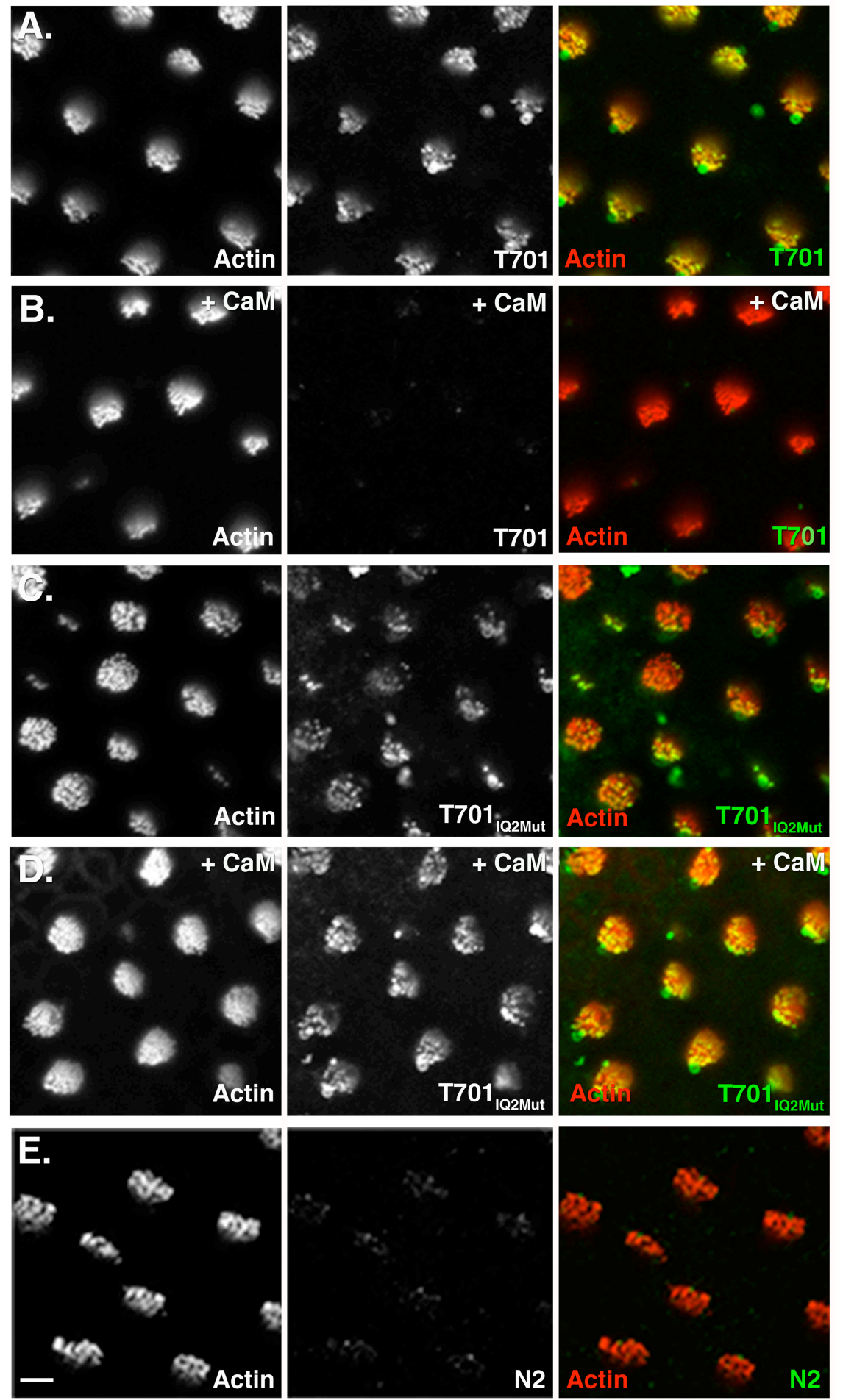

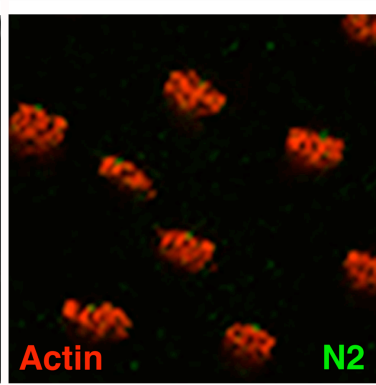

Figure 2. Binding of Myo1c fragments to stereociliary receptors. Each panel shows a single confocal section containing 10 hair bundles of a wholemount bullfrog sacculus. Each group of three panels depicts the following: left, fluorescently conjugated phalloidin labeling of filamentous actin; middle, bound recombinant Myolc fragments; right, overlay of actin (red) and Myolc binding (green). A) Binding of Myolc-T701 to receptors at the tips of stereocilia. B) Excess CaM abolishes Myo1c-T701 binding to stereociliary receptors. C) Myo1c-T701 ${ }_{\text {IQ2Mut }}$ binding to stereociliary receptors. D) Excess CaM does not block interactions of Myo1c-T701 IQ2Mut with stereociliary receptors. E) Myo1c-N2 does not bind to stereociliary receptors. Scale bar: (in $E$ ) $5 \mu \mathrm{m}$. 
A.

B.

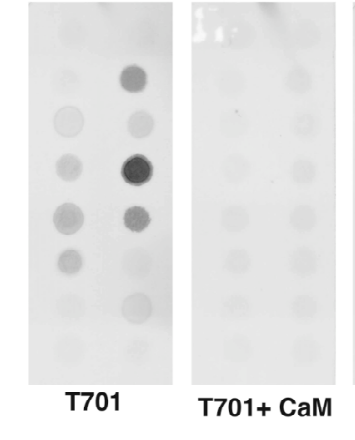

c.

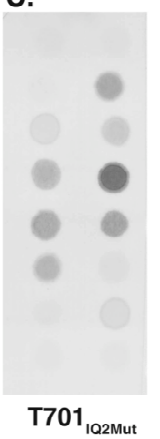

D.

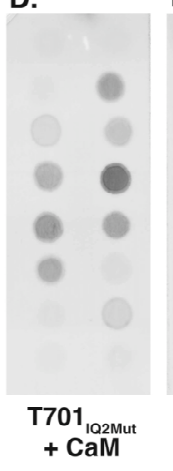

E.

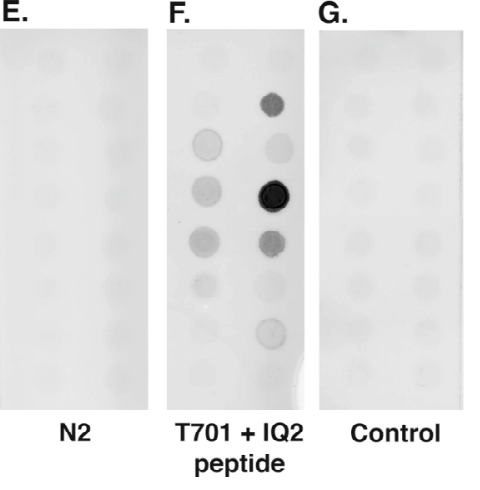

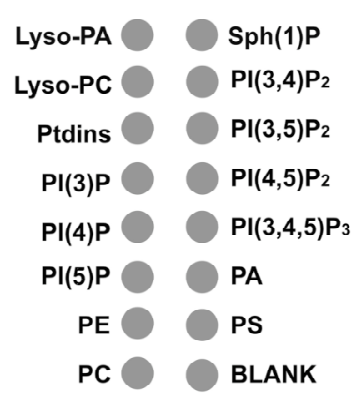

Figure 3. Binding of Myo1c fragments to anionic phospholipids. A-F) Each panel shows one PIP-strip, a nitrocellulose membrane, which has been spotted with anionic lipids, that has been incubated with the indicated Myo1c fragment. Bound Myo1c fragments were detected by virtue of the N-terminal Xpress epitope tag. The diagram to the right indicates the location and identity of the anionic lipids. A) T701-Myolc binds weakly to several of the anionic lipids and strongly to $\mathrm{PI}(4,5) \mathrm{P}_{2}\left(\mathrm{PIP}_{2}\right)$. B) The addition of excess CaM abolishes Myo1c-T701 interactions with anionic lipids. C) Myo1c-T701 ${ }_{\text {IQ2Mut }}$ binds to the same subset of anionic lipids as Myo1c-T701. D) Excess $\mathrm{CaM}$ does not block the interactions of Myo1c-T701 ${ }_{\text {IQ2Mut }}$ with anionic lipids. E) Myo1c-N2 does not bind anionic lipids. F) Excess IQ2 peptide, when incubated with Myo1c-T701, does not block the binding of Myolc-T701. G) Antibody only control. 

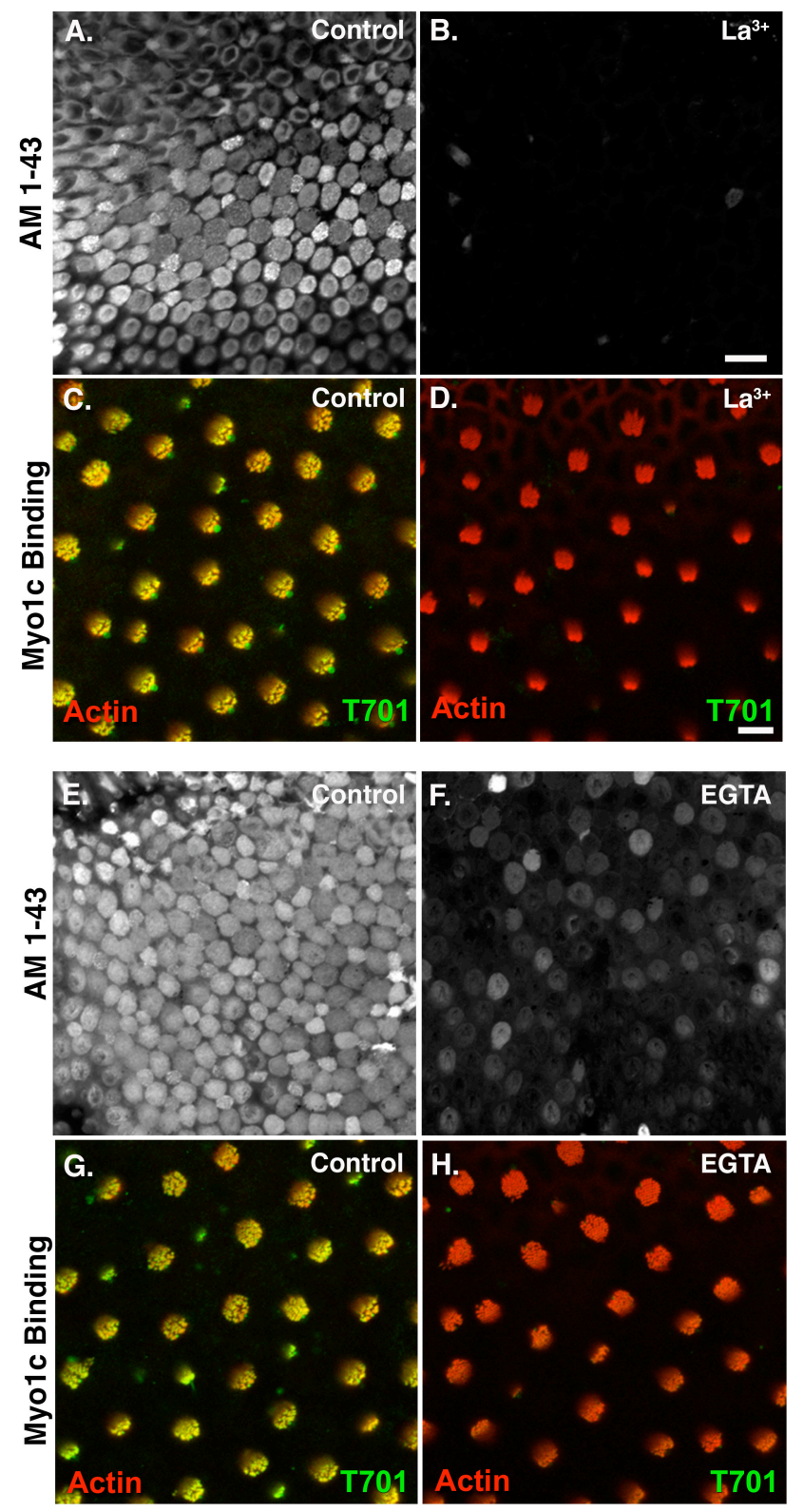

Figure 4. Myo1c binding to stereociliary receptors in the bullfrog sacculus requires intact tip links. A) Sensory epithelium of a bullfrog sacculus showing loading of hair cells with AM1-43, which enters through open transduction channels. B) Treatment of a sacculus with $5 \mathrm{mM} \mathrm{La}^{+3}$ breaks tip links as assayed by the loss ofAM143 entry into hair cells. C \& D) Treatment with $5 \mathrm{mM} \mathrm{La}^{+3}$ results in the loss of Myo1c-T701 binding to stereociliary tips. E) Bullfrog sacculus showing AM1-43 loading of hair cells. F) Treatment with $5 \mathrm{mM}$ EGTA breaks tip links as assayed by the marked reduction of AM1-43 entry into hair cells. G \& H) Treatment with $5 \mathrm{mM}$ EGTA results in the loss of Myolc-T701 binding to stereociliary tips. All images are single confocal sections. Scale bars: (in $B$ ) $A, B, E, F, 20 \mu \mathrm{m}$; (in $D$ ) $C, D, G, H, 5 \mu \mathrm{m}$. AM1-43 uptake is white, phalloidin labeling of filamentous actin is red, and Myo1c-T701 binding is green. 

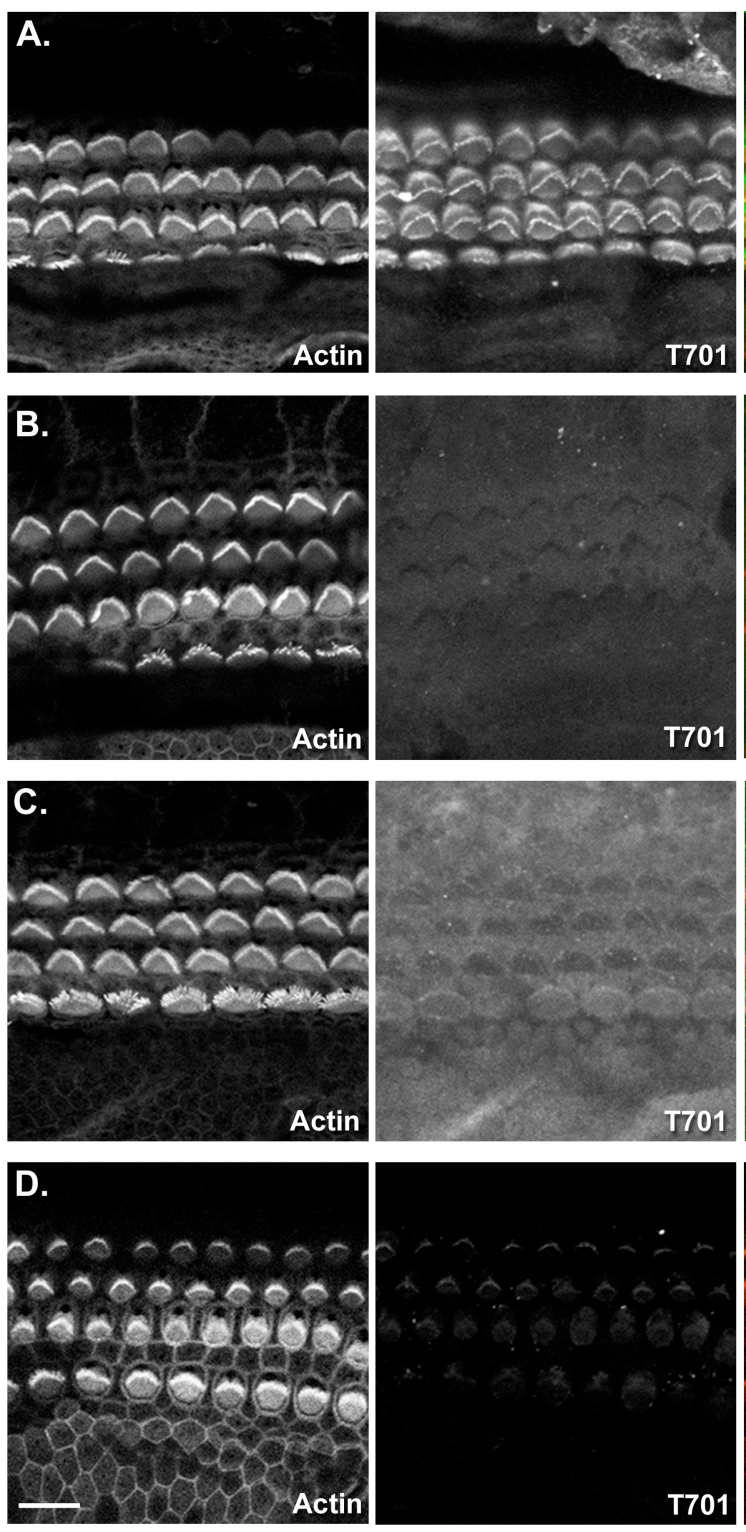
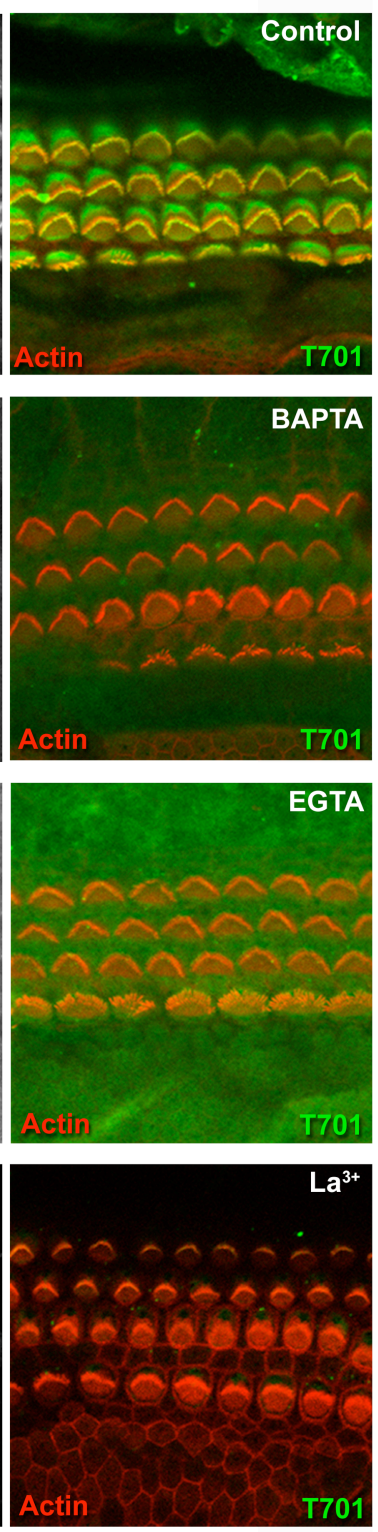

Figure 5. Myo1c binding to stereocmary receptors in the mouse organ of Corti requires intact tip links. Each panel shows a single confocal section containing inner and outer hair cells from a whole-mount mouse organ of Corti. Left column, Fluorescently conjugated phalloidin labeling of filamentous actin; middle column, bound recombinant Myolc fragments; right column, overlay of actin (red) and Myo1c binding (green). A) Binding of Myo1c-T701 to mouse cochlear hair cells. B-D) Treatment of the organ of Corti with $5 \mathrm{mM}$ BAPTA, EGTA, or $\mathrm{La}^{+3}$ results in the loss or marked reduction of Myo1c-T701 binding to stereociliary tips. Scale bar: (in $D$ ) $10 \mu \mathrm{m}$. 

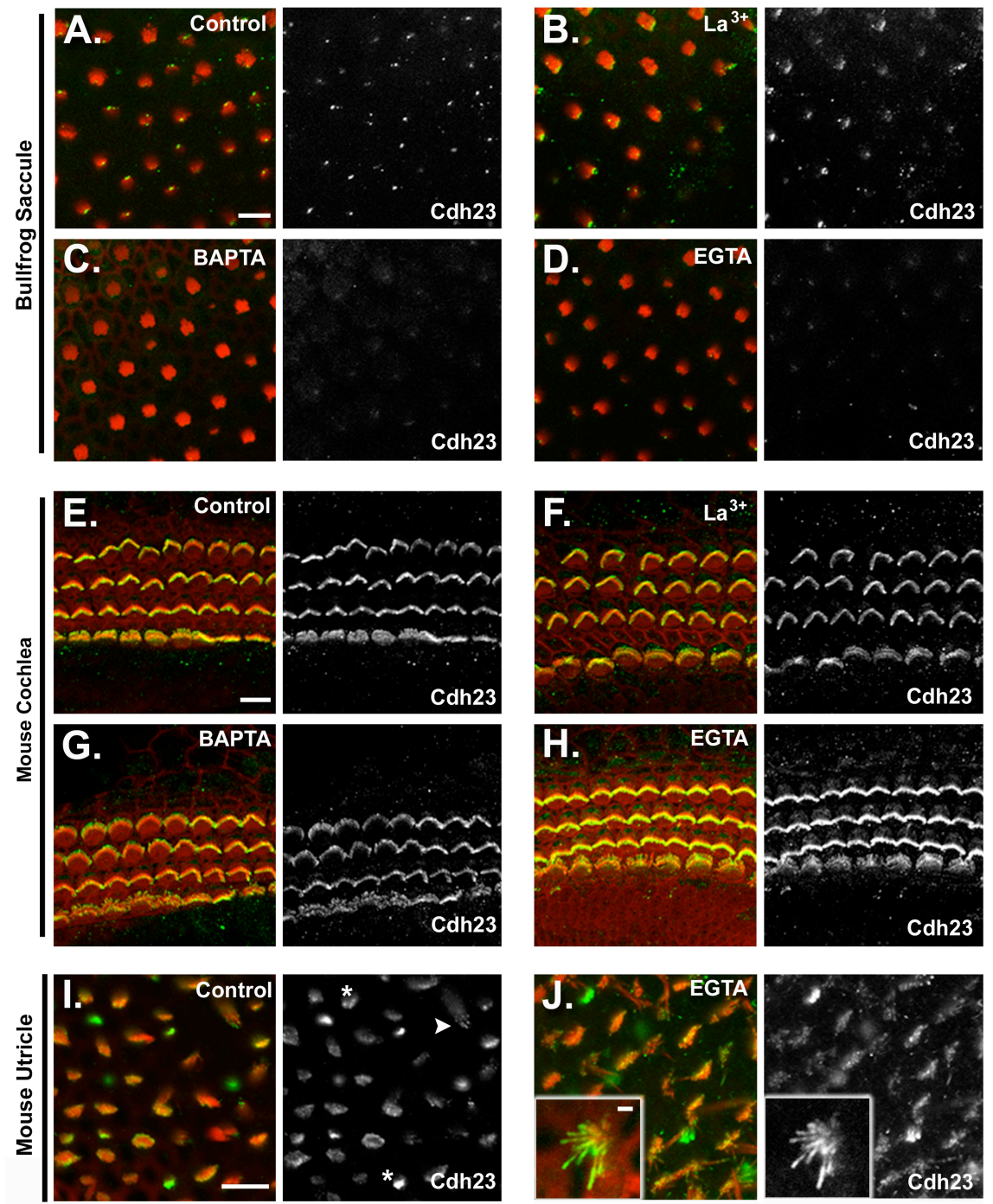

Figure 6. Cdh23 immunolocalization in hair cells after loss of tip links. Each panel depicts a single confocal section of whole-mounted bullfrog saccule, mouse cochlea, or mouse utricle. The left panel for each group shows the merged image of actin (red) and Cdh23 immunolocalization (green). The right panel depicts the Cdh23 immunolabeling channel alone. A) Cdh23 immunolocalization in the bundles of bullfrog saccular hair cells. B-D) Cdh23 immunolocalization in the bundles of bullfrog saccular hair cells after treatment with $5 \mathrm{mM} \mathrm{La}{ }^{+3}$, BAPTA, or EGTA, respectively. E) Cdh23 immunolocalization in the bundles of mouse cochlear hair cells ( $\mathrm{P} 1$ plus $1 \mathrm{~d}$ in vitro). $\mathrm{F}-\mathrm{H}$ ) Cdh23 immunolocalization in the bundles of mouse cochlear hair cells after treatment with $5 \mathrm{mM}$ $\mathrm{La}^{+3}$, BAPTA, or EGTA, respectively. I) Cdh23 immunolocalization in the bundles of mouse (P6) utricular hair cells. Asterisks demark representative small hair bundles, which are intensely labeled. An arrowhead denotes an example of stereociliary tip labeling. J) Cdh23 immunolocalization in the bundles of mouse utricular hair cells (P6) after treatment with $5 \mathrm{mM}$ EGTA. Inset, A small hair bundle with labeling along the length of the stereocilium. This example is from a P3 mouse utricule treated with EGTA at $4{ }^{\circ} \mathrm{C}$. Similar results were seen with $\mathrm{P} 6$ utricles treated at room temperature. Scale bars: $A, E, I$, (for $A-D$, $E-H, I-J), 10 \mu \mathrm{m} ; J$, inset, $2 \mu \mathrm{m}$. 


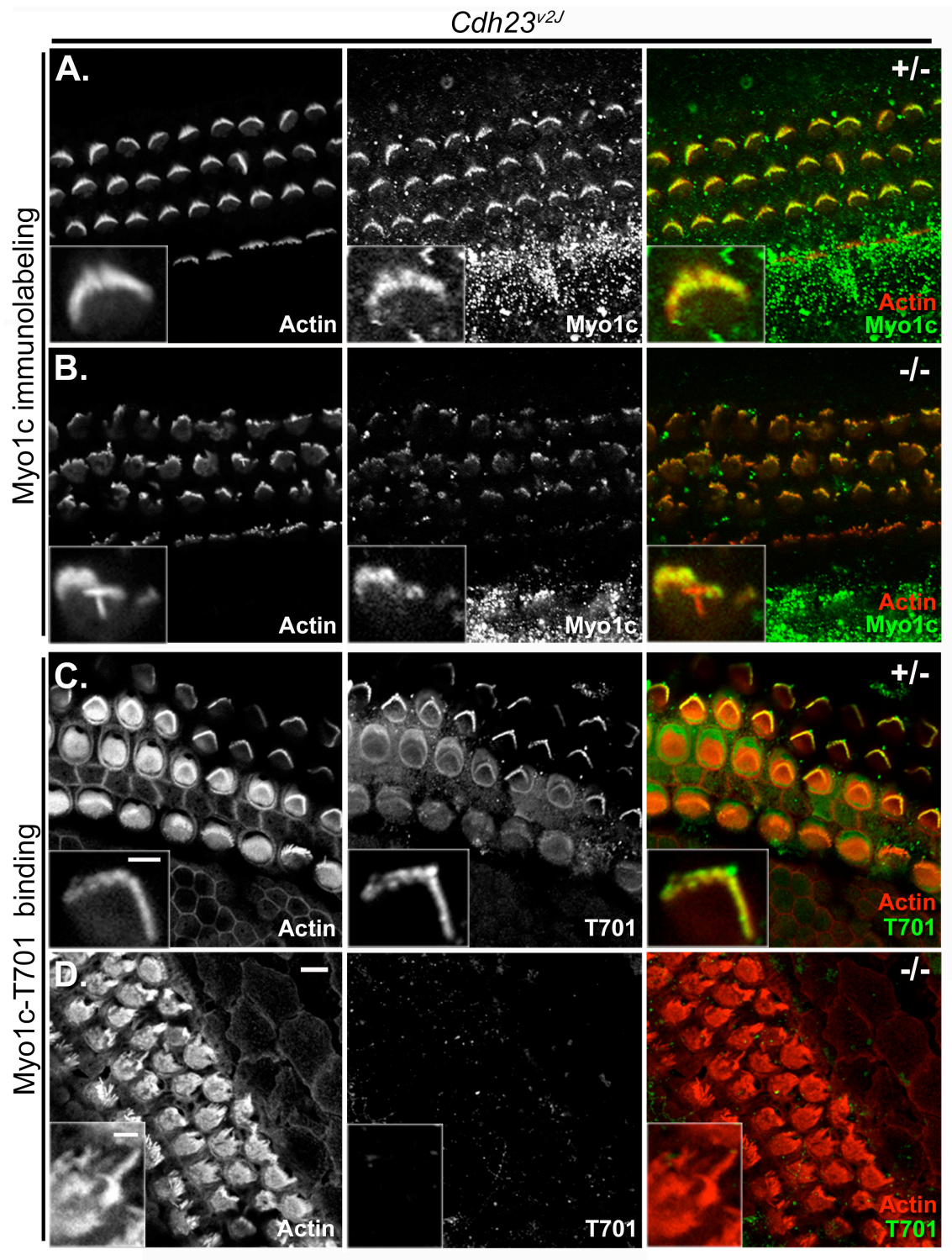

Figure 7. Myo1c and Myo1c receptor localization in cochlear hair cells of $\boldsymbol{C d h} 23^{v 2 J}$ mice. Each panel shows three rows of outer and one row of inner hair cells of heterozygous (+/-) or homozygous (-/-) $C d h 23^{v 2 J}$ mutant mice (P2-P4). The left column of each panel shows phalloidin labeling alone, and the middle column of each panel shows the bound Myolc antibody or Myo1c-T701 binding alone. The right column of each panel shows the overlay of phalloidinlabeled filamentous actin (red) and the binding of either a Myolc antibody (green; $A, B)$ or the Myo1c-T701 fragment (green; $C, D$ ). A-D) Cochlear cultures from $C d h 23^{v 2 J}$ mice. $A \& B$, Endogenous Myo1c is present in stereocilia of both the $C d h 23^{v 2 J}$ heterozygous and homozygous mice. C) The Myolc receptor is detected in the stereocilia of the $C d h 23^{v 2 J}$ heterozygous mice. D) Myolc receptor is undetectable in the stereocilia of $C d h 23^{v 2 J}$ homozygous mice. Insets depict the hair bundles of outer hair cells. Scale bar: (in $D) 5 \mu \mathrm{m}$; (in $C$, inset), $A, B, C$, insets, $2 \mu \mathrm{m} ; D$, inset, $2 \mu \mathrm{m}$. 

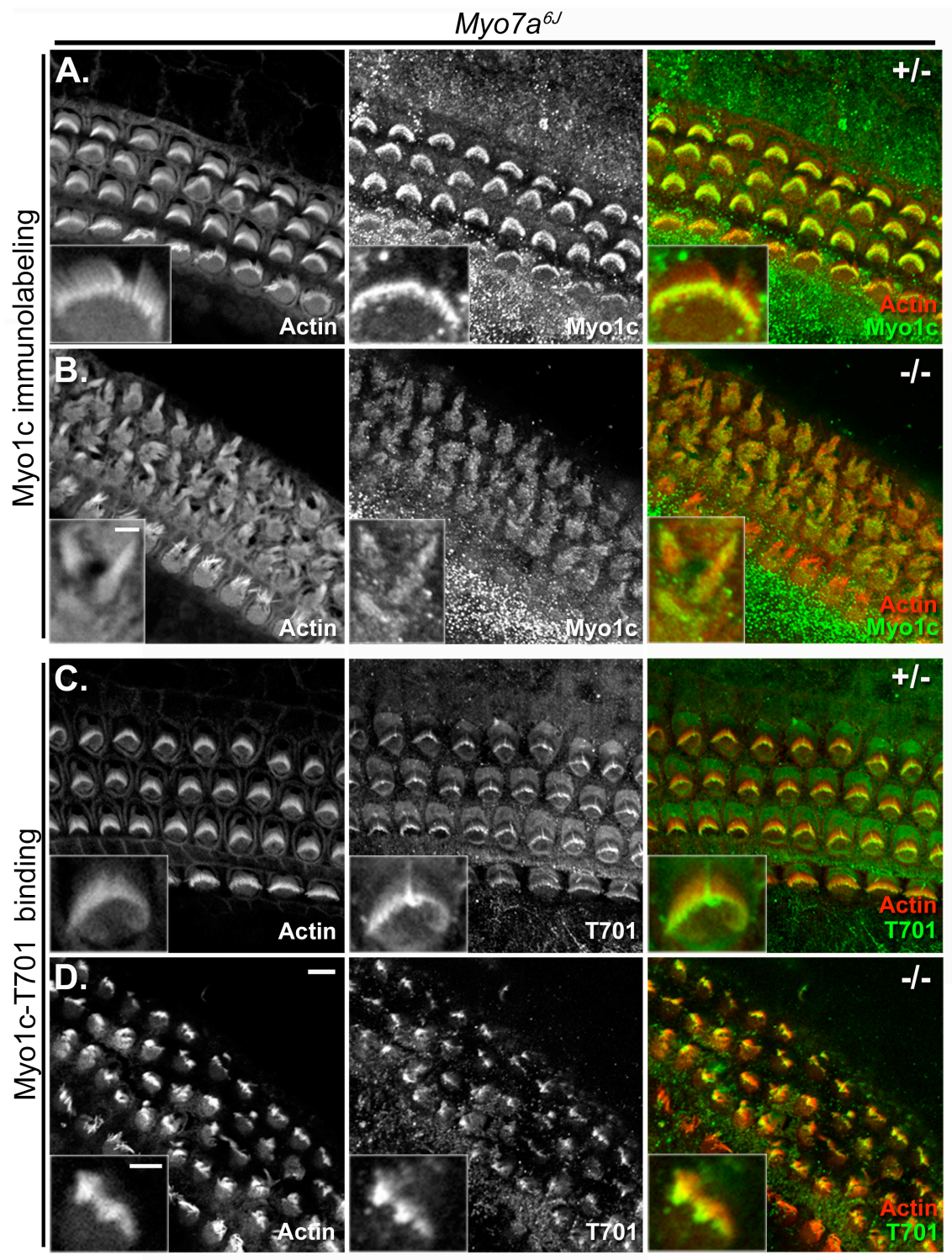

Figure 8. Myo1c and Myo1c receptor localization in cochlear hair cells of $\operatorname{Myo} 7 \boldsymbol{a}^{6 J}$ mice. Cochlear cultures from Myo $7 a^{6 J}$ heterozygous (+/-) or homozygous (-/-) mice (P2-P4) are shown in each panel. The left column of each panel shows phalloidin labeling of filamentous actin, and the middle column of each panel shows Myolc antibody or Myolc-T701 binding alone. The right column of each panel shows the overlay of phalloidin labeling (red) and the binding of either a Myolc antibody (green; $A, B$ ) or the Myolc-T701 fragment (green; $C, D)$. A \& B) Endogenous Myolc is present in the stereocilia of both $M y o 7 a^{6 J}$ heterozygous and homozygous mice. C \& D) The Myolc receptor is detected in the hair cells of $M y o 7 a^{6 J}$ heterozygous and homozygous mice. All insets are the hair bundles of outer hair cells except for that in $A$, which is an inner hair cell. Scale bars: (in $D) 5 \mu \mathrm{m}$; $B$, inset, $2 \mu \mathrm{m}$; (in $D$, inset) $A, C, D$, insets, $2 \mu \mathrm{m}$. 

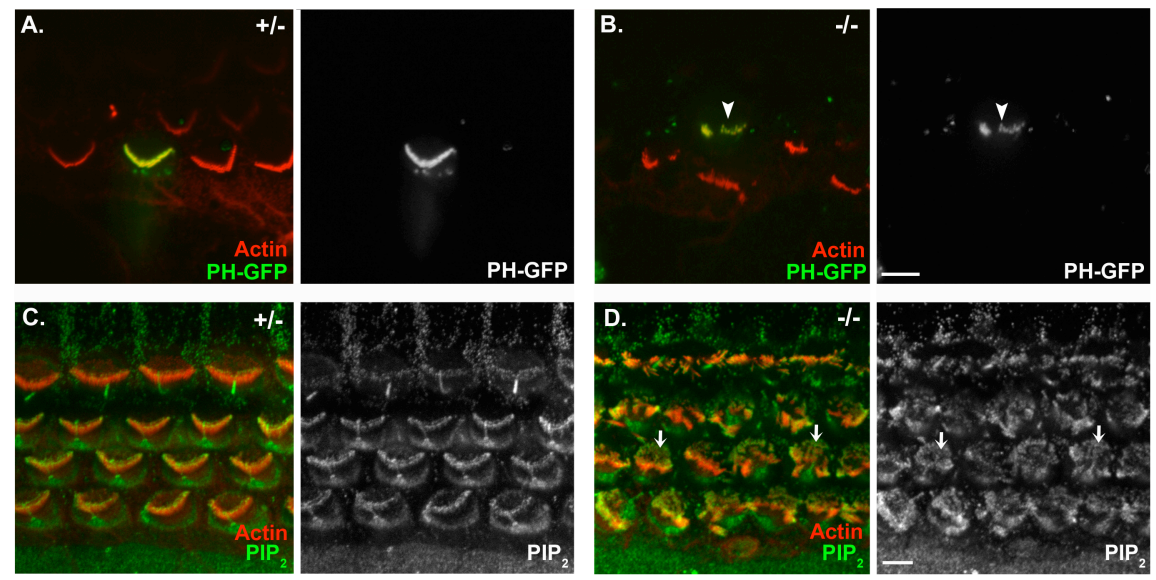

Figure 9. PIP2 is present in the stereocilia of $\boldsymbol{C d h} 23^{v 2 J}$ mice. A \& B) Localization of $\mathrm{PIP}_{2}$ in a cochlear apical coil from a heterozygous, $A$, and a homozygous, $B, C d h 23^{v 2 J}$ mouse using the PH domain of PLC 1 conjugated to EGFP as a fluorescent indicator of PIP $_{2}$ localization. C \& D) Immunolocalization of $\mathrm{PIP}_{2}$ in a cochlear basal coil from a heterozygous, $C$, and a homozygous, $D$, $C d h 23^{\text {v2 }}$ mouse. All images are single confocal sections. In the merged image to the left, phalloidin-labeled filamentous actin is depicted in red, and PLC 1PHEGFP or an anti-PIP ${ }_{2}$ antibody is green. In the image on the right, PLC 1PHEGFP or the antibody labeling alone is shown. The arrowhead in $B$ denotes a fluorescent mutant hair bundle. The arrows in $D$ denote microvilli labeling. Scale bars: (in $B) A, B, 5 \mu \mathrm{m}$; (in $D$ ) $C, D, 5 \mu \mathrm{m}$. 

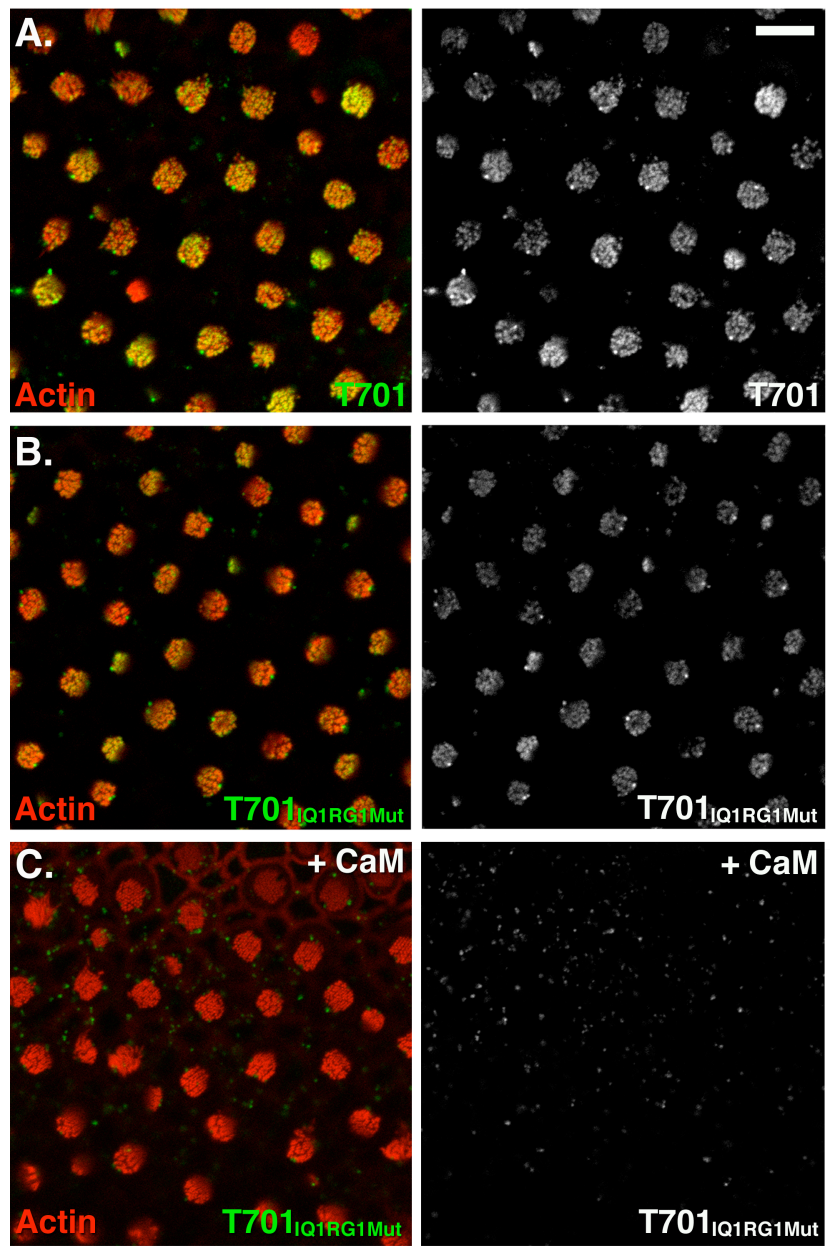

Supplemental Figure 1. Myo1c-T701 ${ }_{\text {IQ1RG1Mut }}$ binds to stereociliary receptors and binding is blocked by CaM. A-C) Each panel shows a single confocal microscopy section containing $\sim 40$ hair bundles of a whole-mount bullfrog sacculus. Left panel shows the overlay of the phallodin labeling of filamentous actin (red) and the bound Myo1c protein (green). Right panel shows Myo1c fragment binding only. A) Wildtype Myo1c-T701 binding to stereociliary receptors. B) Myo1c-T701 $1_{\mathrm{IQ} 1 \mathrm{RG} 1 \mathrm{Mut}}$ binding to stereociliary receptors. C) Excess CaM blocks Myo1c-T701 IQ1RG1Mut $_{\text {binding to }}$ stereociliary receptors. Scale bar in $A$ is $10 \mu \mathrm{m}$ and applies to all panels. 


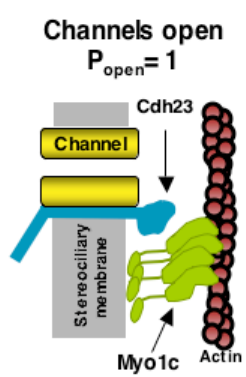

High $\left[\mathrm{Ca}^{2+}\right]$

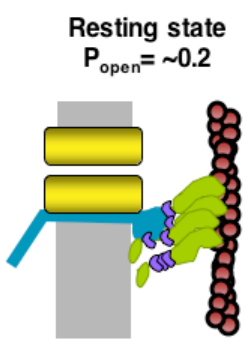

Intermediate $\left[\mathrm{Ca}^{2+}\right]$
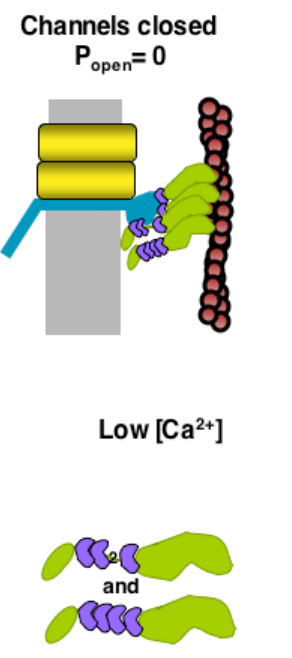

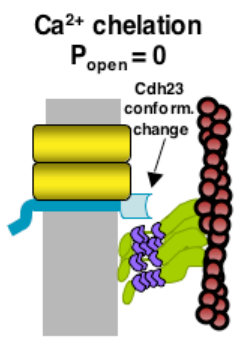

Low $\left[\mathrm{Ca}^{2+}\right]$

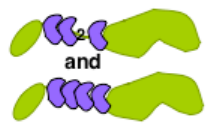

Supplemental Figure 2. Proposed model for Myo1c and receptor interactions. Predicted influence of transduction-channel open probability and thus intracellular $\mathrm{Ca}^{2+}$ concentration on Myo1c interactions with stereociliary receptors, presumably Cdh23, depicted at the top. Myo1c head, IQ domains (numerals 1-4), and tail are indicated. The stereociliary membrane (gray), transduction channel (yellow), Cdh23 (blue), Myo1c (green), CaM (purple) and an actin filament (red) are shown. The predicted effect of $\mathrm{Ca}^{2+}$ concentration on the CaM occupancy of the Myo1c IQ domains for each condition is depicted at the bottom. High intracellular $\mathrm{Ca}^{2+}$ concentrations $\left(\mathrm{High}\left[\mathrm{Ca}_{2}+\right]^{\text {int }}\right)$ would be expected to strip all CaMs from Myo1c and prevent Myo1c interactions with Cdh23 (left panel). Myo1c interactions with $\mathrm{Cdh} 23$ would be predicted to occur at $\mathrm{Ca}_{2}+$ concentrations that favor disassociation of CaM from IQ2 (second and third panels). In vitro, when the extracellular $\mathrm{Ca}^{2+}$ concentration is very low due to chelation $\left(\mathrm{Low}\left[\mathrm{Ca}_{2+}\right]^{\text {ext }}\right.$ ), the tip link breaks which closes the transduction channel and the cytoplasmic domain of $\mathrm{Cdh} 23$ is predicted to undergo a conformational change rendering it unable to bind to Myo1c (right panel). Conditions that favor CaM occupancy of all Myo1c IQ domains would also be predicted to block Myo1c interactions with Cdh23. The ability of IQ4, which has a weak IQ consensus sequence, to bind CaM is uncertain, but if it occurs would only be predicted to occur in low $\mathrm{Ca}^{2+}$ and high CaM concentrations. Based upon its proposed role as a tip-link component, $\mathrm{Cdh} 23$ is drawn as an integral membrane protein that interacts with the transduction channel. Both its designation as the tip link and its interaction with the transduction channel await further verification. 


\section{References}

Assad JA, Shepherd GM, Corey DP (1991) Tip-link integrity and mechanical transduction in vertebrate hair cells. Neuron 7:985-994.

Baumann M, Roth A (1986) The $\mathrm{Ca}++$ permeability of the apical membrane in neuromast hair cells. J Comp Physiol [A] 158:681-688.

Cyr JL, Dumont RA, Gillespie PG (2002) Myosin-1c interacts with hair-cell receptors through its calmodulin-binding IQ domains. J Neurosci 22:2487-2495.

Di Palma F, Holme RH, Bryda EC, Belyantseva IA, Pellegrino R, Kachar B, Steel KP, Noben-Trauth K (2001) Mutations in Cdh23, encoding a new type of cadherin, cause stereocilia disorganization in waltzer, the mouse model for Usher syndrome type 1D. Nat Genet 27:103-107.

Downes CP, Gray A, Lucocq JM (2005) Probing phosphoinositide functions in signaling and membrane trafficking. Trends Cell Biol 15:259-268.

Dumont RA, Zhao YD, Holt JR, Bahler M, Gillespie PG (2002) Myosin-I isozymes in neonatal rodent auditory and vestibular epithelia. J Assoc Res Otolaryngol 3:375389.

Gale JE, Marcotti W, Kennedy HJ, Kros CJ, Richardson GP (2001) FM1-43 dye behaves as a permeant blocker of the hair-cell mechanotransducer channel. J Neurosci 21:7013-7025.

Gillespie PG, Cyr JL (2002) Calmodulin binding to recombinant myosin-1c and myosin1c IQ peptides. BMC Biochem 3:31.

Gillespie PG, Cyr JL (2004) Myosin-1c, the hair cell's adaptation motor. Annu Rev Physiol 66:521-545.

Gillespie PG, Gillespie SK, Mercer JA, Shah K, Shokat KM (1999) Engineering of the myosin-ibeta nucleotide-binding pocket to create selective sensitivity to $\mathrm{N}(6)$ modified ADP analogs. J Biol Chem 274:31373-31381.

Goodyear RJ, Marcotti W, Kros CJ, Richardson GP (2005) Development and properties of stereociliary link types in hair cells of the mouse cochlea. J Comp Neurol 485:75-85.

Gopalakrishna R, Anderson WB (1982) $\mathrm{Ca}^{2+}$-induced hydrophobic site on calmodulin: application for purification of calmodulin by phenyl-Sepharose affinity chromatography. Biochem Biophys Res Commun 104:830-836.

Hirono M, Denis CS, Richardson GP, Gillespie PG (2004) Hair cells require phosphatidylinositol 4,5-bisphosphate for mechanical transduction and adaptation. Neuron 44:309-320.

Hokanson DE, Ostap EM (2006) Myolc binds tightly and specifically to phosphatidylinositol 4,5-bisphosphate and inositol 1,4,5-trisphosphate. Proc Natl Acad Sci U S A 103:3118-3123.

Holt JR, Gillespie SK, Provance DW, Shah K, Shokat KM, Corey DP, Mercer JA, Gillespie PG (2002) A chemical-genetic strategy implicates myosin-1c in adaptation by hair cells. Cell 108:371-381.

Howard J, Hudspeth AJ (1987) Mechanical relaxation of the hair bundle mediates adaptation in mechanoelectrical transduction by the bullfrog's saccular hair cell. Proc Natl Acad Sci U S A 84:3064-3068.

Hudspeth AJ (1989) How the ear's works work. Nature 341:397-404. 
Kros CJ, Marcotti W, van Netten SM, Self TJ, Libby RT, Brown SD, Richardson GP, Steel KP (2002) Reduced climbing and increased slipping adaptation in cochlear hair cells of mice with Myo7a mutations. Nat Neurosci 5:41-47.

Lagziel A, Ahmed ZM, Schultz JM, Morell RJ, Belyantseva IA, Friedman TB (2005) Spatiotemporal pattern and isoforms of cadherin 23 in wild type and waltzer mice during inner ear hair cell development. Dev Biol 280:295-306.

Michel V, Goodyear RJ, Weil D, Marcotti W, Perfettini I, Wolfrum U, Kros CJ, Richardson GP, Petit C (2005) Cadherin 23 is a component of the transient lateral links in the developing hair bundles of cochlear sensory cells. Dev Biol 280:281294.

Pickles JO, Comis SD, Osborne MP (1984) Cross-links between stereocilia in the guinea pig organ of Corti, and their possible relation to sensory transduction. Hear Res 15:103-112.

Rhoads AR, Friedberg F (1997) Sequence motifs for calmodulin recognition. Faseb J 11:331-340.

Richardson GP, Forge A, Kros CJ, Fleming J, Brown SD, Steel KP (1997) Myosin VIIA is required for aminoglycoside accumulation in cochlear hair cells. J Neurosci 17:9506-9519.

Rzadzinska A, Schneider M, Noben-Trauth K, Bartles JR, Kachar B (2005) Balanced levels of Espin are critical for stereociliary growth and length maintenance. Cell Motil Cytoskeleton 62:157-165.

Rzadzinska AK, Schneider ME, Davies C, Riordan GP, Kachar B (2004) An actin molecular treadmill and myosins maintain stereocilia functional architecture and self-renewal. J Cell Biol 164:887-897.

Schneider ME, Belyantseva IA, Azevedo RB, Kachar B (2002) Rapid renewal of auditory hair bundles. Nature 418:837-838.

Self T, Mahony M, Fleming J, Walsh J, Brown SD, Steel KP (1998) Shaker-1 mutations reveal roles for myosin VIIA in both development and function of cochlear hair cells. Development 125:557-566.

Siemens J, Lillo C, Dumont RA, Reynolds A, Williams DS, Gillespie PG, Muller U (2004) Cadherin 23 is a component of the tip link in hair-cell stereocilia. Nature 428:950-955.

Sollner C, Rauch GJ, Siemens J, Geisler R, Schuster SC, Muller U, Nicolson T (2004) Mutations in cadherin 23 affect tip links in zebrafish sensory hair cells. Nature 428:955-959.

Stauffer EA, Scarborough JD, Hirono M, Miller ED, Shah K, Mercer JA, Holt JR, Gillespie PG (2005) Fast adaptation in vestibular hair cells requires myosin-1c activity. Neuron 47:541-553.

Wu YC, Ricci AJ, Fettiplace R (1999) Two components of transducer adaptation in auditory hair cells. J Neurophysiol 82:2171-2181. 


\section{Two novel antigens in the hair bundle detected using myosin-1a directed antibodies}

\section{Introduction}

Hair-cell stereocilia have been compared to the brush border (BB) microvilli of intestinal enterocytes for decades (Flock and Cheung, 1977). Groups of both processes extend away from the apical surface of their respective cell and are structurally dependent upon parallel actin bundle (PAB) arrays that compose their core (see chapter 1, Fig 5B $\& C)$. In each case, the PABs share uniform polarity and are oriented with the positive end of the actin filaments extending away from the cell body (Flock and Cheung, 1977). As well, in both stereocilia and microvilli, the rootlet of each PAB tapers and inserts into a dense cytoskeletal network, referred to as the cuticular plate and the terminal web, respectively (see chapter 1, Fig 2C \& 5C; DeRosier and Tilney, 1989). Despite structural similarities, stereocilia and microvilli have unique roles. Minute movements of stereocilia in relation to one another dictate an organism's perception of hearing and balance, while microvilli provide structural expansion to the dense surface area of the small intestine, allowing for the maximum adsorption of nutrients. Despite these functional differences, the core components of the stereocilia and microvilli remain the same and consequently the two structures share many of the same proteins. The actin bundling proteins, fimbrin and espin, have been identified in both the stereocilia and microvilli (reviewed in Mooseker, 1985; Tilney et al., 1989; Bartles et al., 1998; Zheng et al., 2000). As well, both projections utilize unconventional myosins. These motors are a subclass of the myosin superfamily, which is the only family of molecular motors identified to move on actin filaments.

The most abundant unconventional myosin of the enterocyte $\mathrm{BB}$ domain is Myosin-1a (Myo1a; Heintzelman et al., 1994). Myo1a, initially referred to as 110K-CM in the early literature, was first identified as a $110 \mathrm{kDa}$ protein that closely associates with calmodulin (CaM; reviewed in Mooseker, 1985). It was classified as an unconventional myosin isoform in 1989 and given the name brush border myosin I, which was later changed to myosin-1a (Mooseker and Coleman, 1989; Gillespie et al., 2001). Myo1a, 
like other members of the unconventional myosin class, has three domains: a single catalytic head domain, a neck domain composed of three tandem IQ motifs capable of binding $\mathrm{CaM}$, and a $\mathrm{C}$-terminal tail consisting of a $\mathrm{TH} 1$ domain that binds directly to acidic phospholipids (Mooseker and Cheney, 1995). Myola is located along the length of the microvilli, and appears to crosslink the space between the PAB and the microvillar membrane (see chapter 1, Fig 5C; Mooseker and Coleman, 1989).

Despite the high concentration of Myola in the microvilli of the enterocyte, its specific role remains unclear. Since its identification in 1989, investigators have hypothesized that Myola may act to tether the PABs to the microvillar membrane, buffer intracellular $\mathrm{Ca}^{2+}$ levels by virtue of its associated $\mathrm{CaM}$ molecules, or power vesicle trafficking to the BB membrane (Fath et al., 1994; reviewed in Tyska and Mooseker, 2002). To address these hypotheses and elucidate the contributions of Myo1a to the organization and function of the enterocyte brush border domains, a Myola knockout (KO) mouse was developed (Tyska et al., 2005). In these mice, the first three exons of the Myo1a gene, including its start site for protein synthesis, were replaced with a neomyocin resistance cassette. This mutated allele was expressed in $129 \mathrm{X} 1 / \mathrm{SvJ}$ mice and was bred to homogeneity. Both immunoblot and immunolocalization experiments assaying intestinal tissue indicate that mice homozygous for this mutation, denoted Myo1a $^{-/}$, do not express Myo1a protein (see chapter 1, Fig 5D \& E; Tyska et al., 2005). As well, evidence of the full-length Myola mRNA transcript was not detected in Myo1 a ${ }^{1-}$ mice (Tyska et al., 2005). Despite the null expression of Myo1a, Myo1 ${ }^{-/-}$mice exhibit no overt phenotype. Animal size, intestinal function, and reproductive rates of Myola $\mathrm{a}^{-/}$ mice were not significantly different than wild-type mice of the same background (Tyska et al., 2005). However, a detailed analysis of the epithelium of the gut did uncover subtle abnormalities in the organization of the enterocyte BB domains. In the Myola $\mathrm{a}^{-/}$ mouse, microvillar packing was less organized and some microvilli exhibited herniations of the membrane (Tyska et al., 2005). In addition, the intestinal epithelium appeared to be in a prolonged state of stress and had an increased number of apoptotic cells as reported by TUNEL staining (Tyska et al., 2005). As expected, no cross-bridges between the $\mathrm{PAB}$ and the microvillar membrane were observed in the Myo1 $\mathrm{a}^{-/ .}$mice and the 
membrane often was collapsed onto the PAB core (Tyska et al., 2005). Most interesting, the addition of ATP to BB preps of wild-type mice activated terminal web contractility, attributed to the conventional myosin, myosin $2 \mathrm{a}$, and initiated the shedding of the microvillar apical membrane. However, in BB preps from Myo $1 \mathrm{a}^{-/-}$mice only terminal web contractility was observed (Tyska et al., 2005). This suggests that Myola is required for the ATP-dependant microvillar membrane shedding observed in these in vitro assays.

Investigators also assayed the expression of other proteins in the Myola $\mathrm{a}^{-/-}$mouse intestinal epithelium relative to their expression in wild-type mice. While the expression of many proteins was unaltered, a decrease in myosin-1e and CaM was noted, as well as an increase in cytokeratins 8 and 18, and myosin-1c (Myolc; Tyska et al., 2005). The increase in Myolc expression was confirmed using immunofluorescence experiments that showed its redistribution from the enterocyte cell body to the microvilli at the cell periphery (Tyska et al., 2005). Investigators hypothesized that the subtle phenotypical differences detected in Myola ${ }^{-/-}$mouse may be the result of Myo1c's compensation for the absence of Myola (Tyska et al., 2005). This is the first recorded observation supporting the potential compensation between unconventional myosin molecules.

Myosin isoforms expressed in the hair bundle were identified during investigations aimed at identifying candidate molecules for the hair-cell adaptation motor. In the first of these screens, Myola mRNA was detected in the sensory cells of bullfrog sacculus (Solc et al., 1994). Subsequently, these results were repeated using mouse utricle (Dumont et al., 2002). However, in each study the amount of Myola mRNA detected was very low, and investigators were skeptical as to whether Myola protein was expressed in the hair cell (Solc et al., 1994; Dumont et al., 2002). Despite these results, Myola has recently been implicated in hearing loss (Donaudy et al., 2003). Because MYO1A was mapped to DFNA48, a DNA locus attributed to nonsyndromic autosomal-dominant hearing-loss defects, a large pool of hearing impaired patients were screened for mutations in MYO1A (D'Adamo et al., 2003; Donaudy et al., 2003). These studies indicate that a MYO1A nonsense mutation and six missense mutations occur concurrently with hearing loss (Donaudy et al., 2003). This study also repeats the 
detection of Myola transcript in acousticolateralis end organs (Solc et al., 1994; Donaudy et al., 2003).

Based on these recent findings, our lab in collaboration with Matthew Tyska, Ph.D. (Vanderbilt, TN) sought to characterize the potential expression and localization of Myola protein in the hair cell. At our disposal were both the Myo1a ${ }^{-/-}$mice used in Dr. Tyska's previous studies and polyclonal antibodies raised against the Myola head and tail domains (Tyska et al., 2005). To our dismay, these antibodies proved to be nonspecific in the cochlea, despite previous characterization showing their specificity in gut epithelial tissue. As such, we were unable to identify any labeling in hair cells that could be attributed specifically to Myola. However, both antibodies tested did detect specific antigens that are expressed in the cochlear hair cells of both Myo1a ${ }^{+/+}$and Myola $\mathrm{a}^{-/-}$mice. These antigens occur in distinct patterns and may represent two novel hair-bundle proteins.

\section{Methods}

Myola KO mice Myola KO mutant mice were supplied by Matthew Tyska (Vanderbilt, TN) as part of the collaborative project (referenced in Tyska et al., 2005).

Genotyping Tail samples were taken from all mice immediately following sacrifice and stored at $-20^{\circ} \mathrm{C}$. DNA was extracted using Wizard Genomic DNA Purification Kit (Promega, Madison, WI). To assess the incorporation of the neomycin cassette into the Myo1a locus, resulting in a nonfunctional Myola allele, we used the following primers; Myo1aF1584: 5'-TCAGGTGGGCAGACAGAGGTAGT-3'， Myo1aR3330： 5' CCCCTCCCACCGTTAACTATCAGA-3', and Neof1a 5' GGATTGCACGCAGGTTTCC-3' in a PCR cocktail with the puReTaq Ready-To-Go PCR beads (GE Healthcare, Piscataway, NJ) and purified DNA. PCR gave products of $1800 \mathrm{bp}$ for wild-type samples, $1400 \mathrm{bp}$ for homozygous Myola KO samples and both $1800 \mathrm{bp}$ and $1400 \mathrm{bp}$ for heterozygotes. 
Cochlear samples for RT-PCR Six to ten cochleas were acutely dissected in minimal essential medium (MEM) with Glutamax supplemented with 10 mM HEPES (Invitrogen, Carlsbad, CA) and stored in RNAlater buffer (Qiagen, Valencia, CA). RNA was extracted using RNAeasy RNA isolation kit (Qiagen). To digest any contaminating genomic DNA, DNAse I was incubated with the RNA sample while on the RNA isolation column for 15 minutes at RT. Isolated RNA was used as a template for the reverse-transcription reactions using the Thermoscript RT kit (Invitrogen). As an additional control for genomic contamination, one sample did not receive reverse transcriptase (-RT). The synthesized cDNA and the -RT control were used in PCR reactions with primers complementary to the head and tail domains of Myo1a (completed in the Tyska laboratory).

Scanning Electron Microscopy Cochleas were harvested as described above and fixed overnight at $4{ }^{\circ} \mathrm{C}$ using $3 \%$ gluteraldehyde in SEM Buffer (0.1 M Na-phosphate buffer and $0.1 \mathrm{M}$ sucrose). Samples were washed 2 X 5 minutes using SEM buffer and subjected to an additional fixation using $1 \%$ osmium tetroxide on ice for 1 hour. Samples were again washed 2 X 5 minutes using SEM buffer and then dehydrated using a series of ethanol washes $(35 \%, 50 \%, 70 \%, 95 \%$ and $100 \% ; 15$ minutes each). Samples were either stored at this step or the ethanol was replaced with hexamethyldisilazane (HMDS). The HMDS was then evaporated in the hood and sample was mounted and coated with gold. Samples were imaged on a Hitachi X-650 scanning electron microscope.

Primary Antibodies Primary polyclonal antibodies were supplied by Matthew Tyska (Vanderbilt, TN) as part of the collaborative project. Anti-brush border I ( $\alpha \mathrm{BBI})$ was raised against a portion of the Myola tail domain and characterized extensively in the gut epithelium tissue (see chapter 1, Fig 5 D \& E; Tyska et al., 2005). The antibodies 3p1 and $4 \mathrm{p} 1$ were raised against multiple peptides of the head domain of Myo1a. The denotations $3 \mathrm{p} 1$ and $4 \mathrm{p} 1$ correspond to the rabbit identification number followed by the specific peptide used for antibody purification on an affinity column. Peptide 1, consisting of amino acids 1-14 of the Myo1 a head domain; MPLLEGSVGVEDLV, was 
used for the purification of both antibodies. The monoclonal antibody, 6a, also recognizes Myo1a, and was supplied by Dr. Tyska (Carboni et al., 1988).

Immunocytochemistry Following sacrifice at P7, cochleas were acutely dissected in MEM with Glutamax supplemented with 10 mM HEPES (Invitrogen). Some samples were incubated with $5 \mathrm{mM}$ 1,2-bis $(O$-aminophenoxy)ethane- $N, N, N 9, N 9$-tetraacetic acid (BAPTA) for 20 minutes to break tip links. All samples were fixed using 3\% paraformaldehyde diluted from a 16\% stock (EM Sciences, Hatfield, PA) in cold phosphate buffered saline (PBS; $137 \mathrm{mM} \mathrm{NaCl}, 2.7 \mathrm{mM} \mathrm{KCl}, 4.3 \mathrm{mM} \mathrm{Na}_{2} \mathrm{HPO}_{4}$, and 1.5 $\mathrm{mM} \mathrm{KH} \mathrm{PO}_{4}, \mathrm{pH}$ 7.4). Following a brief PBS wash, samples were permealibilized using $0.5 \%$ Triton X-100 in PBS for 30 minutes. Samples were washed 2 X 10 minutes in PBS and blocked for 1 hour in 2\% BSA (fraction V; Calbiochem, La Jolla, CA) and 5\% goat serum (Jackson Laboratories, West Grove, PA) in PBS at room temperature (RT). Primary antibodies were incubated at 1:200 with samples overnight at $4^{\circ} \mathrm{C}$ in PBS with $2 \%$ BSA and 5\% goat serum. Samples were washed 3 X 10 minutes in PBS- $0.1 \%$ Tween-20 and incubated with Alexa 488 goat anti-rabbit secondary antibody $(13 \mu \mathrm{g} / \mathrm{ml}$; Invitrogen) and $33 \mathrm{nM}$ Alexa 568 phalloidin (Invitrogen) for 2 hours at RT. Samples were washed $3 \times 10$ minutes in PBS-0.1\% Tween-20 and 1 X 10 minutes in PBS, mounted with Vectashield (Vector laboratories, Burlingame, CA) and imaged on a LSM510 Meta confocal microscope (Zeiss, Thornwood, NY).

Immunoblot Tissue Preparation Following sacrifice at age P7, the entire murine gut was immediately extracted and submerged in $1 \mathrm{~mL}$ of cold sucrose dissociation buffer (SDB; $200 \mathrm{mM}$ sucrose, $0.02 \%$ sodium azide, $12 \mathrm{mM}$ EDTA-K, $19 \mathrm{mM} \mathrm{KH}_{2} \mathrm{PO}_{4}$ monobasic, 78 $\mathrm{mM} \mathrm{Na}_{2} \mathrm{HPO}_{4}$ anhydrous, dibasic) and incubated on ice up to 30 minutes. The cochleas of each animal were dissected in $10 \mathrm{mM}$ HEPES-buffered MEM with Glutamax (Invitrogen, Carlsbad, CA) and submerged in $1 \mathrm{~mL}$ of cold SDB and incubated on ice up to 30 minutes. All samples were agitated in $1.5 \mathrm{~mL}$ microcentrifuge tubes using micro stir-bars for 30 minutes at $4^{\circ} \mathrm{C}$. Solubilized tissue was removed and centrifuged at 14000 rpm for an additional 30 minutes at $4{ }^{\circ} \mathrm{C}$. Cell pellets were resuspended in cold homogenization buffer (10 mM imidazole, $\mathrm{pH}$ 7.2, 4 mM EDTA-K, 1 mM EGTA-K, 
$0.02 \%$ sodium azide), supplemented with $1 \mathrm{mM}$ DTT and $1 \mathrm{mM}$ Pefablock ${ }^{\circledR}$ SC (Pentapharm, Norwalk, CT). Samples were homogenized using a motorized hand homogenizer for $15 \mathrm{sec}$. An equal volume of $10 \mathrm{X}$ sample buffer (8\% SDS, $2.4 \% 10 \mathrm{X}$ stacking gel buffer [1.4 M Trizma base, $1.2 \mathrm{~N} \mathrm{HCl}, \mathrm{pH} 6.8$ ], $580 \mathrm{mM}$ sucrose, 9.5\% 2$\beta$ Mercaptoethanol, $3 \mathrm{mM}$ bromphenol blue, $10 \mathrm{mM}$ EGTA-K) was added. Samples were boiled for 5 minutes and either frozen at $-20^{\circ} \mathrm{C}$ or immediately used for immunoblots.

Immunoblotting Samples were separated on a 4-12\% gradient NuPage Bis-Tris gel in MES buffer (Invitrogen). Gel was transferred overnight at $4{ }^{\circ} \mathrm{C}$ onto HyBond ECL nitrocellulose membrane (GE Healthcare) and blocked with 5\% nonfat dry milk in trisbuffered saline-Tween-20 (TBS-T; 1.5 M NaCl, 0.5 M Trizma base, 0.1\% Tween-20, pH 8.0) for 1.5 hours at RT. Primary antibodies ( $\alpha$ BBI, 3p1, 4p1, or 6a) were added at 1:1000 in TBS-T for 2 hours at RT. Membranes were washed 3X10 minutes in TBS-T and incubated with goat anti-rabbit or goat anti-mouse conjugated to horseradish peroxidase secondary antibody (1:1000; Cell Signaling, Danvers, MA) for 1 hour at RT. ECL Plus Western Blotting Detection System (GE Healthcare) was used to detect bound secondary antibody.

\section{Results}

\section{Myola mRNA expression}

The past characterization of Myola expression in the Myo1 $\mathrm{a}^{-/-}$mouse was based upon null RT-PCR screens directed at exons 2-8 $\left(\right.$ head $\left.^{2-8}\right)$ of the Myola head domain (Tyska et al., 2005). Because this sequence occurs early in the Myola protein, it was felt to be an accurate indicator of Myola expression in the Myola $\mathrm{a}^{-/-}$mouse. However, a recent entry into Genbank, based upon analysis of the MYO1A gene's open reading frame, predicts the expression of a short isoform of Myola that results from a novel start site in exon 24 of the Myola tail domain (XP_904541; www.ncbi.nlm.nih.gov/Genbank, 
Fig 1A). Based on these predictions, we felt it imperative to any future experiments to complete a thorough characterization of Myola transcript expression in both the Myola $^{+/+}$and in vivo in the small intestinal epithelium of either the Myola ${ }^{+/+}$or Myola $\mathrm{a}^{-/-}$ mouse. To determine whether this novel tail isoform, denoted Myola ${ }^{\text {TAIL }}$, is transcribed in mouse, primers were designed to amplify the previously screened exons, head ${ }^{2-8}$, as well as exons 13-16 of the head domain (head ${ }^{13-16}$ ), exons 24-27 of the Myola tail domain (tail ${ }^{24-27}$ ), and the unique sequence specific to Myola ${ }^{\text {TAIL }}$. Results of these experiments replicate past data that detect mRNA transcripts that code for head ${ }^{2-8}$ of Myola in the gut of the Myola ${ }^{+/+}$but not the Myola ${ }^{-/-}$mouse. However, mRNA that codes for head ${ }^{13-16}$, as well as Myola $\mathrm{a}^{\mathrm{TAIL}}$, is detected in gut epithelial tissue of the Myola $^{+/+}$mouse, as well as the Myola ${ }^{-/-}$mouse (unpublished data, M. Tyska; Fig 1B). This suggests that Myola ${ }^{\text {TAIL }}$, as well as an additional isoform containing the head ${ }^{13-16}$ sequence, may be transcribed in the gut epithelium of both the Myola ${ }^{+/+}$and Myo1a $\mathrm{a}^{-/-}$ mouse.

Previous experiments have identified Myola mRNA transcripts in the vestibular organs of the bullfrog as well as in mouse utricle and cochlea (Solc et al., 1994; Dumont et al., 2002; Donaudy et al., 2003). However, the published experimental methods provided little technical detail. Therefore, we wished to replicate these experiments using the $129 \mathrm{X} 1 / \mathrm{SvJ}$ mouse strain, as well as explore the potential expression of Myo $1 \mathrm{a}^{\mathrm{TAIL}}$ in the cochleas of both the Myola ${ }^{+/+}$and Myo1a ${ }^{-/-}$mouse. Cochleas from Myo1a ${ }^{+/+}$and Myo1a $^{-/-}$littermates, age P7, were acutely dissected. A cDNA pool was made from the RNA extracted from these samples and used as a template in PCR reactions designed to amplify the head ${ }^{2-8}$ of Myola. Like similar reactions done in gut, DNA sequence complementary to mRNA transcript coding for head ${ }^{2-8}$ of Myola was detected in the Myola $^{+/+}$cochlear sample and was absent in the Myola ${ }^{-/-}$cochlear sample (Fig 1C). In contrast to results using gut tissues, a product of approximately $750 \mathrm{bps}$, in addition to the expected 600 bp product that corresponds to head ${ }^{2-8}$, was detected in Myola ${ }^{+/+}$cochleas. Sequencing of the novel $750 \mathrm{bp}$ product reveals two distinct mRNAs; one with a $99 \mathrm{bp}$ intronic insertion, denoted 750a, and one with 198 bp intronic insertion, denoted 750b (Fig 1D). When translated to amino acid sequence, the $750 \mathrm{~b}$ transcript codes for multiple 
in-frame stop codons, suggesting that it is likely to be an incompletely spliced mRNA artifact (Fig 1D \& E; red sequence). However, the 750a transcript codes for no stop codons in its open reading frame. As this transcript is never detected in gut samples, it may represent a cochlear specific Myo1a isoform (Fig 1D \& E; green sequence). DNA sequence complementary to mRNA coding for Myola ${ }^{\text {TAIL }}$ and tail ${ }^{24-27}$ was also amplified in Myola ${ }^{+/+}$and Myola $\mathrm{a}^{-/-}$cochlear samples, similar to what was observed using gut epithelium (Fig 1C).

\section{Cochlear morphology of Myo1 a ${ }^{-/-}$mice}

A first step in the assessment of a potential role of Myola in the hair cell is the examination of the cochlear morphology of the Myo1 $\mathrm{a}^{-/}$mouse. If Myola plays a significant role in hearing, then its absence may lead to the physical perturbation of the cochlear hair cells, as is the common result of many mutations that lead to hearing loss. Cochlear samples, postnatal day 7 (P7), of Myola ${ }^{+/+}$and Myo1a ${ }^{-/-}$litter-mates were acutely dissected and processed for scanning electron microscopy (SEM). Surprisingly, no significant cochlear morphological differences between the Myo1 $\mathrm{a}^{+/+}$and the Myo1 $\mathrm{a}^{-/-}$ mouse were noted, indicating that the absence of Myola in the Myol $\mathrm{a}^{-/-}$mouse did not grossly effect either the organ of Corti or the hair cell structural integrity at this age (Fig 2, A\&B). In some samples, regardless of genotype, large irregular gaps between stereocilia were observed (Fig 2C). As well, the bundles of some samples appeared to be relaxed, making the characteristic "V" shape of the cochlear bundle indiscernible (Fig 2C). As a control, an alternate strain of mouse, FVB/NJ, was processed. The cochlear bundles of this mouse strain were uniformly packed and the "V" shape of the hair bundle was easily identified (Fig 2D).

\section{Immunoflourescent localization of the anti-brush border I ( $\alpha B B I)$ antibody}

Next we sought to determine whether Myola is expressed in the hair cell and if so, its location. The antibody used in these experiments, $\alpha \mathrm{BBI}$, was raised against a portion of the tail domain of Myola. It had been previously used to characterize Myola 
expression in the gut where it recognized only Myo1a in Myo1a ${ }^{+/+}$mice and had no immunoreactivity in Myo1a $\mathrm{a}^{-/-}$mice, as indicated by immunoblots and immunocytochemistry (see chapter 1, Fig 5D \& E; Tyska et al., 2005). For all immunolabeling experiments, $\mathrm{P} 7$ cochleas from FVB/NJ, Myola ${ }^{+/+}$, or $\mathrm{Myola}^{-/-}$mice were used. In FVB/NJ and Myola ${ }^{+/+}$mice, $\alpha \mathrm{BBI}$ localized weakly to the bottom twothirds of the stereocilia (data not shown), and was strongly concentrated at the tips of the stereocilia (Fig 3A-D). In inner hair cells the tips of the tallest stereocilia were only weakly labeled relative to the tips of shorter stereocilia (Fig 3C). In outer hair cells the tips of the middle and shorter rows of stereocilia were brightly labeled while the tallest row of stereocilia were only occasionally labeled (Fig 3D). The $\alpha$ BBI antigen was also highly expressed in surrounding pillar and Dieter cells (Fig 3A). Immunolabeling experiments were repeated on Myola $\mathrm{a}^{-/-}$mice and an identical labeling was observed (data not shown). No discrepancies between Myo1 ${ }^{+/+}$and $\mathrm{Myola}^{-/-}$mice could be detected, either in the hair cells or in surrounding supporting cells in the organ of Corti.

Because $\alpha$ BBI recognizes an antigen at the tip of stereocilia, concurrent with the location of the mechanoelectrical transduction (MET) channel complex, we wished to further characterize antigen localization following treatment with the $\mathrm{Ca}^{2+}$ chelator, BAPTA, which disrupts the tip links which are part of the MET channels. Following such treatment, $\alpha B B I$ immunoreactivity could not be detected at either the tips of the stereocilia or in supporting cells (data not shown, J. Cyr).

We also wished to characterize $\alpha \mathrm{BBI}$ immunoreactivity in vestibular hair cells. In the bullfrog sacculus, $\alpha$ BBI bound to antigens expressed in the supporting cells of the sensory epithelium, but did not recognize any antigens in the hair cell (Fig 3E\&F). As well, no aBBI immunoreactivity was observed in mouse vestibular organs (data not shown). 


\section{Immunofluorescent localization of the 3p1/4p1 antibody}

In response to the identification of the Myo1 $\mathrm{a}^{\mathrm{TAIL}}$ transcript that may code for a headless Myo1a isoform in the Myo1a ${ }^{-/-}$mouse and the apparent non-specificity of $\alpha B B I$ in the cochlea, two new affinity purified antibodies, $3 \mathrm{p} 1$ and $4 \mathrm{p} 1$, were generated by Dr. Tyska's laboratory. These antibodies were affinity-purified against a peptide identical to the first 14 amino acids of the Myola head domain, and were predicted to detect only the full-length isoform of Myo1a. In intestinal epithelial tissue, 3p1 and 4p1 showed identical patterns of reactivity, specifically recognizing Myola in immunocytochemistry experiments and on immunoblots (M. Tyska, personal communication). In the cochlea, the immunoreactivity of $3 \mathrm{p} 1$ and $4 \mathrm{p} 1$ was also identical, and showed a localization pattern distinct from the $\alpha$ BBI antibody. In outer hair cells $3 p 1 / 4 p 1$ localized to the bottom two-thirds of the stereociliary shaft, extending well into the cuticular plate of the hair cell (Fig 4A, sections 2-5). In inner hair cells immunoreactivity was observed only at the base of the stereocilia, extending into the cuticular plate (Fig 4B, sections $3 \& 4$ ). Supporting cells in the organ of Corti were unlabeled (Fig 4A \& B). The reactivity of $3 \mathrm{p} 1 / 4 \mathrm{p} 1$ was identical in Myo1 $\mathrm{a}^{-/}$mice, indicating that despite the specificity of the $3 \mathrm{p} 1 / 4 \mathrm{p} 1$ antibody in gut tissue, the immunoreactivity observed using the $3 \mathrm{p} 1 / 4 \mathrm{p} 1$ antibody in the cochlea may not be attributed to Myola localization (Fig 5). As well, no immunoreactivity was observed using the $3 \mathrm{p} 1 / 4 \mathrm{p} 1$ antibody on wild-type mouse vestibular hair cells (Fig 6).

\section{Cochlear immunoblots using 3p1/4p1 antibody}

In an effort to use an alternative method to assess Myola protein expression, and perhaps identify the unknown antigens of the $3 \mathrm{p} 1 / 4 \mathrm{p} 1$ antibody, we used cochlear samples for immunoblot experiments. In all immunoblotting experiments we used purified gut microvillar samples and crude gut extract samples as positive controls. The immunoreactivity of $3 \mathrm{p} 1 / 4 \mathrm{p} 1$ with purified microvillar samples was highly specific; usually only 1-2 bands were observed (Fig 7; MV). The most intense band ran at approximately $120 \mathrm{kDa}$, the size of Myo1a. A smaller band was sometimes observed at $90 \mathrm{kDa}$ and is believed to be a degradation product of Myo1a. Crude gut extract, 
prepared in our lab, was also run as a positive control (Fig 7; Myola ${ }^{+/+}$gut: WTg, and Myo1a ${ }^{+/-}$gut: HETg). In these samples a $120 \mathrm{kDa}$ band was clearly visible along with a laddering of proteins from approximately 80-50 kDa. Because crude gut extract samples taken from Myola ${ }^{-/-}$mice show no immunoreactivity (Fig 7; KOg), this laddering is also thought to be degradation products of Myo1a, accelerated due to the method of sample preparation. The absence of a $120 \mathrm{kDa}$ band in the Myola ${ }^{-/-}$crude gut extract sample indicates that, as previously published, full-length Myola is not expressed in the gut of these animals (Fig 7 B\&C; Tyska et al., 2005). Cochlear samples had very low immunoreactivity (Fig 7; Myo1a ${ }^{+/+}$cochlea: WTe, and Myo1a ${ }^{+/-}$cochlea: HETe, and Myo1a ${ }^{-/ 2}$ cochlea: KOe). In cochlear samples from wild-type, heterozygous and homozygous mice, no protein band at the expected size of $120 \mathrm{kDa}$ could be detected (Fig $7 \mathrm{~B} \& \mathrm{C}$ ). This was true for $3 \mathrm{p} 1$ and $4 \mathrm{p} 1$ antibodies in addition to a monoclonal Myola antibody (6A; data not shown). A few proteins of various molecular weights are observed inconsistently between samples, but even at long exposures no protein was ever observed at $120 \mathrm{kDa}$. Five attempts to immunoprecipitate Myo1 a from cochlea using the $4 \mathrm{p} 1$ antibody were unsuccessful.

\section{Discussion}

\section{The Myo1 ${ }^{-/-}$mouse may express a novel Myola isoform, Myo1a ${ }^{\text {TAIL }}$}

Prior to this investigation, Myola $\mathrm{a}^{-/}$mice had not been screened for the presence of alternative mRNA transcripts (Tyska et al., 2005). Because a neomyocin cassette was inserted in the place of the first three exons of Myola, including the start site, it had been assumed that all potential for Myo1a protein production had been eliminated. Accordingly, the absence of Myola protein was confirmed using the $\alpha \mathrm{BBI}$ antibody in gut epithelial tissue of Myo1a ${ }^{-/}$mice (see chapter 1, Fig 5E; Tyska et al., 2005). However, the identification of the novel start site in exon 24 of the Myola gene spurred the reexamination of mRNA expression in Myola ${ }^{-/-}$mice. Unexpectedly, in Myola ${ }^{+/+}$ and Myola ${ }^{-/-}$gut samples, mRNA coding for head ${ }^{13-16}$, tail ${ }^{24-27}$, and the novel tail isoform, Myo1a ${ }^{\text {TAIL }}$ were detected (Fig 1D and data not shown). These transcripts were also detected in the cochleas of both Myola ${ }^{+/+}$and Myola $\mathrm{a}^{-/-}$mice. It is unknown, however, 
whether any of these transcripts are ever translated in vivo in either tissue. In the gut, immunofluorescence data using $\alpha \mathrm{BBI}$, an antibody directed at the Myola tail, suggests that despite the existence of the head ${ }^{13-16}$, tail ${ }^{24-27}$, and Myo1a ${ }^{\text {TAIL }}$ transcripts in the Myola $^{-/ /}$mouse, the corresponding protein remains untranslated (see chapter 1, Fig 5E; Tyska et al., 2005). In cochlear tissue, where immunoreactivity with $\alpha$ BBI was observed in both the Myola ${ }^{+/+}$and Myola $\mathrm{a}^{-/-}$samples, the head ${ }^{13-16}$, tail ${ }^{24-27}$, or Myola ${ }^{\text {TAIL }}$ transcripts may be the antigenic source, as discussed below.

\section{Detection of cochlear-specific Myola transcripts}

In the cochlea, in addition to the expected $600 \mathrm{bp}$ product that correlates to head ${ }^{2-8}$, a larger product of approximately 750 bp was also detected by RT-PCR. Sequencing of this product showed two distinct Myola transcripts, containing segments of intron 6 sequence, that we refer to as 750a and 750b (Fig 1A, pink box). The smaller insertion, 750a, maintains the open reading frame of the Myola protein, while $750 \mathrm{~b}$ sequence codes for multiple stop codons (Fig 1E, underlined codons). Analysis of the 750a sequence reveals that the additional 99 bps code for 33 amino acids that, if translated, would lie in the globular head domain of Myola. The potential function of the 750a insertion is unknown. Protein database searches indicate that no conserved protein domains exist in this sequence (http://www.ncbi.nlm.nih.gov/Structure/cdd/wrpsb.cgi). As well, the 750a sequence is composed of 18 percent proline residues, making it unlikely that the alpha-helical tertiary structure of the Myola head domain could be maintained consequent to the expression of this sequence (Fig 1F). Because this disruption would occur very close to the Myo1a ATP-binding pocket, the 750a sequence may alter the motor activity of Myola, possibly rendering it inactive. Therefore, the expression of the 750a transcript in vivo could act as a dominant negative isoform, regulating Myo1a function in a cochlear specific manner. However, it seems more likely that both the $750 \mathrm{a}$ and $750 \mathrm{~b}$ transcripts are the products of incompletely spliced mRNAs.

While the various expression patterns of Myola mRNA in the gut and cochlea are very intriguing, such experiments do not reflect protein expression. From these data we 
can only conclude that full-length Myola is not expressed in the gut epithelium or the cochlea of the Myo1a ${ }^{-/-}$mouse. Alternate mRNA transcripts that are detected in Myo1a $^{+/+}$and Myo1a $\mathrm{a}^{-/-}$mice, as well as the full-length Myola transcript detected in the cochlea, may or may not lead to protein translation. To unequivocally determine protein expression, antibodies specific to the amino acid sequence coded for by the novel mRNA transcripts must be generated and tested on tissue using either immunofluorescent or immunoblotting techniques.

\section{Cochlear morphology of Myo1 a ${ }^{-/-}$mice}

Many mutations linked to hearing-loss manifest in a disruption of the structural organization and morphology of the hair bundle. In the microvilli, which share many structural features with the hair bundle, Myola expression is quite robust. As such, we felt that the characterization of the cochlear morphology of Myola $\mathrm{a}^{-/-}$mice, with specific focus on bundle integrity, might provide substantial insight into the pathogenesis of the hearing loss recently linked to Myola mutations (Donaudy et al., 2003). We were dismayed however, to find that the structural integrity of the wild-type $129 \mathrm{X} 1 / \mathrm{SvJ}$ hair bundles was compromised in some samples. Consequently, any subtle changes that may exist between Myola ${ }^{+/+}$and Myola ${ }^{-/-}$hair bundle morphology are undetectable. Any minor perturbation that may occur as a result of the absence of Myola may be masked by the overall nonconformity of the cochlear sample. To determine whether the abnormalities could be attributed to experimental technique, wild-type mice from an alternate strain, FVB/NJ, were also processed. Hair bundles from these animals looked as expected, providing evidence of a $129 \mathrm{X} 1 / \mathrm{SvJ}$ strain-specific problem. As a result, breeding is underway to move the Myola ${ }^{-/-}$mutation to the FVB/NJ background for future experiments.

\section{Immunofluorescent localization of the $\alpha B B I$ and the 3p1/4p1 antibodies}

Using the Myola antibodies, directed to Myola head and tail domain, 3p1/4p1 and $\alpha$ BBI respectively, we were unable to detect any immunolocalization that could be 
attributed to full-length Myo1 a protein expression in the cochlea. The immunolabeling observed using these antibodies was identical in both the Myo1a ${ }^{+/+}$and Myo1 $\mathrm{a}^{-/-}$mice. Because no subset of immunolabeling observed in the Myo1a ${ }^{+/+}$mice was absent in Myola $^{-/}$mice, we must conclude that if full-length Myola protein is expressed in cochlear hair cells, it exists at a concentration too low to detect with our reagents. However, both antibodies displayed extraordinary patterns of non-specific reactivity suggesting that each recognizes potentially novel proteins in the cochlear hair bundle.

The $\alpha \mathrm{BBI}$ antibody recognizes antigens present at the tips of hair bundles, sparsely along the length of the stereocilium and in the supporting cells. Of particular interest was the immunoreactivity at the tip of the stereocilia. Any protein localized to this area has the potential to interact with the mechanoelectrical transduction (MET) channel complex. To pursue this hypothesis, we repeated immunolocalization experiments with $\alpha \mathrm{BBI}$ following hair cell exposure to BAPTA, a reagent known to disrupt tip links, vital components of the MET channel complex. In these experiments, immunoreactivity at the tip of the hair bundle and in the pillar and Dieter cells was absent, suggesting that the conformation of the $\alpha \mathrm{BBI}$ antigen, and its reactivity with the $\alpha B B I$ antibody, may be linked to MET complex integrity.

The immunoreactivity of the $\alpha B B I$ antibody was identical in the Myola ${ }^{+/+}$and Myola $^{-/-}$cochlear tissues. Because the mRNA message for full-length Myola can not be detected in Myo1 $\mathrm{a}^{-/-}$cochlea, we must conclude that the $\alpha \mathrm{BBI}$ antibody does not detect full-length Myo1a in these tissues. However, mRNA representing the novel tail isoform of Myola, Myola $\mathrm{a}^{\text {TAIL }}$, is expressed in the Myo1 $\mathrm{a}^{-/-}$cochlea. Therefore, the unique localization of the $\alpha$ BBI antigen may be attributed to the expression of the Myo1a ${ }^{\text {TAIL }}$ transcript. The localization of this headless Myo1a isoform at the tips of stereocilia would position it for association with the intricate scaffolding network that occurs at the stereociliary tip. Because calcium chelation experiments also link the localization of the $\alpha B B I$ antigen to tip-link integrity, and its concentration is increased in shorter stereocilia, one might predict that the Myo1 $\mathrm{a}^{\mathrm{TAIL}}$ isoform may interact directly with tip-link complex at the prolate tip of the shorter stereocilia. Because no protein has been identified that 
contributes to tip-link asymmetry observed using high-resolution microscopy (Kachar 2001), this would be a novel and interesting avenue to pursue.

The $\alpha \mathrm{BBI}$ antibody did not react with any antigen in the saccular cells of bullfrog or mouse vestibular organs, but it was visible at the apical surface of supporting cells. This was as expected; Myo1 $\mathrm{a}^{-/-}$mice show no overt vestibular dysfunction (i.e. circling) as is often observed in mutant mice with vestibular defects (Tyska et al., 2005).

The antibodies $3 \mathrm{p} 1 / 4 \mathrm{p} 1$ recognize antigens expressed along the bottom two-thirds of the stereocilia in outer hair cells and at the stereociliary base in inner hair cells. In both types of hair cells, the immunoreactivity extended several microns into the cuticular plate. As well, no supporting cells in the organ of Corti were labeled with $3 p 1 / 4 p 1$. Like the $\alpha B B I$ antibody, the immunoreactivity observed in the Myola ${ }^{+/+}$and Myola $\mathrm{a}^{-/-}$was identical. These data, coupled with the absence of Myola mRNA transcripts complementary to the first twelve exons of Myola in the Myo1 $\mathrm{a}^{-/-}$mouse, allowed us to eliminate Myo1a as the $3 \mathrm{p} 1 / 4 \mathrm{p} 1$ antigen. Concurrently, we hypothesized that the $3 \mathrm{p} 1 / 4 \mathrm{p} 1$ antibody may be recognizing an alternate myosin, such as myosin-6 (Myo6). Myo6 is localized to the rootlet of the stereocilia and robustly in the cuticular plate (Hasson et al., 1997). Comparison of the expression patterns of the 3p1/4p1 antigen and Myo6 clearly precludes this possibility. In the OHC, the immunoreactivity of the $3 \mathrm{p} 1 / 4 \mathrm{p} 1$ antibody is associated with a large portion of the stereocilia. In both cell types, this labeling pattern continues along the stereocilia taper in the cuticular plate; no extraneous labeling in the actin meshwork of the cuticular plate is observed. Therefore, we can safely eliminate Myo6 as a candidate for the $3 \mathrm{p} 1 / 4 \mathrm{p} 1$ antigen. However, because their localizations overlap, once the $3 \mathrm{p} 1 / 4 \mathrm{p} 1$ epitope is identified, further experiments to test for its interaction with Myo6 may be intriguing. To our knowledge, the reported $3 \mathrm{p} 1 / 4 \mathrm{p} 1$ antigen expression pattern has never before been described in the hair bundle. Such a localization pattern would lend itself to stereociliary maintenance at the negative end of the PAB or stereociliary anchorage to the cuticular plate. Little is known about either of these processes. 


\section{Cochlear immunoblots using 3p1/4p1 antibody}

Despite our inability to detect Myo1a on immunoblots using the $3 \mathrm{p} 1 / 4 \mathrm{p} 1$ antibodies in cochlear samples, we can not eliminate the possibility of Myo1a protein expression. Many factors may contribute to Myo1a's absence in immunoblotting experiments. Perhaps the number of cochleas used per gel sample was too low. If Myola is expressed at a very low concentration in the cochlea, an increased number of cochleas may have to be used for each gel sample. As well, the preparation of the sample, while optimized for Myola preservation in gut samples, may not be appropriate for the cochlea. A nuance in sample preparation could result in Myola degradation and its inability to be detected by immunoblot.

In addition to the detection of Myo1a, we also hoped to identify other proteins that may act as the epitope responsible for the non-specific labeling in $3 \mathrm{p} 1 / 4 \mathrm{p} 1$ immunocytochemistry experiments. In addition to Myola, we also routinely detected a smaller protein, migrating at $40 \mathrm{kDa}$ (Fig 7B\&C, blue asterisk). This protein was present

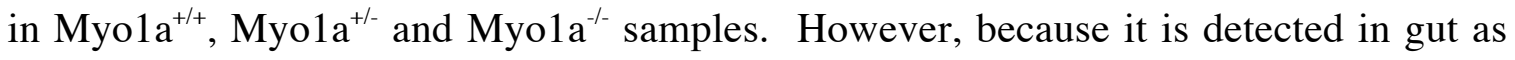
well as the cochlea, and we do not observe non-specific binding in the Myo1 ${ }^{-/-}$gut samples, this protein is not likely to be the $3 \mathrm{p} 1 / 4 \mathrm{p} 1$ antigen observed in the cochlea. As well, an additional protein, which migrated slightly higher than Myola was detected in in Myo1a $^{+/+}$, Myo1a ${ }^{+/-}$and Myo1a ${ }^{-/-}$cochlear samples (Fig 7B\&C, black asterisk). This protein is the strongest candidate for the $3 \mathrm{p} 1 / 4 \mathrm{p} 1$ antigen, however its detection varied across experiments. We did not observe any further candidates, although the same technical problems listed above may also apply. As well, because our sample preparation was biased for myosins, we may have eliminated the non-specific proteins from the sample preparation.

The future direction of this project will depend upon the optimization of immunoblot experiments. We will pursue this by increasing the number of cochleas per gel sample, as well as modifying the protein extraction method based on both myosin and non-myosin protocols. The detection of Myo1a protein in cochlear samples would prompt us to return to immunocytochemistry experiments to examine non-sensory cells 
of the cochlea for Myola expression. If we are able to reliably detect a candidate for the observed binding observed in hair cells with the immunocytochemistry experiments, we will continue our research with $3 \mathrm{p} 1 / 4 \mathrm{p} 1$ immunoprecipitation experiments in an attempt to identify these unique hair-cell antigens. 
A.

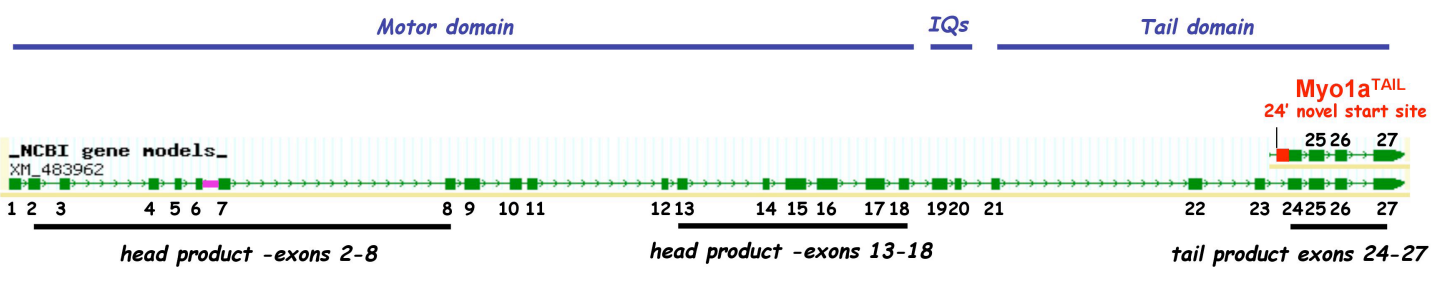

B.

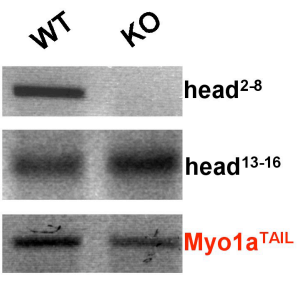

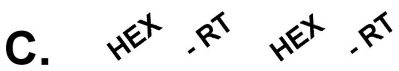

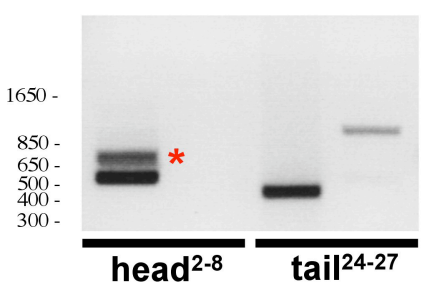

D.

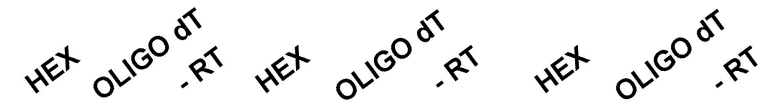

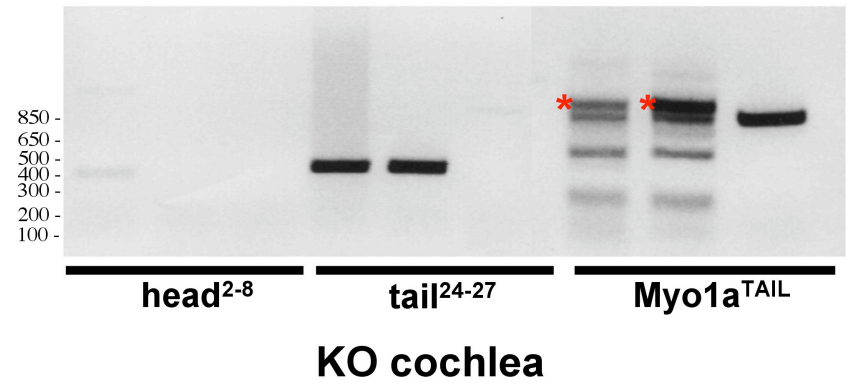

E.

MYO1A 523

INTRON 6

GGCGGTGTCATCACCAACTGGCGGTGTCATCACCAACTGTATGTGTCCCCCTCTCATAAGCCTCACCAACACTCTCCACTTCTGTCCCTTTATGCCCATCTGCTCCTGCAGGCAAGAG

GATTGTTAGGTTTCAGGTTTCAGGAAACTCCCCAACTCTTAGGAACTCTGGGGCTTGGGGCAGAATGGGAGGGATCTGCTGAGAGTCCCCTGGGCTT

$$
\text { -ATCTGCTTGAGAAGT- Full Length MYO1A }
$$

---ATGGATGCATCCTAACTCCCTCCCAGATCTGCTTGAGAAGT- 750a MYO1A insertion TCAGATGGATGCATCCTAACTCCCTCCCAGATCTGCTTGAGAAGT- 750b MYO1A insertion

$$
\text { MYO1A } 756
$$

F.

Amino Acid translation; Wild type Myo1a amino acids \# 175-185

GGVITN

-YLLEK

predicted Amino Acid translation; Myo1a insertion, 750a, detected using RT-PCR

GGVITNCMCPPLISLTNTLHFCPFMPICSCRWMHPNSLPDLLEK 
Figure 1. Myo1a mRNA expression in $\mathbf{M y o 1 a}^{+/+}$and Myo1a ${ }^{-/-}$tissues. A) Blue diagram depicts basic Myo1a protein structure. The Myo1a introns (green line) and exons (green boxes) are shown. The novel start site for the predicted tail isoform of Myola, Myola ${ }^{\text {TAIL }}$, is shown in red. Intron 6, which is alternatively spliced into the mRNA transcripts, 750a and 750b, is shown in pink. PCR primers were designed to amplify regions denoted in black as well as the novel start site shown in red. B) The expression of Myola mRNA in Myo1a ${ }^{+/+}(\mathrm{WT})$ and Myo1 a ${ }^{-/-}(\mathrm{KO})$ gut tissue was assayed using primers that amplified exons 2-8 and 13-16 of the head domain as well as the novel start site of Myo1 $\mathrm{a}^{\text {TAIL }}$ transcript diagrammed in A. C) The expression of Myola mRNA in Myo1a ${ }^{+++}$(WT) cochlear tissue was assayed using the head and tail primer sets diagrammed in $A$. HEX: cDNA template was amplified using random hexamer primers. $-R T$ : negative control, no reverse transcriptase was added to cDNA reaction. Oligo dT: cDNA template was amplified using oligo dT primers. The red asterisk denotes the cochlear variants described in $D \& E$. D) The expression of Myo1a mRNA in Myo1 a $\mathrm{a}^{-/-}$cochlear samples. The expected products are marked with a red asterisk $(*)$. The product amplified in Myo1a ${ }^{\text {TAIL }}$-RT lane is believed to be non-specific, and not the result of genomic DNA contamination. E) DNA sequence of products shown in C, lane: WT cochlea, head primers, HEX template. The lower band in $C$ corresponds to WT Myola sequence, black. The top band in $C$ corresponds to two variant sequences: 750a and 750b, green and red respectively. Underlined DNA bases in red sequence code for translational stops. Intron 6 sequence lies within the gray box. F) Amino-acid translation of the wild-type Myo1a sequence and the 750a sequence, black and green respectively. 

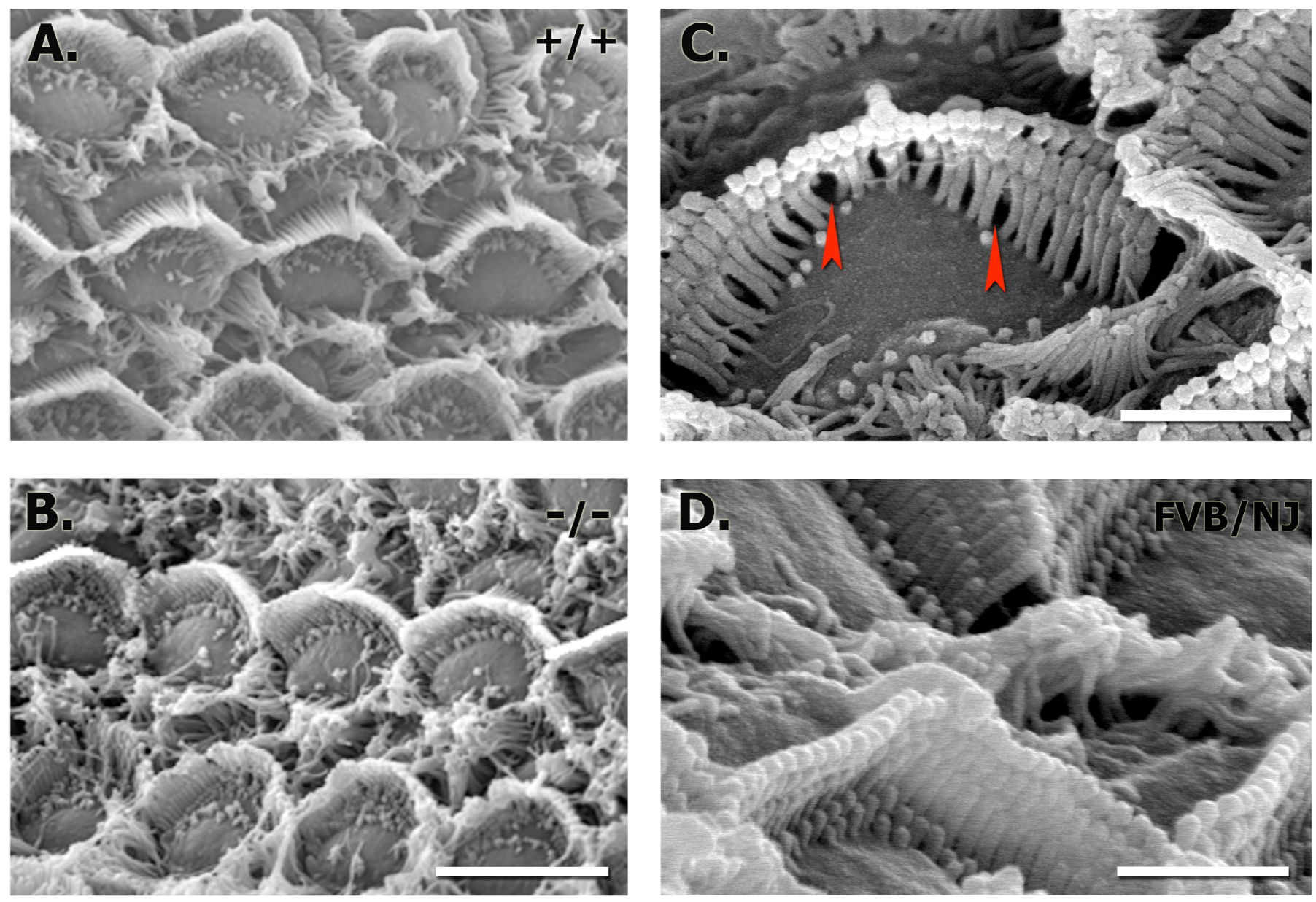

Figure 2. Scanning electron micrograph of Myo1a mutant cochlea. Acutely dissected cochlea from Myola mutant mice, P7, were fixed, dehydrated, and imaged using a scanning electron microscope. A) Three rows of outer hair cells from a Myo1 $\mathrm{a}^{+/+}$mouse. B) Two rows of outer hair cells from Myo1 $\mathrm{a}^{-/-}$mouse. C) Outer hair cell from sample with irregularities in stereocilliary packing in a Myo1a ${ }^{-/-}$mouse. Spaces are indicated with red arrows. D) Outer hair cell from FVB/NJ mouse strain. Scale bar in $B$ also applies to $A$ and is equal to $4.29 \mu \mathrm{m}$, in $C$ is equal to $1.50 \mu \mathrm{m}$, and in $D$ is equal to $1.20 \mu \mathrm{m}$. 

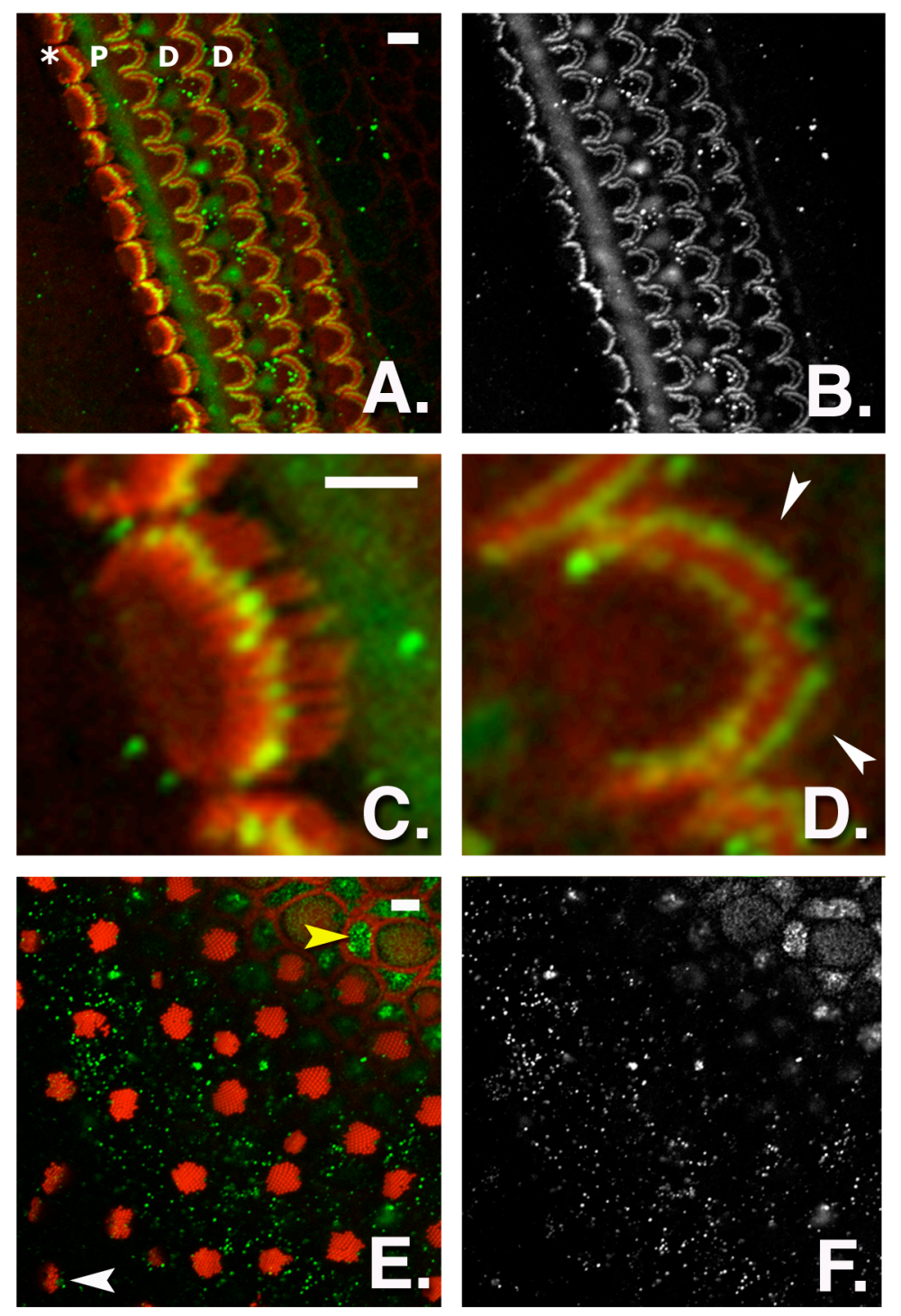

Figure 3. The $\alpha$ BBI antibody interaction with cochlear hair cells. A) The $\alpha$ BBI antibody interacts with antigens at the tips of stereocilia and in the supporting cells of the cochlea. In all panels the $\alpha \mathrm{BBI}$ antibody is labeled green and actin is labeled red. The inner hair cell row is marked with an asterisk (*). The three rows of hair cells to the right are outer hair cells. The row of supporting cells between the inner and outer hair cells are pillar cells, $P$, and the rows of supporting cells between outer hair cells are Dieter cells, $D$. B) The same image as shown in A, but $\alpha$ BBI (green) channel only. C) Magnified view of an inner hair cell. Stereociliary-tip labeling is less intense in the tallest row of stereocilia. D) Magnified view of an outer hair cell. Stereociliary-tip labeling is most intense in middle and short rows of stereocilia. Arrowheads point to stereocilia of the tallest row. E) Bullfrog saccular hair cells. No $\alpha$ BBI labeling is observed in the stereociliary tip (white arrow), but is present in surrounding supporting cells (yellow arrow). Scale bars in $A$ also applies to $B$, in $C$ also applies to $D$, and in $E$ also applies to $F$. Scale bars in $A$ and $E$ are equal to $5 \mu \mathrm{m}$. Scale bar in $C$ is equal to $2.5 \mu \mathrm{m}$. 

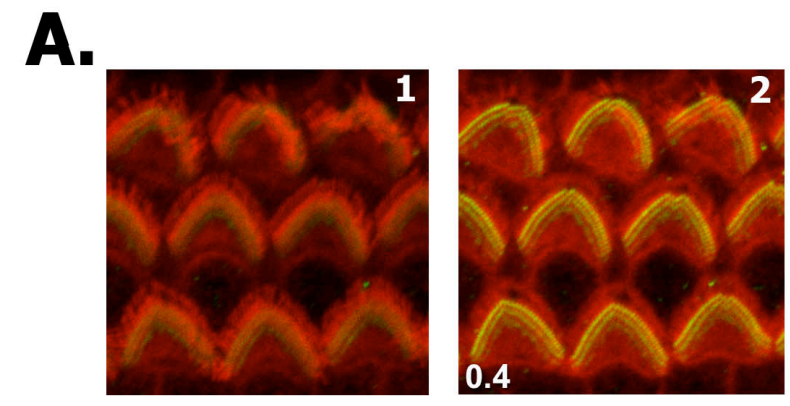

B.
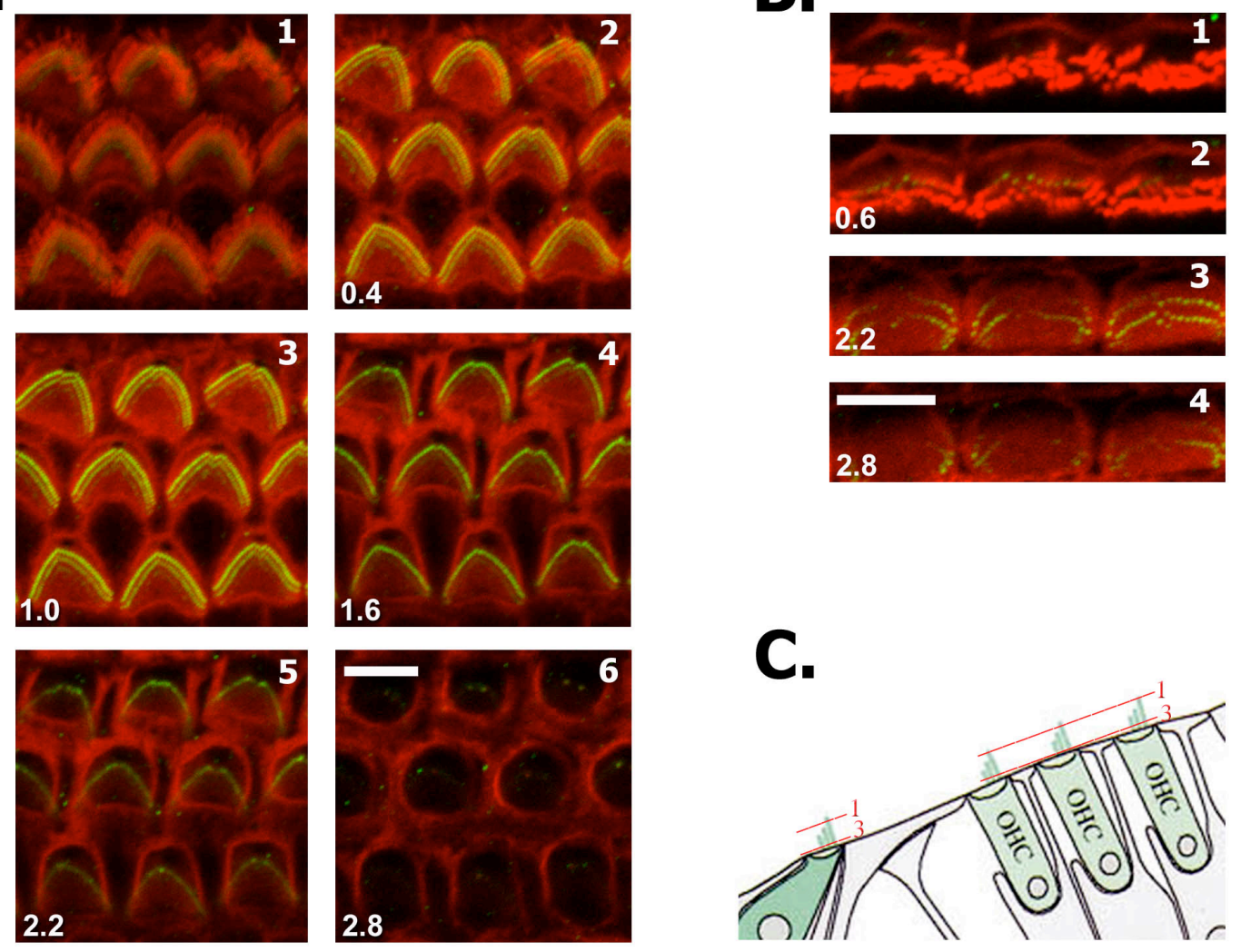

Figure 4. The 4p1/3p1 antibody interaction with cochlear hair cells. In all data panels, the 4p1/3p1 antibody is labeled in green and actin is labeled in red. Numbers in bottom left corners are in $\mu \mathrm{m}$ and denote the distance from slice 1. A; 1-6) serial confocal sections of outer hair cell bundles labeled with the 4p1/3p1 antibody. No immunoreactivity is observed at the tips of stereocilia (1). Approximately $1 / 3^{\text {rd }}$ down the length of the stereocilia, $4 \mathrm{p} 1 / 3 \mathrm{p} 1$ labeling can be detected in all three rows of stereocilia (2). Labeling begins to fade in the shortest row of stereocilia at the cuticular plate (3). Labeling of the middle row of stereocilia also fades (4). Labeling remains in the rootlet of the tallest row of stereocilia several microns into the apical surface of the hair cell (5). Labeling fades and is undetectable approximately $2 \mu \mathrm{m}$ below the apical surface of the cell $(6)$. B) Serial confocal sections of inner hair cell bundles. No 4p1/3p1 immunoreactivity is detected at the tips or in the shaft of stereocilia (1 \& 2). The 4p1/3p1 anitobody interacts with epitopes located in each inner hair cell stereocilia rootlet, extending into the cuticular plate ( $3 \& 4)$. Scale bars in A6 and B4 are equal to $5 \mu \mathrm{m}$. C) Cartoon of the cochlear hair cells, depicting the focal plane for the first and third slices shown in both the three rows of OHC, depicted in panels A1-6 and the IHC, depicted in panels B1-4. 


\section{stereociliary tips}
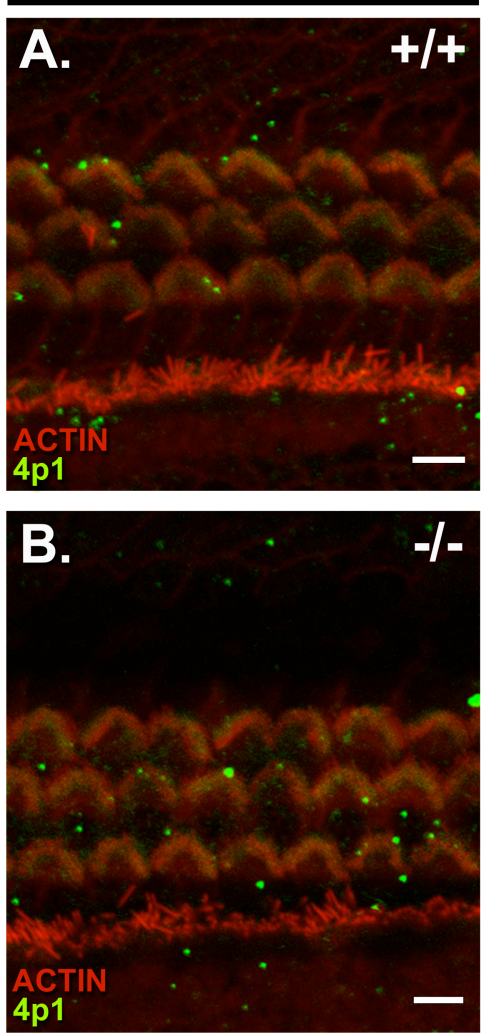

stereociliary shaft
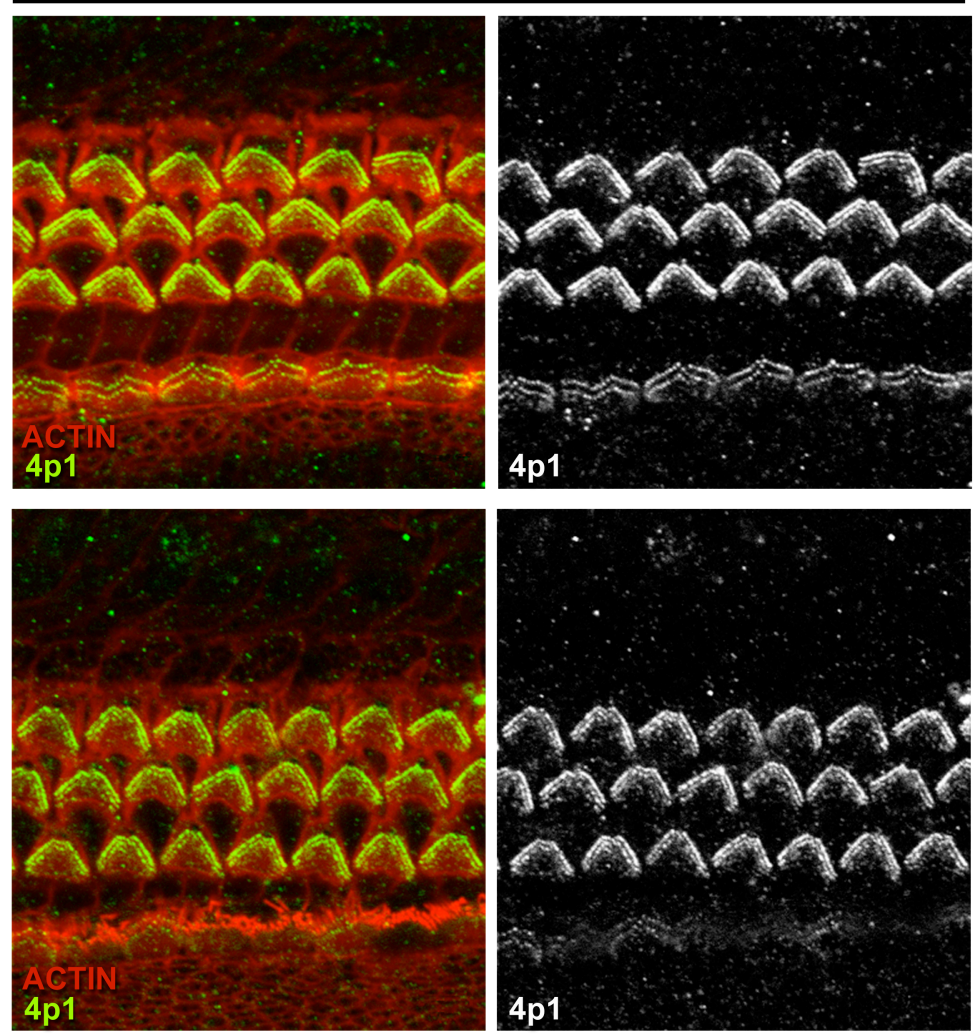

Figure 5. 4p1 immunolabeling of Myo1a mutant mice in cochlear hair cells. Cochleas were acutely dissected from Myo1a mutant mouse littermates at P7. In all overlayed images (A \& B, left and middle panels) actin-labeled phalloidin is shown in red and the $4 \mathrm{p} 1$ antibody is shown in green. A) Myo1a ${ }^{+/+}$mouse. B) Myola $\mathrm{a}^{-/ /}$mouse. In the left panels of A \& B the focal plane is at the tip of the hair bundle. In the middle and right panels of $\mathrm{A} \& \mathrm{~B}$, the focal plane is at the base of the hair bundle. Scale bars in $A$ and $B$ is $5 \mu \mathrm{m}$ and applies to each panel of the respective figure. 

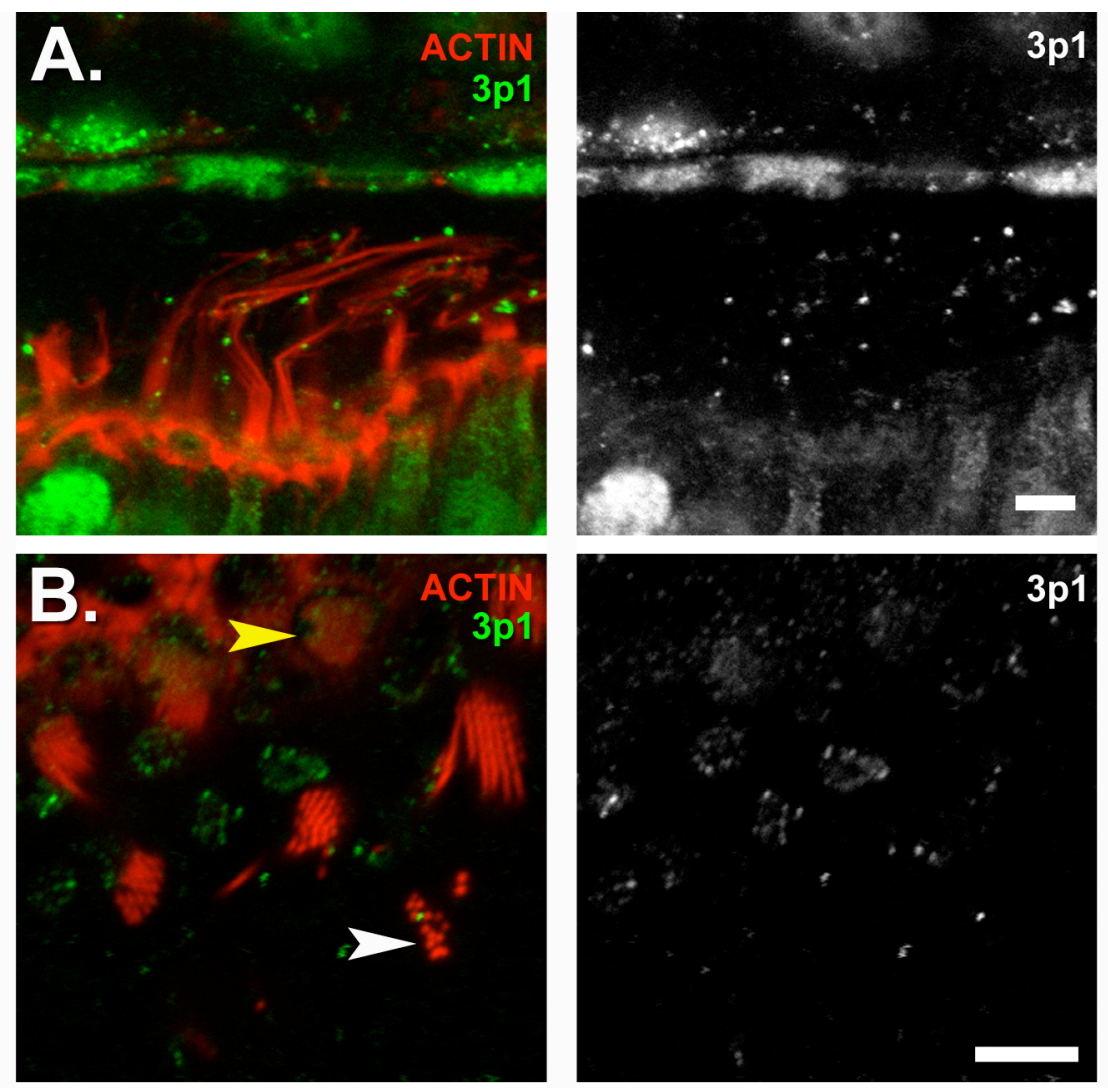

Figure 6. 3p1 immunolabeling of murine vestibular hair cells. Accutely dissected wild-type mouse vestibular organs. A) Confocal image of the sagital plane of vestibular hair cells. Actin is labeled with phalloidin, shown in red, and 3p1 antibody is shown in green. B) Confocal image of the horizontal plane of vestibular hair cells. Yellow arrowhead points to the cuticular plate at the base of hair cells, white arrowhead points to the tip of a hair bundle. Scale bars shown in the right panels are equal to $5 \mu \mathrm{m}$. 

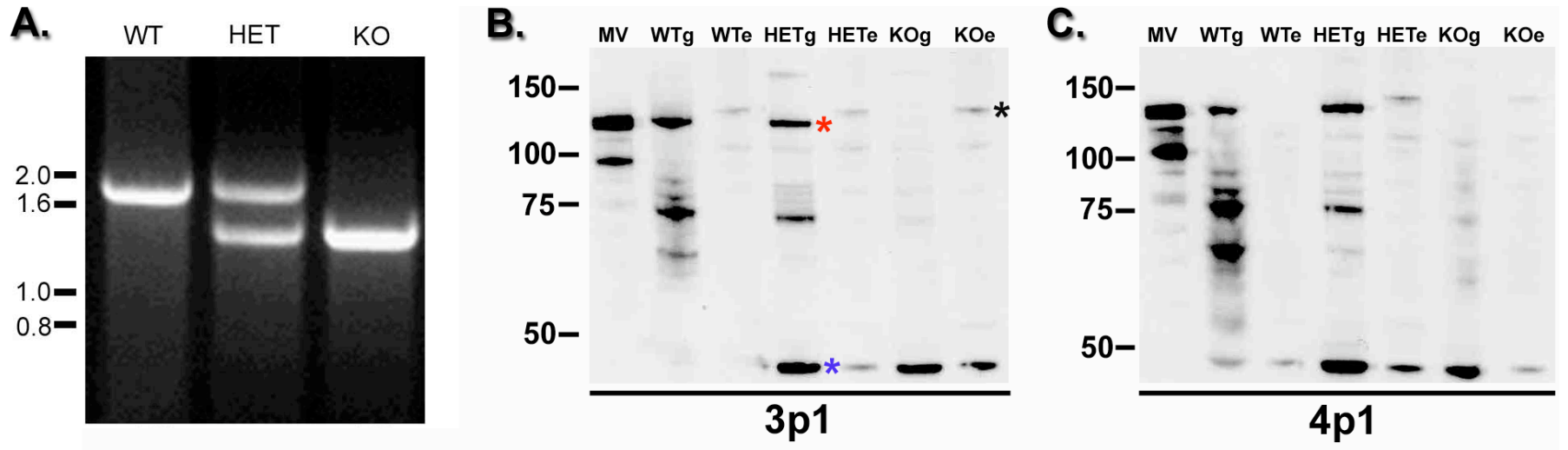

Figure 7. $3 \mathrm{p} 1 / 4 \mathrm{p} 1$ antibody immunoblots. A) DNA agarose gel with products of Myo1a mutant genotyping PCR reaction. Each reaction contains a forward primer, complimentary to the DNA sequence upstream of exon 1, and 2 reverse primers, one complementary to the DNA sequence in intron 3 and one complementary to the neomyosin cassestte, indicative of the knockout allele. WT, Myo1a ${ }^{+/+}$DNA, HET, Myo1a ${ }^{+/-}$DNA and KO, Myo1a ${ }^{-/-}$DNA. B \& C) Gut and cochlear samples were ran on SDS page gels and immunoblotted using antibodies 3p1 and 4 p1. Ladders, shown to left are in KD. Each lane as labeled: $M V$, microvilar positive control. WTg, wild-type gut sample. WTe, wild-type cochlear sample. HETg, Myo1a KO ${ }^{+/-}$ mouse gut sample. HETe, Myola $\mathrm{KO}^{+-}$mouse cochlea sample $\mathrm{KOg}$, Myola $\mathrm{KO}^{-/-}$mouse gut sample. KOe, Myola $\mathrm{KO}^{-/-}$mouse cochlea sample. Myola is denoted with a red asterisk. The $40 \mathrm{kDa}$ antigen is denoted with a blue asterisk. The protein marked with the black asterisk is a potential candidate for the $3 \mathrm{p} 1 / 4 \mathrm{p} 1$ antigen. 


\section{References}

Bartles JR, Zheng L, Li A, Wierda A, Chen B (1998) Small espin: a third actin-bundling protein and potential forked protein ortholog in brush border microvilli. J Cell Biol 143:107-119.

Carboni JM, Conzelman KA, Adams RA, Kaiser DA, Pollard TD, Mooseker MS (1988) Structural and immunological characterization of the myosin-like $110-\mathrm{kD}$ subunit of the intestinal microvillar 110K-calmodulin complex: evidence for discrete myosin head and calmodulin-binding domains. J Cell Biol 107:1749-1757.

D'Adamo P, Pinna M, Capobianco S, Cesarani A, D'Eustacchio A, Fogu P, Carella M, Seri M, Gasparini P (2003) A novel autosomal dominant non-syndromic deafness locus (DFNA48) maps to 12q13-q14 in a large Italian family. Hum Genet 112:319-320.

DeRosier DJ, Tilney LG (1989) The structure of the cuticular plate, an in vivo actin gel. J Cell Biol 109:2853-2867.

Donaudy F, Ferrara A, Esposito L, Hertzano R, Ben-David O, Bell RE, Melchionda S, Zelante L, Avraham KB, Gasparini P (2003) Multiple mutations of MYO1A, a cochlear-expressed gene, in sensorineural hearing loss. Am J Hum Genet 72:1571-1577.

Dumont RA, Zhao YD, Holt JR, Bahler M, Gillespie PG (2002) Myosin-I isozymes in neonatal rodent auditory and vestibular epithelia. J Assoc Res Otolaryngol 3:375389.

Fath KR, Trimbur GM, Burgess DR (1994) Molecular motors are differentially distributed on Golgi membranes from polarized epithelial cells. J Cell Biol 126:661-675.

Flock A, Cheung HC (1977) Actin filaments in sensory hairs of inner ear receptor cells. J Cell Biol 75:339-343.

Gillespie PG, Albanesi JP, Bahler M, Bement WM, Berg JS, Burgess DR, Burnside B, Cheney RE, Corey DP, Coudrier E, de Lanerolle P, Hammer JA, Hasson T, Holt JR, Hudspeth AJ, Ikebe M, Kendrick-Jones J, Korn ED, Li R, Mercer JA, Milligan RA, Mooseker MS, Ostap EM, Petit C, Pollard TD, Sellers JR, Soldati T, Titus MA (2001) Myosin-I nomenclature. J Cell Biol 155:703-704.

Hasson T, Gillespie PG, Garcia JA, MacDonald RB, Zhao Y, Yee AG, Mooseker MS, Corey DP (1997) Unconventional myosins in inner-ear sensory epithelia. J Cell Biol 137:1287-1307.

Heintzelman MB, Hasson T, Mooseker MS (1994) Multiple unconventional myosin domains of the intestinal brush border cytoskeleton. J Cell Sci 107 ( Pt 12):35353543.

Mooseker MS (1985) Organization, chemistry, and assembly of the cytoskeletal apparatus of the intestinal brush border. Annu Rev Cell Biol 1:209-241.

Mooseker MS, Coleman TR (1989) The 110-kD protein-calmodulin complex of the intestinal microvillus (brush border myosin I) is a mechanoenzyme. J Cell Biol 108:2395-2400.

Mooseker MS, Cheney RE (1995) Unconventional myosins. Annu Rev Cell Dev Biol 11:633-675. 
Solc CK, Derfler BH, Duyk GM, Corey D (1994) Molecular Cloning of Myosins from the Bullfrog Saccular Macula: A Candidate for the Hair Cell Adaptation Motor. Auditory Neuroscience 1:63-75.

Tilney MS, Tilney LG, Stephens RE, Merte C, Drenckhahn D, Cotanche DA, Bretscher A (1989) Preliminary biochemical characterization of the stereocilia and cuticular plate of hair cells of the chick cochlea. J Cell Biol 109:1711-1723.

Tyska MJ, Mooseker MS (2002) MYO1A (brush border myosin I) dynamics in the brush border of LLC-PK1-CL4 cells. Biophys J 82:1869-1883.

Tyska MJ, Mackey AT, Huang JD, Copeland NG, Jenkins NA, Mooseker MS (2005) Myosin-1a is critical for normal brush border structure and composition. Mol Biol Cell 16:2443-2457.

Zheng L, Sekerkova G, Vranich K, Tilney LG, Mugnaini E, Bartles JR (2000) The deaf jerker mouse has a mutation in the gene encoding the espin actin-bundling proteins of hair cell stereocilia and lacks espins. Cell 102:377-385. 